\title{
Promoting Role of MXene Nanosheets in Biomedical Sciences : Therapeutic and Biosensing Innovations
}

\section{Soleymaniha, Mohammadreza}

2019-01-10

Soleymaniha , M , Shahbazi , M-A , Rafieerad, A R , Maleki , A \& Amiri , A 2019 , '

Promoting Role of MXene Nanosheets in Biomedical Sciences : Therapeutic and Biosensing

Innovations ' , Advanced Healthcare Materials , vol. 8 , no. 1 , 1801137 . https://doi.org/10.1002/adhm.201801137

http://hdl.handle.net/10138/326786

https://doi.org/10.1002/adhm.201801137

unspecified

acceptedVersion

Downloaded from Helda, University of Helsinki institutional repository.

This is an electronic reprint of the original article.

This reprint may differ from the original in pagination and typographic detail.

Please cite the original version. 


\section{WILEY-VCH}

DOI: 10.1002/ ((please add manuscript number))

\section{Article type: Review} Promoting Role of MXene Nanosheets in Biomedical Sciences: Therapeutic and
Biosensing Innovations

Mohammadreza Soleymaniha, Mohammad-Ali Shahbazi*, Ali Reza Rafieerad, Aziz Maleki, Ahmad Amiri*

Mohammadreza Soleymaniha

Department of Mechanical Engineering, Texas A\&M University, College Station, TX, USA

Dr. Mohammad-Ali Shahbazi

Department of Micro- and Nanotechnology, Technical University of Denmark, Ørsteds Plads, DK-2800 Kgs, Lyngby, Denmark

Department of Pharmaceutical Nanotechnology, School of pharmacy, Zanjan University of Medical Sciences, Zanjan, Iran

E-mail: mohs@nanotech.dtu.dk and ma.shahbazi@zums.ac.ir

Ali Reza Rafieerad

St. Boniface Hospital Research Centre, Department of Physiology, University of Manitoba, Winnipeg, Canada

Dr. Aziz Maleki

Department of Pharmaceutical Nanotechnology, School of pharmacy, Zanjan University of Medical Sciences, Zanjan, Iran

Zanjan Pharmaceutical Nanotechnology Research Center (ZPNRC), Zanjan University of Medical Sciences, Zanjan, Iran

Dr. Ahmad Amiri

Department of Mechanical Engineering, Texas A\&M University, College Station, TX, USA

E-mail: ahmadamiri@tamu.edu

Keywords: MXenes; photothermal therapy; drug delivery; theranostics; Biosensor. 


\section{WILEY-VCH}

Abstract

MXene nanosheets have emerged as biocompatible transition metal structures, which illustrate desirable performance for various applications due to their unique structural, physicochemical and compositional features. MXenes are currently expanding their usage territory from mechanical, optical, chemical and electronic fields toward biomedical areas. This is mainly originated from their large surface area and strong absorbance in near-infrared region, which in combination with their facile surface functionalization with various polymers or nanoparticles, make them promising nanoplatforms for drug delivery, cancer therapy, precise biosensing and bioimaging. The facile surface modification of the Mxenes can mediate the better in vivo performance of them through reduced toxicity, enhanced colloidal stability and extended circulation within the body. Herein, we emphasize on the state-of-theart progresses of MXene nanosheets designed for biomedical applications, such as structuraland dose-dependent antimicrobial activity, photothermal therapy, drug delivery and implants. Besides, biosensing applications are highlighted and a comprehensive discussion on photoacoustic imaging, magnetic resonance imaging, computed tomography imaging and optical imaging of MXenes is presented. The challenges and future opportunities of applying MXene nanomaterials in the biomedicine areas are also discussed. 


\section{WILEY-VCH}

\section{Introduction}

Two-dimensional (2D) nanostructures, including dichalcogenide nanosheets, ${ }^{[1]}$ hexagonal boron nitride, ${ }^{[2]}$ graphene, ${ }^{[3]}$ phosphorene, ${ }^{[4]}$ and antimonene, ${ }^{[5]}$ have recently gained tremendous attention in biomedical applications, such as photothermal/photodynamic therapy, drug delivery, regenerative medicine, biosensing and diagnostic imaging. This is mainly due to their unique physico-chemical properties, including ultrathin atomic thickness, superior surface-to-volume ratio, controllable electronic and mechanical properties, and tunable lateral size. ${ }^{[1 a]}$ In 2011, a novel family of 2D-nanostructures, named MXenes, was introduced by Gogotsi et al. ${ }^{[6]}$ These 2D-materials are composed of transition metal carbides, nitrides, or carbonirides with structural formula of $\mathrm{M}_{\mathrm{n}+1} \mathrm{X}_{\mathrm{n}}(\mathrm{n}=1-3)$, where $\mathrm{M}$ is a transition metal (e.g., Sc, Ti, Zr, Hf, V, Ta, Nb, Cr, Mo, etc.) and X corresponds to carbon and/or nitrogen. ${ }^{[7]}$ More than seventy forms of MXenes have been synthesized so far, most of which are prepared by wet-chemical etching of their corresponding MAX phase .i.e., $M_{n+1} A X_{n}$, where A belongs mainly to the group 13 and 14 of the periodic table (Figure 1a). Through this method, the A layer is selectively etched out by F-containing etchants, such as HF, resulting in the replacement of A element with other surface termination groups, such as $-\mathrm{OH},-\mathrm{F}$, and/or $-\mathrm{O}$ (Figure 1b). ${ }^{[7 c]}$ Under this condition, a new layered material with general formula of $M_{n+1} X_{n} T_{x}$ will be produced, where $T_{x}$ corresponds to the terminated functional group. As a result, a diverse library of MXenes with different properties can be prepared by right combination of $\mathrm{M}$ and $\mathrm{X}$ atoms, surface-terminated with different $\mathrm{T}_{\mathrm{x} .}{ }^{[7 \mathrm{c}]}$ Interestingly, MXenes with more than one transition metal are also reported, greatly expanding the family of 2D MXenes with various structures and ultimately diverse properties. ${ }^{[8]}$

MXene are recently the focus of fundamental researches to develop various advanced technologies. This is mainly related to the cost-effective scale up production of MXenes, considered as a superior benefit in compare with other carbon-based matrices. In addition, owning to superior crystal structures, different chemical compositions, rich chemistries, high 


\section{WILEY-VCH}

metallic conductivities, excellent thermal/mechanical properties, unique morphology, and hydrophilic surface properties, MXenes have exploited as promising candidates in transistors, energy storage devices, ${ }^{[7 c]}$ electrocatalysts, ${ }^{[9]}$ water desalination, ${ }^{[10]}$ electromagnetic interference shielding, ${ }^{[11]}$ electrochemical supercapacitors, ${ }^{[9 b,}{ }^{12]} \mathrm{Li}$ ion batteries, ${ }^{[0,}$, 13$]$ conducting thin films, ${ }^{[14]}$ and many other applications. ${ }^{[7 b, 7 c]}$ Moreover, with ever-increasing attention to MXenes, these burgeoning 2D-materials have successfully applied in biomedical applications ${ }^{[7 b]}$ such as photothermal therapy (PTT) in near-infrared-I (NIR-I; 750-1000 nm) and NIR-II bio-windows $(1000-1350 \mathrm{~nm}),{ }^{[15]}$ diagnostic imaging, ${ }^{[15 b, 15 e, 16]}$ antimicrobial formulations, ${ }^{[17]}$ biosensing, ${ }^{[18]}$ drug delivery, ${ }^{[19]}$ and even tissue engineering. ${ }^{[20]}$ Thanks to abundant oxygen-containing groups within the structure of MXenes, they possess high degree of functionalization capability, allowing the surface engineering of MXene nanosheets for desirable performance in biomedicine. Compared to the conventional photothermal agents (noble metal nanostructures), the large surface area of MXenes have rendered them high band spanning from UV to NIR regions as well as high light-to-heat conversion efficiency for successful PTT of cancer. Moreover, the superior capability of NIR light in deep penetration to the target tissue, which turns to rapid and effective treatment, quick recovery and minimum invasiveness, has highlighted the future role of MXenes in the medicine. ${ }^{[15 c]}$ In biosensing applications, MXenes have also opened a new gateway. These materials are promising candidates to create biologically compatible devices for rapid, easy, and label-free detection of biological events. For instance, MXenes are applied for the fabrication of wearable gas sensors, which can efficiently operate at room temperature. ${ }^{[18 c, 21]}$ Some studies have also focused on biomedical capability of MXenes for the coating applications to strengthen and toughen implants. ${ }^{[22]}$ The bioinert $\mathrm{Ti}_{3} \mathrm{SiC}_{2}$ MXene is known for this application since it does not elicit foreign body reactions. ${ }^{[23]}$ These applications stems from the facile surface modification of MXenes as well as their biocompatiblity and biodegradability, opening new doors for the fabrication of novel multifunctional MXenes in near future. 


\section{WILEY-VCH}

Based on the rapid development of MXene nanosheets in biomedicine, ${ }^{[7 \mathrm{~b}]}$ it is timely to summarize substantive findings of the original researches focused on the potential of MXenes in drug delivery, cancer therapy, bio-imaging, biosensors, and implants. We have tried to prepare a comprehensive literature review, which allows researchers to easily update their knowledge in biomedical applications of MXenes through reading all the recent advances, challenges, and future perspectives of MXenes.

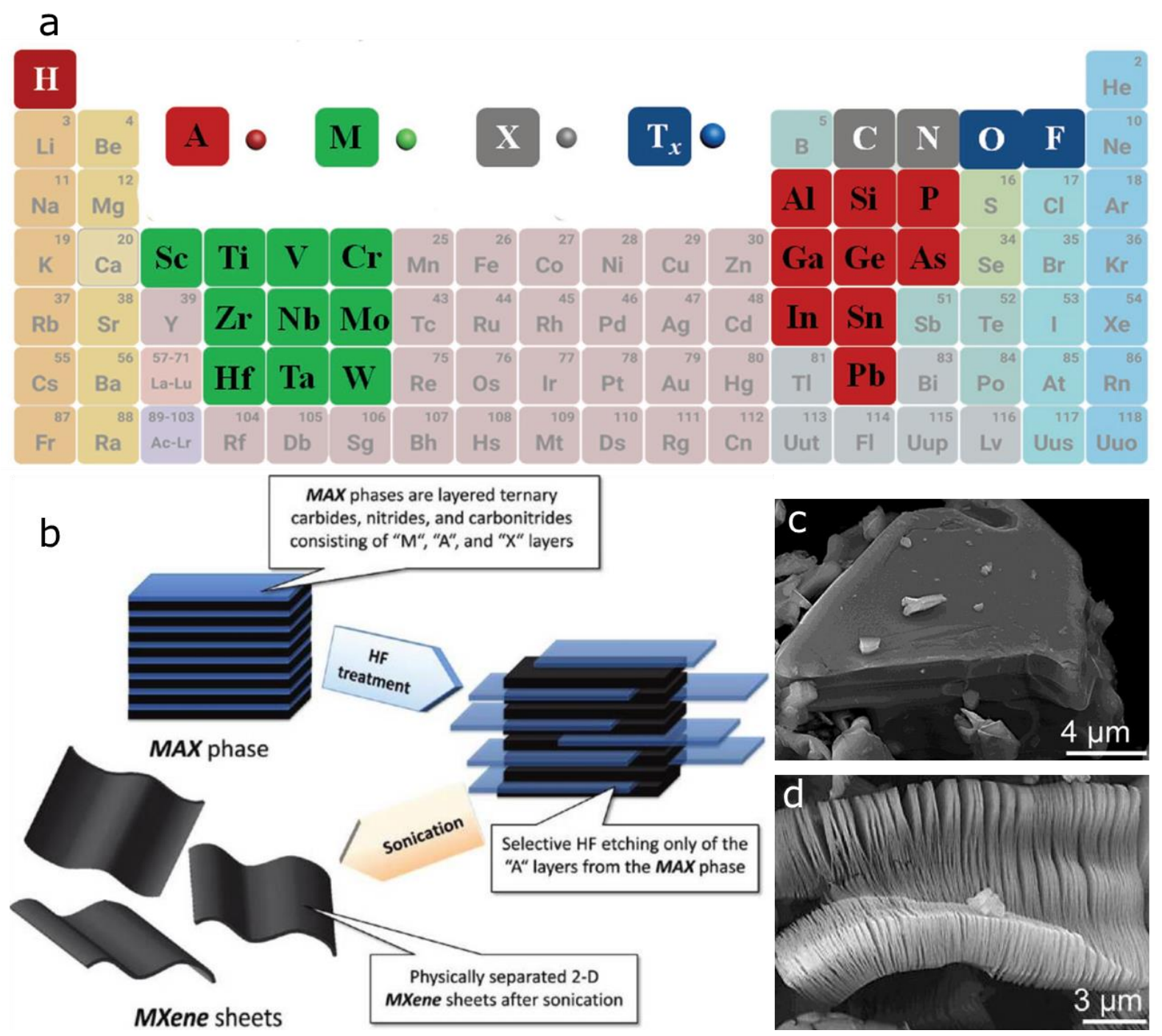

Figure 1. (a) The periodic table presenting the elements used for the formation of MAX phase, i.e. $\mathrm{M}_{n+1} \mathrm{AX}_{n}$. Reproduced with permission. ${ }^{[0 \mathrm{~b}]}$ Copyright 2017, Wiley-VCH. (b) Schematic representation of the exfoliation process of MAX phase and the formation of MXene nanosheets. Scanning electron microscopy (SEM) images of $\mathrm{Ti}_{3} \mathrm{AlC}_{2}$ particles (c) before and (d) after HF treatment. Reproduced with permission. ${ }^{[24]}$ Copyright 2012, American Chemical Society. 


\section{WILEY-VCH}

\section{Synthesis of MXenes: etching and delamination}

MXenes are synthesized by selective removal of A-layer from the corresponding MAX phase. Recent studies have extensively concentrated on efficient methods for selective extraction of the $\mathrm{A}$ element from the parent $\mathrm{M}_{\mathrm{n}+1} \mathrm{AX}$ n phases. For example, heating treatment at elevated temperature, high temperature chlorination, and selective etching are suggested for the removal of the A element from the MAX phases. ${ }^{[25]}$ In heating treatment, some drawbacks like partial loss of layering and structural transformation hinder its promotion. ${ }^{[26]}$ In addition, chlorination at high temperature is not a selective method and causes the elimination of both metals ( $\mathrm{M}$ and $\mathrm{A}$ ), fabricating porous carbide derived carbons (CDCs). ${ }^{[27]}$ Therefore, using an etchant (e.g. aqueous HF) within a certain concentration and a specific time period is the dominant method for the fabrication of MXene nanosheets (Figure 1b). After etching step, centrifugation or filtration is mostly performed in order to separate solid particles after washing with deionized (DI) water until the $\mathrm{pH}$ of solution reaches to around 5. Under this condition, a compacted-packed structure converts to a loosely-packed one similar to an accordion, as shown in Figures 1c and 1d. Afterwards, utilizing sonication process, the asprepared multilayered $\mathrm{M}_{\mathrm{n}+1} \mathrm{X}_{\mathrm{n}} \mathrm{T}_{\mathrm{x}}$ can be delaminated into isolated sheets or monolayers (Figure 1b). It is noteworthy to point out that delamination without intercalating agents (IAs) results in low yield of the single-layered MXenes. Therefore it is essential to use IAs for weakening interlayer interaction between the cohesive layers in order to harvest MXene single sheets in high yields. Two types of IAs, including polar organic molecules and aqueous solution of ionic materials are used for the intercalation of MXenes. The delamionation of multilayerd MXenes to single-stack sheets by polar organic molecules (e.g. DMSO, ${ }^{[28]}$ isopropylamine, ${ }^{[29]}$ tetraalkylammonium compounds, ${ }^{[30]}$ and $n$-butylamine ${ }^{[30]}$ ) is usually followed by mechanical vibration, while single-stack Mxenes can be obtained through delaminatrion in aqueous solution of ionic materials with or without mechanical vibration. ${ }^{[12 \text {, }}$ 


\section{WILEY-VCH}

${ }^{31]}$ Mashtalir et al. ${ }^{[32]}$ reported spontaneous intercalation of cations into multilayer $\mathrm{Ti}_{3} \mathrm{C}_{2} \mathrm{OH}$ and Osti et al. ${ }^{[33]}$ used potassium ions during the intercalation process and could improve homogeneity and aqueous stability for the high yield fabrication of single-layered $\mathrm{Ti}_{3} \mathrm{C}_{2} \mathrm{~T}_{\mathrm{x}}$ MXenes. Nevertheless, there are also other factors, discussed in the next sections, which play a key role in the efficient formation of MXene nanosheets.

Since the discovery of the first $\mathrm{Ti}_{3} \mathrm{C}_{2}$ MXene, more than twenty types of MXenes are synthesized and more than seventy MAX phases are experimentally produced. ${ }^{[7 \mathrm{a}, 7 \mathrm{c}]}$ In all of them, the yield of production, rate of defect, particle size, conductivity, and surface properties heavily depend on the optimization of reaction condition. ${ }^{[7 a, 12,31 b, 34]}$ For example Ffunctionalized MXenes were produced by HF as etchant, whereas O-functionalized MXenes were obtained by etching in a $\mathrm{LiF} / \mathrm{HCl}$ mixture. ${ }^{[34]}$ Table 1 has summarized different etching and delamination condition as well as intercalants used for the synthesis of MXenes with different chemical composition.

As previously mentioned, the ternary carbides/nitrides/carbonitride MAX phases are interleaved by A-element atoms. In the MAX phases, M-X bond is stronger than M-A bond and it possesses both metallic properties and covalent bonding, whereas the M-A bond is metallic and thus more chemically active. Therefore, the A layer can be selectively and easily removed by an appropriate etchant, resulting in multilayered MXenes with 2D layers stabilized by hydrogen bonds and van der Waals forces. ${ }^{[7 a, 7 c]}$ Generally, F-containing etchants, such as $\mathrm{HF}^{[6-7]}$, in situ-formed $\mathrm{HF}$ (e.g. generated by $\left.\mathrm{HCl} / \mathrm{LiF}\right),{ }^{[11,31 b]}$ and ammonium bifluoride $\left(\mathrm{NH}_{4} \mathrm{HF}_{2}\right)^{[35]}$ are employed to eliminate A-element atomic layers from the MAX phase. For example, efficient selective HF etching of the parent $M_{n+1} A X_{n}$ phases composed of Al was reported through the below summarized consecutive chemical reactions:

$$
\begin{array}{ll}
\mathrm{M}_{\mathrm{n}+1} \mathrm{AlX}_{\mathrm{n}}+3 \mathrm{HF} \rightarrow & \mathrm{M}_{\mathrm{n}+1} \mathrm{X}_{\mathrm{n}}+\mathrm{AlF}_{3}+1.5 \mathrm{H}_{2} \\
\mathrm{M}_{\mathrm{n}+1} \mathrm{X}_{\mathrm{n}}+2 \mathrm{H}_{2} \mathrm{O} \rightarrow & \mathrm{M}_{\mathrm{n}+1} \mathrm{X}_{\mathrm{n}}(\mathrm{OH})_{2}+\mathrm{H}_{2}
\end{array}
$$




\section{WILEY-VCH}

$\mathrm{M}_{\mathrm{n}+1} \mathrm{X}_{\mathrm{n}}+2 \mathrm{HF} \rightarrow \mathrm{M}_{\mathrm{n}+1} \mathrm{X}_{\mathrm{n}} \mathrm{F}_{2}+\mathrm{H}_{2}$

Equation 1 shows the generation of $\mathrm{M}_{\mathrm{n}+1} \mathrm{X}_{\mathrm{n}}$ MXene layers from the corresponding MAX phase of $\mathrm{M}_{\mathrm{n}+1} \mathrm{AlX}$. Equations 2 and 3 demonstrate the fabrication of $-\mathrm{OH}$ and $-\mathrm{F}$ terminated $\mathrm{M}_{\mathrm{n}+1} \mathrm{X}_{\mathrm{n}}$ from the initial compound through selective etching. ${ }^{[6]}$ In fact, after replacing the strong M-A bonds with the weak bonds of terminates, multi-layered stacked MXenes may become easily intercalated and delaminated to fabricate single layer MXenes. For example, the multi-layered $\mathrm{Ti}_{3} \mathrm{C}_{2} \mathrm{~T}_{\mathrm{x}}$ and $\mathrm{Mo}_{2} \mathrm{CT}_{\mathrm{x}}$ were easily and completely delaminated via a simple sonication in aqueous $\mathrm{HCl} / \mathrm{LiF}$ media. ${ }^{[12,36]}$ The desirable performance of delamination was related to the intercalated water and possibly cations sipped into the layers, which act as a lubricant and causes easier exfoliation in the presence of shearing. Molar ratio of LiF to multilayered MXene was a key experimental condition for efficient delamination yield. Wet etching performed in this study was a desirable replacement to mechanical exfoliation that gives a low yield of layer separation due to the strong metallic bonds between M-A and M-X elements. ${ }^{[37]}$ Nevertheless, much more studies should be conducted to improve the yield of methods for mass production of MXenes in order to move toward the commercialization of the MXene nanosheets. Gogotsi et al. ${ }^{[7 \mathrm{a}]}$ demonstrated that HF concentration is an important factor for determining the quality of MXenes. They showed that very high concentration of HF generates more defects in $\mathrm{Ti}_{3} \mathrm{C}_{2} \mathrm{~T}_{\times}$MXenes. ${ }^{[31 \mathrm{a}]}$ Their studies showed that 50 wt. \% HF, room temperature (RT), and $2 \mathrm{~h}$ of etching is enough to selectively extract $\mathrm{Al}$ from the $\mathrm{Ti}_{3} \mathrm{AlC}_{2}$ powder. ${ }^{[28]}$ They also studied the impact of etchant concentration on MXene morphologies. Synthesis of $\mathrm{Ti}_{3} \mathrm{C}_{2}$ with 10 wt.\% HF did not give an accordion like structure, whereas higher dosage of HF could result in such morphologies. ${ }^{[7 a]}$ It should be added that etching parameters, such as duration, type of transition metal $\mathrm{M}$, and operational temperature needs to be different for various types of $\mathrm{M}_{\mathrm{n}+1} \mathrm{AlX}$ in order to obtain favorable nanosheets. ${ }^{[7 \mathrm{c}, 38]}$ For instance, $2 \mathrm{~h}$ etching at RT by $50 \% \mathrm{HF}$ results in $\mathrm{Ti}_{3} \mathrm{C}_{2} \mathrm{~T}_{\mathrm{x}}$ flakes from $\mathrm{Ti}_{3} \mathrm{AlC}_{2}$, whereas the same procedure 


\section{WILEY-VCH}

will dissolve $\mathrm{Ti}_{2} \mathrm{AlC}$ since it needs lower $\mathrm{HF}$ concentration at the same temperature and etching time. ${ }^{[24]}$ Also, the higher bonding energy between $\mathrm{M}$ and A elements, correlating to the number of $\mathrm{M}$ valence electrons, requires higher $\mathrm{HF}$ concentration and longer etching time for removing $\mathrm{Al}$ from the parent $\mathrm{MAX}$ phase. For example, $\mathrm{Ti}_{2} \mathrm{AlC}$ needs lower concentration of the $\mathrm{HF}$ compared to $\mathrm{Nb}_{2} \mathrm{AlC}$ due to its lower atomic number. ${ }^{[24,39]}$ Temperature also plays a key role in the outcome of etching in certain ways, such as recrystallization or decomposition of $\mathrm{M}_{\mathrm{n}+1} \mathrm{X}_{\mathrm{n}} \mathrm{T}_{\mathrm{x}}$ at high temperatures. ${ }^{[24]}$ It is important to note that different wet etching techniques can create different surface properties and result in various characteristics for the manufactured MXenes. Meshkian et al. ${ }^{[40]}$ reported a successful procedure of selective etching of $\mathrm{Ga}$ using $\mathrm{HF}$ in $\mathrm{Mo}_{2} \mathrm{Ga}_{2} \mathrm{C}$ to synthesize $\mathrm{Mo}_{2} \mathrm{CT}_{\mathrm{x}}$ layers, while Zhou et al. ${ }^{[41]}$ produced $\mathrm{Zr}_{3} \mathrm{C}_{2} \mathrm{~T}_{\mathrm{x}}$ sheets by $\mathrm{HF}$ etching of $\mathrm{Zr}_{3} \mathrm{Al}_{3} \mathrm{C}_{5}$ that does not follow the general reaction for the formation of $M_{n+1} X_{n} T_{x}$.

Although acidic solution of HF is utilized as effective etchant, it is highly corrosive, harmful and even can decrease the performance of MXenes. Other alternative etchants to avoid harmful effects of $\mathrm{HF}$ are $\mathrm{NH}_{4} \mathrm{HF}_{2}{ }^{[35]}$ and $\mathrm{HCl} / \mathrm{LiF} \cdot{ }^{[1-12,31 \mathrm{a}]}$ For example, a safer etching of $\mathrm{Al}$ element in MAX phase was introduced by Halim et al. ${ }^{[42]}$, who fabricated $\mathrm{Ti}_{3} \mathrm{C}_{2}$ MXenes by replacing $\mathrm{HF}$ with $1 \mathrm{M} \mathrm{NH} \mathrm{NHF}_{2}$ solution to etch $\mathrm{Al}$ elements through the electrochemical intercalation of cations. They suggested that larger interlayer spacing obtained by this method can be related to intercalating of $\mathrm{NH}_{4}{ }^{+}$ions and water molecules between the inter layer space of MXenes. Wang et al. ${ }^{[44]}$ showed the remarkable impact of etching time, temperature and the concentration of $\mathrm{NH}_{4} \mathrm{HF}_{2}$ on the the quality of $\mathrm{Ti}_{3} \mathrm{C}_{2} \mathrm{~T}_{\mathrm{x}}$ flakes. In addition to $\mathrm{NH}_{4} \mathrm{HF}_{2}$, other bifluoride solutions, such as $\mathrm{KHF}_{2}$ and $\mathrm{NaHF}_{2}$ are successfully investigated for the transition of $\mathrm{Ti}_{3} \mathrm{AlC}_{2}$ to $\mathrm{Ti}_{3} \mathrm{C}_{2}$ nanosheets. ${ }^{[43]}$ In addition to bifluoride solutions as etchant, Ghidu et al. ${ }^{[12]}$ proposed a high yield method for preparing $\mathrm{Ti}_{3} \mathrm{C}_{2} \mathrm{~T}_{\mathrm{x}}$ using in situ-formed $\mathrm{HF}$ (i.e. generated by $\mathrm{HCl} / \mathrm{LiF}$ ). $\mathrm{HCl} / \mathrm{LiF}$ provides much milder and safer etching condition compared to HF and produced MXenes are less defective with larger lateral dimensions. ${ }^{[7 a]}$ It 


\section{WILEY-VCH}

should be noted that the concentration of the salt and strong acid has a great impact on the quality and size of MXene flakes. ${ }^{[7 a, 12,31]}$

Although HF treatment works well with carbides and carbonitride MXenes, it fails to eliminate A layer from nitride-based MXenes. In order to solve this problem, Urbankowski et $a l .{ }^{[45]}$ used molten salts, such as $\mathrm{LiF}, \mathrm{NaF}$, and $\mathrm{KF}$ to remove $\mathrm{Al}$ layers from $\mathrm{Ti}_{4} \mathrm{AlN}_{3}$. In 2018, fluorine- free, alkali-assisted synthesis of MXenes was reported by Li et al. ${ }^{[46]}$ In this study, selective removal of A layers was successfully performed by $27.5 \mathrm{M} \mathrm{NaOH}$ at $270{ }^{\circ} \mathrm{C}$, opening a new way toward the synthesis of MXenes without $\mathrm{HF}$ as etchant. However, $\mathrm{NaOH}$ mediated ething may only remove $\mathrm{Al}$ at the surface rather than in the bulk. ${ }^{[47]}$ Urbankowski et $a l{ }^{[48]}$ reported the transformation of $\mathrm{Mo}_{2} \mathrm{CT}_{\mathrm{x}}$ and $\mathrm{V}_{2} \mathrm{CT}_{\mathrm{x}}$ into nitride MXenes by ammoniation at $600{ }^{\circ} \mathrm{C}$ via the replacement of the $\mathrm{N}$ atoms with $\mathrm{C}$ atoms during the decomposition of ammonia molecules. The resulted $\mathrm{Mo}_{2} \mathrm{~N}$ could maintain the structure of MXenes while $\mathrm{V}_{2} \mathrm{CT}_{\mathrm{X}}$ transformed into a mixed layered structure of trigonal $\mathrm{V}_{2} \mathrm{~N}$ and cubic $\mathrm{VN}$. These examples show that many of MXenes have been prepared from Al-containing MAX phases. In contrast, Gogotsi et al. ${ }^{[49]}$ have recently developed a universal method for the large scale synthesis of $\mathrm{Ti}_{3} \mathrm{C}_{2}$ MXenes via oxidant-assisted selective etching of silicon from Si-containing MAX precursors. Various HF-oxidants, such as $\mathrm{HF} / \mathrm{H}_{2} \mathrm{O}_{2}, \mathrm{HF} /\left(\mathrm{NH}_{4}\right)_{2} \mathrm{~S}_{2} \mathrm{O}_{8}, \mathrm{HF} / \mathrm{HNO}_{3}$, $\mathrm{HF} / \mathrm{FeCl}_{3}$, and $\mathrm{HF} / \mathrm{KMnO}_{4}$ were employed to etch out $\mathrm{Si}$ layers from $\mathrm{Ti}_{3} \mathrm{SiC}_{2}$ and produce $\mathrm{Ti}_{3} \mathrm{C}_{2}$. In general, all these examples proved that the synthesis method has undeniable effect on the resulting MXene in terms of surface termination, yield of MXene formation and physicochemical properties. ${ }^{[7 \mathrm{a}]}$ 


\section{WILEY-VCH}

Table 1. Different etching and delamination condition used for the synthesis of MXene nanosheets.

\begin{tabular}{|c|c|c|c|c|c|c|c|}
\hline \multirow{2}{*}{$\begin{array}{l}\text { MAX- } \\
\text { phase }\end{array}$} & \multirow{2}{*}{ MXene } & \multicolumn{4}{|c|}{ Etching condition } & \multirow{2}{*}{ Delamination } & \multirow{2}{*}{ Ref. } \\
\hline & & Etchant & Concentration & $\begin{array}{c}\text { Time } \\
\text { (h) }\end{array}$ & $\mathrm{T}\left({ }^{\circ} \mathrm{C}\right)$ & & \\
\hline \multirow{7}{*}{$\mathrm{Ti}_{3} \mathrm{AlC}_{2}$} & \multirow{7}{*}{$\mathrm{Ti}_{3} \mathrm{C}_{2} \mathrm{~T}_{\mathrm{x}}$} & \multirow{2}{*}{$\mathrm{HF}$} & $10 \mathrm{wt} \%$ & 24 & RT & $\begin{array}{c}\text { Without } \\
\text { delamination }\end{array}$ & [34] \\
\hline & & & $50 \mathrm{wt} \%$ & 2 & $\mathrm{RT}$ & $\begin{array}{c}\text { Without } \\
\text { delamination }\end{array}$ & [24] \\
\hline & & $\mathrm{HCl} / \mathrm{LiF}$ & $\begin{array}{l}\mathrm{HCl}(6 \mathrm{M}) / \mathrm{LiF} \\
\quad(7.5 \mathrm{~mol})\end{array}$ & 24 & 35 & $\begin{array}{c}\text { Hand shaking } \\
\text { intercalated with } \\
\text { metal cations }\end{array}$ & {$[31 \mathrm{~b}]$} \\
\hline & & $\mathrm{HCl} / \mathrm{LiF}$ & $\begin{array}{l}\mathrm{HCl}(9 \mathrm{M}) / \mathrm{LiF} \\
\quad(5 \mathrm{~mol})\end{array}$ & 24 & 35 & $\begin{array}{c}\text { Sonication in DI } \\
\text { water } \\
+ \\
\text { intercalation with } \\
\text { metal cations } \\
\end{array}$ & [31b] \\
\hline & & $\mathrm{NH}_{4} \mathrm{OH}$ & $30 \%$ & 18 & RT & $\begin{array}{c}\text { Without } \\
\text { delamination }\end{array}$ & [34] \\
\hline & & $\mathrm{NH}_{4} \mathrm{HF}_{2}$ & $1 \mathrm{M}$ & 120 & RT & $\begin{array}{c}\text { Without } \\
\text { delamination }\end{array}$ & [35] \\
\hline & & $\mathrm{NaOH}$ & $27.5 \mathrm{M}$ & 12 & 270 & DMSO* & [46] \\
\hline $\mathrm{Ti}_{3} \mathrm{SiC}_{2}$ & $\mathrm{Ti}_{3} \mathrm{C}_{2} \mathrm{~T}_{\mathrm{x}}$ & $\mathrm{HF} / \mathrm{H}_{2} \mathrm{O}_{2}$ & $\begin{array}{c}\mathrm{HF}(17 \mathrm{M}) / \mathrm{H}_{2} \mathrm{O}_{2} \\
(11.7 \mathrm{M})\end{array}$ & 47 & $\begin{array}{l}\text { From } 5 \\
\text { to } 40\end{array}$ & $\begin{array}{c}\text { TMAOH* } \\
+ \\
\text { hand shaking or } \\
\text { sonication } \\
\end{array}$ & [49] \\
\hline $\mathrm{Ti}_{4} \mathrm{AlN}_{3}$ & $\mathrm{Ti}_{4} \mathrm{~N}_{3} \mathrm{~T}_{\mathrm{x}}$ & Molten sa & $\begin{array}{l}\text { alts of } \mathrm{LiF}, \mathrm{NaF} \text {, } \\
\text { and } \mathrm{KF}\end{array}$ & 0.5 & 550 & $\begin{array}{c}\text { TBOAH* } \\
+ \\
\text { sonication }\end{array}$ & [45] \\
\hline $\mathrm{Ti}_{3} \mathrm{AlC}_{2}$ & $\mathrm{Ti}_{3} \mathrm{C}_{2} \mathrm{~T}_{\mathrm{x}}$ & $\mathrm{HF}$ & $10 \mathrm{wt} \%$ & 10 & RT & $\begin{array}{c}\text { Without } \\
\text { delamination }\end{array}$ & [24] \\
\hline $\mathrm{Nb}_{2} \mathrm{AlC}$ & $\mathrm{Nb}_{2} \mathrm{CT}_{\mathrm{x}}$ & $\mathrm{HF}$ & $50 \mathrm{wt} \%$ & 90 & RT & $\begin{array}{c}\text { Without } \\
\text { delamination }\end{array}$ & [39] \\
\hline $\mathrm{Nb}_{2} \mathrm{AlC}$ & $\mathrm{Nb}_{2} \mathrm{CT}_{\mathrm{x}}$ & $\mathrm{HF}$ & $50 \mathrm{wt} \%$ & 90 & RT & $\begin{array}{c}\text { Isopropylamine } \\
+ \\
\text { sonication } \\
\end{array}$ & [29] \\
\hline $\begin{array}{c}\mathrm{Mo}_{2} \mathrm{TiAlC} \\
2\end{array}$ & $\begin{array}{c}\mathrm{Mo}_{2} \mathrm{TiC}_{2} \\
\mathrm{~T}_{\mathrm{x}}\end{array}$ & $\mathrm{HF}$ & $50 \mathrm{wt} \%$ & 48 & 55 & $\begin{array}{c}\text { TBOAH or DMSO } \\
+ \\
\text { sonication } \\
\end{array}$ & [8] \\
\hline $\begin{array}{c}\mathrm{Mo}_{2} \mathrm{Ti}_{2} \mathrm{Al} \\
\mathrm{C}_{3}\end{array}$ & $\begin{array}{c}\mathrm{Mo}_{2} \mathrm{Ti}_{2} \mathrm{C} \\
3 \mathrm{~T}_{\mathrm{x}}\end{array}$ & $\mathrm{HF}$ & $50 \mathrm{wt} \%$ & 96 & 55 & $\begin{array}{c}\text { TBOAH or DMSO } \\
+ \\
\text { sonication }\end{array}$ & [8] \\
\hline $\mathrm{Mo}_{2} \mathrm{Ga}_{2} \mathrm{C}$ & $\mathrm{Mo}_{2} \mathrm{CT}_{\mathrm{x}}$ & $\mathrm{HF}$ & $25 \mathrm{wt} \%$ & 160 & 55 & $\begin{array}{c}\text { TBOAH } \\
+ \\
\text { sonication }\end{array}$ & [40] \\
\hline $\mathrm{Zr}_{3} \mathrm{Al}_{3} \mathrm{C}_{2}$ & $\mathrm{Zr}_{3} \mathrm{C}_{2} \mathrm{~T}_{\mathrm{x}}$ & $\mathrm{HF}$ & $50 \mathrm{wt} \%$ & 72 & $\mathrm{RT}$ & $\begin{array}{c}\text { Without } \\
\text { delamination }\end{array}$ & [41] \\
\hline $\mathrm{Ti}_{3} \mathrm{AlC}_{2}$ & $\mathrm{Ti}_{3} \mathrm{C}_{2} \mathrm{~T}_{\mathrm{x}}$ & $\mathrm{KHF}_{2}$ and & $1 \mathrm{M}$ & 2 or 4 & 60 & Without & [43] \\
\hline
\end{tabular}




\begin{tabular}{|c|c|c|c|c|c|c|c|}
\hline & & $\mathrm{NaHF}_{2}$ & & & & delamination & \\
\hline $\mathrm{Ti}_{3} \mathrm{AlC}_{2}$ & $\mathrm{Ti}_{3} \mathrm{C}_{2} \mathrm{~T}_{\mathrm{x}}$ & $\mathrm{HF}$ & $50 \mathrm{wt} \%$ & 40 & $\mathrm{RT}$ & $\begin{array}{c}\text { aryl diazonium } \\
\text { salts }\end{array}$ & {$[50]$} \\
\hline
\end{tabular}

* DMSO: dimethylsolfoxide, TMAOH: tetramethylammonium hydroxide, TBOAH: tetrabutylammonium hydroxide

Multilayered MXenes produced by etching are usually so sticky (interlayer interactions are 6fold stronger than graphite) and delamination is required in order to obtain separated sheets. ${ }^{[7 a}$, 7c, 51] Due to the strong interlayer interaction, simple mechanical approaches, such as sonication results in low yield of single layered sheets. ${ }^{[30]}$ On the other hand, long time sonication may decrease the size of MXene sheets and even increases the rate of defects. ${ }^{[31 b]}$ Therefore, it is suggested to perform delamination process in the presence of an IA to weaken the interactions and thus increase the yield of delamination. ${ }^{[28]}$ The successful delamination of multi-layered MXenes is reported through sonication in water for $60 \mathrm{~min}$, exfoliating into mono-layered $\mathrm{Ti}_{3} \mathrm{C}_{2} \mathrm{~T}_{\mathrm{x}}$ and $\mathrm{Mo}_{2} \mathrm{CT}_{\mathrm{x}} \cdot{ }^{[12,36]} \mathrm{X}$-ray powder diffraction (XRD) measurements of the intercalated $\mathrm{Ti}_{3} \mathrm{C}_{2}$ MXenes showed greater distances between lattices as compared to the HF-treated MXenes. This difference is due to the presence of water or cations, which acts as a spacer between charged layers of MXene. ${ }^{[12]}$ Shorter etching time (24 h instead of $45 \mathrm{~h}$ ) and lower temperature reaction $\left(35{ }^{\circ} \mathrm{C}\right.$ instead of $\left.40{ }^{\circ} \mathrm{C}\right)$ in $\mathrm{Ti}_{3} \mathrm{AlC}_{2}$ gave higher Aluminum content, which was confirmed by energy-dispersive spectroscopy (EDX). This results in higher yield of delamination process. ${ }^{[12]}$ For $\mathrm{Mo}_{2} \mathrm{CT}_{\mathrm{x}}, 1 \mathrm{~h}$-sonication in water could increase the percentage of single flakes from $25 \%$ to $50 \%{ }^{[36]}$ Zhang et al. ${ }^{[52]}$ observed a remarkable increase in the delamination ratio for $\mathrm{Ti}_{3} \mathrm{C}_{2} \mathrm{~T}_{\mathrm{x}}$ MXenes from 6.5 to $29.2 \%$ by only washing with ethanol, followed by sonication in water for $1 \mathrm{~h}$. Lipatov et al. ${ }^{[31 \mathrm{~b}]}$ reported efficient delamination process of large flakes of $\mathrm{Ti}_{3} \mathrm{C}_{2} \mathrm{~T}_{\mathrm{x}}$ with low concentration of defects without sonication by only optimizing the ratio of LiF to MAX phase and increasing the amount of $\mathrm{HCl}$ in the etching step. Two different routes were used to synthesize $\mathrm{Ti}_{3} \mathrm{C}_{2} \mathrm{~T}_{\mathrm{x}}$. In the first route, $\mathrm{Ti}_{3} \mathrm{AlC}_{2}$ powder was immersed into a $\mathrm{LiF} / \mathrm{HCl}$ solution where the molar ratio of $\mathrm{LiF}$ to $\mathrm{MAX}$ phase was equal to $5: 1$. In route 2 , an excess of $\mathrm{Li}^{+}$ions was provided for intercalation 


\section{WILEY-VCH}

through increasing the molar ratio of $\mathrm{LiF}$ to $\mathrm{Ti}_{3} \mathrm{AlC}_{2}$ to $7.5: 1$. The etching of $\mathrm{Al}$ was also facilitated through two time-enhancement of the $\mathrm{HCl}$ to $\mathrm{LiF}$ ratio. As shown in scanning electron microscopy (SEM) images (Figure 2a), the size of the flakes produced by route 1 was $200-500 \mathrm{~nm}$ in diameter and some of them were not completely exfoliated. Route 2 resulted in flakes with substantially larger sizes, ranging from 4 to $15 \mu \mathrm{m}$. High-resolution transmission electron microscopy (HR-TEM) demonstrated hexagonal arrangement of atoms, showing that the crystal structures of both flakes are identical, further confirmed by selected area electron diffraction (SAED) patterns. Atomic force microscopy (AFM) was used to evaluate the thickness and shapes of the flakes produced by both methods (Figure $2 \mathrm{~b}$ ). The height profiles measured along the dashed lines show that the flakes produced by route 1 have non-uniform thicknesses, which supports incomplete exfoliation of MAX phase prepared using the route 1 . By contrast, the blue dashed line shows the same height of $\approx 2.7 \mathrm{~nm}$ for all $\mathrm{Ti}_{3} \mathrm{C}_{2} \mathrm{~T}_{\mathrm{x}}$ flakes prepared via route 2 . XRD patterns of the flakes fabricated with route 1 only showed 001 reflection, proving less ordered stacks compared to the flakes made with route 2 that demonstrated a series of $00 \mathrm{l}$ reflections as an indicative of layered structure of stacked flakes (Figure 2c). In addition, the MXene film made by route 2 required much effort to grind (even after considerable grinding and shredding it still had coarse and big flakes), while route 1 can easily be grounded into a powder (Figure $2 \mathrm{~d}$ ). Therefore, $\mathrm{Ti}_{3} \mathrm{C}_{2} \mathrm{~T}_{\mathrm{x}} \mathrm{MXenes}$ produced by route 2 are expected to form more mechanically stable structures. Figure $2 \mathrm{e}$ shows the schematic process of producing $\mathrm{Ti}_{3} \mathrm{C}_{2} \mathrm{~T}_{\mathrm{x}}$ flakes through the both routes. 


\section{WILEY-VCH}
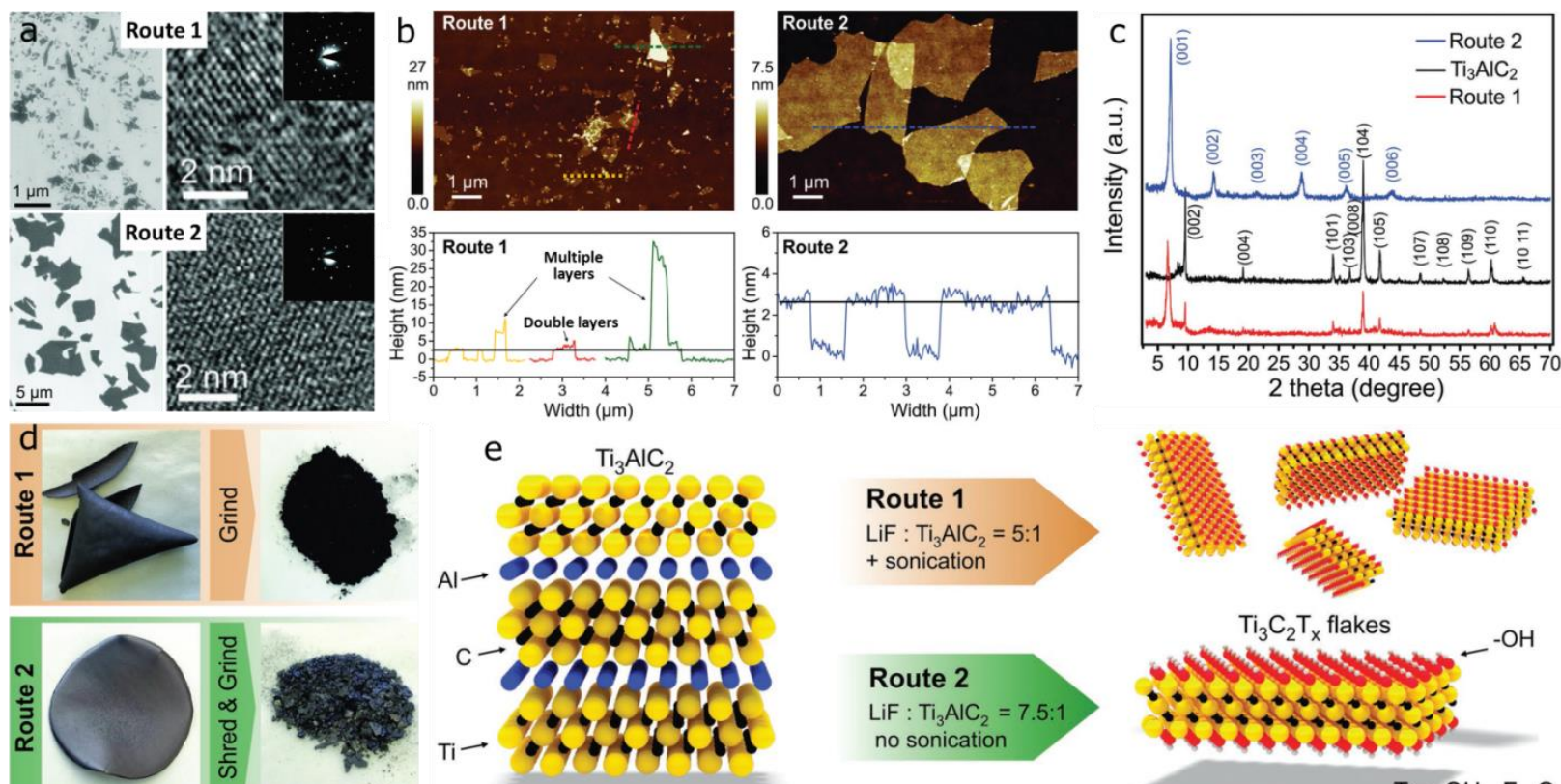

\section{Route 1}

LiF : $\mathrm{Ti}_{3} \mathrm{AlC}_{2}=5: 1$

+ sonication

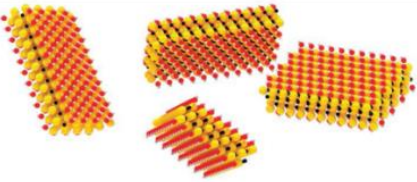

$\mathrm{Ti}_{3} \mathrm{C}_{2} \mathrm{~T}_{\mathrm{x}}$ flakes $-\mathrm{OH}$

\section{Route 2}

$\mathrm{LiF}: \mathrm{Ti}_{3} \mathrm{AlC}_{2}=7.5:$

no sonication

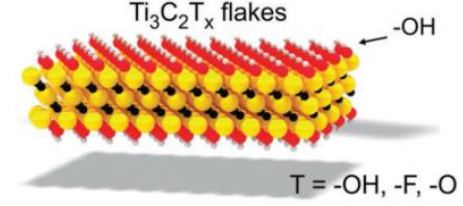

Figure 2. (a) SEM images of $\mathrm{Ti}_{3} \mathrm{C}_{2} \mathrm{~T}_{\mathrm{x}}$ flakes produced using Route 1 and Route 2 as well their HR-TEM images and SAED of monolayer 2D crystals. (b) AFM images of the MXene flakes and their height profiles measured along the dashed lines. The colors of the height profiles correspond to the colors of the dashed lines in AFM images. (c) XRD patterns of original $\mathrm{Ti}_{3} \mathrm{AlC}_{2}$ in comparison with $\mathrm{Ti}_{3} \mathrm{C}_{2} \mathrm{~T}_{\mathrm{x}}$ flakes which are prepared with two different routes. (d) Optical photographs of two different MXene papers before and after grinding (e) Schematic presentation of synthesis process of $\mathrm{Ti}_{3} \mathrm{C}_{2} \mathrm{~T}_{\mathrm{x}}$ flakes using both methods. Reproduced with permission. ${ }^{[31 b]}$ Copyright 2016, Wiley-VCH.

Another similar sonication-less process was proposed by Shahzad et al. ${ }^{[11]}$ They found that using $\mathrm{HCl}$ concentration larger than $6 \mathrm{M}(\mathrm{e} . \mathrm{g} ., 9 \mathrm{M})$ can lead to higher delamination of $\mathrm{Ti}_{3} \mathrm{C}_{2} \mathrm{~T}_{\mathrm{x}}$ and producing higher amount of MXene in colloidal solution. This is mainly due to the higher concentration of $\mathrm{H}^{+}$protons to exchange with lithium ions. Few types of Mxene nanosheets, such as $\mathrm{Ti}_{3} \mathrm{C}_{2} \mathrm{~T}_{\mathrm{x}}$ and $\mathrm{Mo}_{2} \mathrm{CT}_{\mathrm{x}}$, are so far produced via mere $\mathrm{HCl} / \mathrm{LiF}$ etching process to delaminate the MAX phases. Therefore, using the same technique is worthy for the synthesis of single-layered MXenes with other compositions. 


\section{WILEY-VCH}

$\mathrm{HF}$ mediated etching and delamination of $\mathrm{Ti}_{3} \mathrm{C}_{2} \mathrm{~T}_{\mathrm{x}}$ with mechanical sonication is also reported by Ghidiu et al. ${ }^{[12]}$, demonstrating the potential of intercalated water to reduce the shear stress and friction by acting as a lubricant between the layers of the MXenes. This study shows that the delaminating effect of intercalants can depend on the type of MXene and the technique used for its production. Hence, new intercalants and their impact on the delamination of different MXenes should be investigated in future.

Although weak Van der Waals interactions are dominant bonding forces between the layers of MXenes, the mere sonication of the HF-etched MXenes without using proper IAs will not be able to produce flat single flakes in a high yield as reported by Naguib et al. ${ }^{[6]}$ (Figure $\left.3 \mathrm{a}_{1}-3 \mathrm{a}_{3}\right)$. They showed that the exfoliation through sonication in the absence of appropriate IAs caused some nanosheets to roll into scrolls (Figure $3 \mathrm{a}_{4}$ and $3 \mathrm{a}_{5}$ ). In some cases where a high yield process is required to turn the MXene sheets (e.g., $\mathrm{Ti}_{2} \mathrm{C}$ ) into scrolls to form MXene nanotubes, p-phosphonic acid calix[8]arene $\left(\mathrm{PCX}_{8}\right)$ sonication process can be performed to get scrolls with diameters ranging between $0.5-0.9 \mu \mathrm{m},{ }^{[53]}$ as shown in Figure $3 b_{1}$. The effect of PCXn $(n=4,5,6,8)$ on the morphology of MXenes is shown in Figure $3 b_{2}-$ $3 b_{5}$. 


\section{WILEY-VCH}
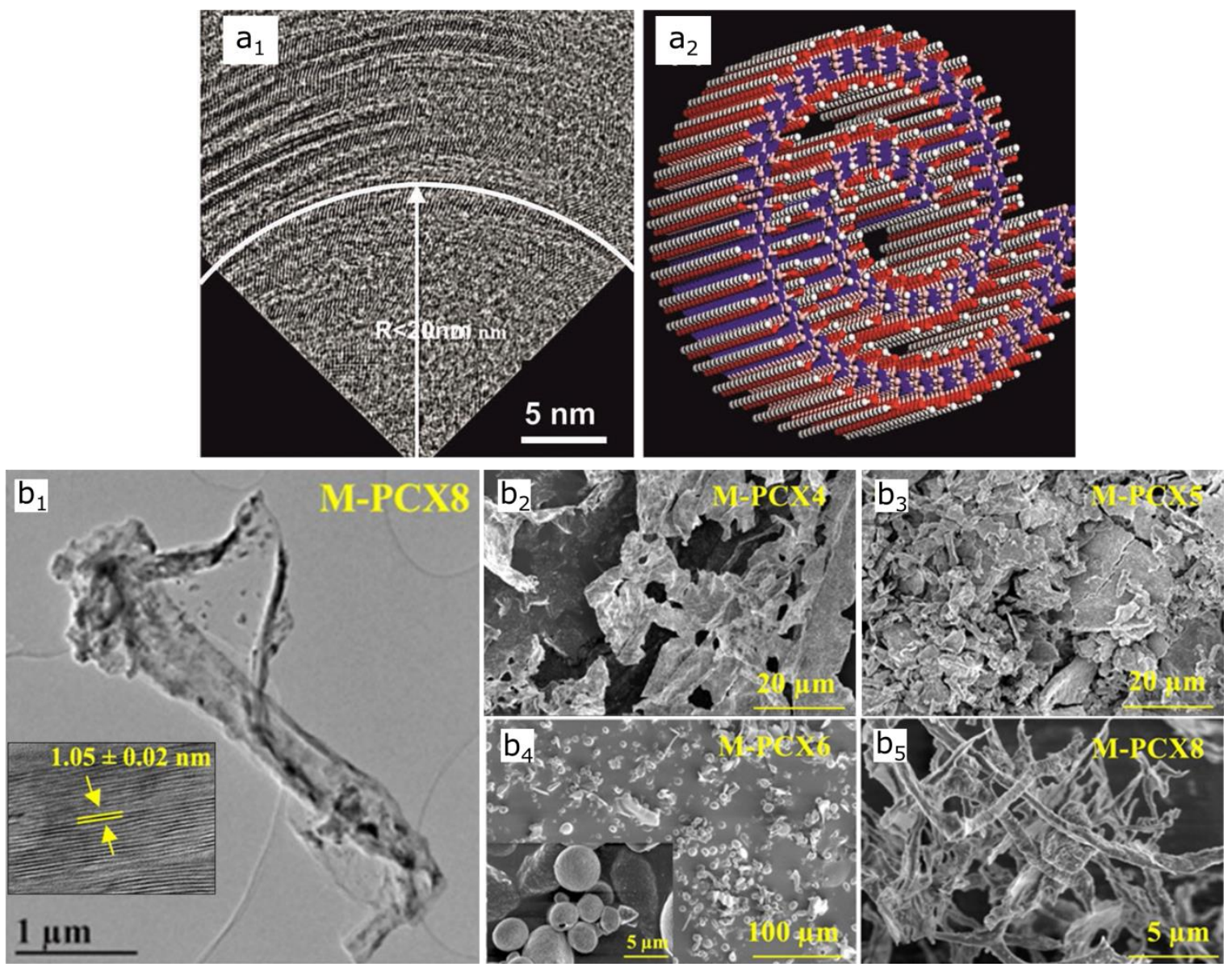

Figure 3. (a) TEM image and simulated structure of scrolled MXene. (a $a_{1}$ Cross-sectional TEM image of a scroll with an inner radius of less than $20 \mathrm{~nm}$. This observation revealed that the exfoliated layers can roll into conical shapes and some can bend to radii of less than 20 nm. (a 2 ) Schematic view of $\mathrm{OH}$-terminated scrolled nanosheet. Reproduced with permission. ${ }^{[6]}$ Copyright 2011, Wiley-VCH. $\left(b_{1}\right)$ TEM image of Scroll-like M-PCX8. The inset shows an average lattice spacing of $1.05 \mathrm{~nm}$ for M-PCX8 sheets, which is similar to reported values for lattice spacing observed for sodium ion intercalated $\mathrm{Ti}_{2} \mathrm{CT}_{\mathrm{x}}{ }^{\left[{ }^{[54]}\right.}\left(\mathrm{b}_{2}-\mathrm{b}_{5}\right)$ SEM images of effect of $\mathrm{PCX}_{\mathrm{n}}(\mathrm{n}=4,5,6$ and 8) assisted sonication on morphology of the MXenes. Thin sheet like morphology $\left(b_{2}\right)$, sheet-like and crumpled morphologies $\left(b_{3}\right)$, spherical particles $\left(b_{4}\right)$, and scroll-like morphologies $\left(b_{5}\right)$ were observed. Reproduced with permission. ${ }^{[53]}$ Copyright 2017, Wiley-VCH.

Mashtalir et al. ${ }^{[28]}$ reported high yield intercalation of Fluorine-terminated $\mathrm{Ti}_{3} \mathrm{C}_{2}(\mathrm{~F}-$ $\mathrm{Ti}_{3} \mathrm{C}_{2}$ ) with urea, hydrazine monohydrate $\mathrm{N}_{2} \mathrm{H}_{4} \cdot \mathrm{H}_{2} \mathrm{O}(\mathrm{HM})$, HM dissolved in $N, N$ dimethylformamide (DMF), and dimethyl sulphoxide (DMSO). They showed that $18 \mathrm{~h}$ stirring of $\mathrm{F}_{-} \mathrm{Ti}_{3} \mathrm{C}_{2}$ at room temperature with intercalant, followed by a weak sonication in water (6 h at RT) could produce MXene sheets. In the same work, other organic intercalants such as acetone, ethanol, tetrahydrofuran, toluene, chloroform, formaldehyde and thiophene were tested. However, only the intercalation of DMSO could efficiently delaminate stacked F- 


\section{WILEY-VCH}

$\mathrm{Ti}_{3} \mathrm{C}_{2}$ layers into separated 2D sheets. Urea and $\mathrm{HM}$ dissolved in DMF also showed desirable results by demonstrating an increase in c-lattice parameter (c-LP) from $19.5 \pm 0.1 \AA$ to 25.00 $\pm 0.02 \AA$ and $26.8 \pm 0.1 \AA$ for urea and HM in DMF, respectively. SEM images of F$\mathrm{Ti}_{3} \mathrm{C}_{2}$, before and after HM treatment in DMF revealed that the MXene remains exfoliated after intercalation and the multilayers thicken by assembly of individual monolayers together, forming 20-50-nm-thick lamellas (Figure 4a and Figure 4b). SAED patterns of F$\mathrm{Ti}_{3} \mathrm{C}_{2}$ intercalated with $\mathrm{HM}$ in DMF demonstrated unchanged basal planes' hexagonal structure of the MXenes after intercalation (Figure 4c and Figure 4d). Shifts of major XRD patterns (Figure 4e) after the intercalation of DMSO and urea proved the success of these intercalants for the delamination of $\mathrm{Ti}_{3} \mathrm{C}_{2} \mathrm{~T}_{\mathrm{x}}$ according to the process shown in Figure $4 \mathrm{f}$. 


\section{WILEY-VCH}

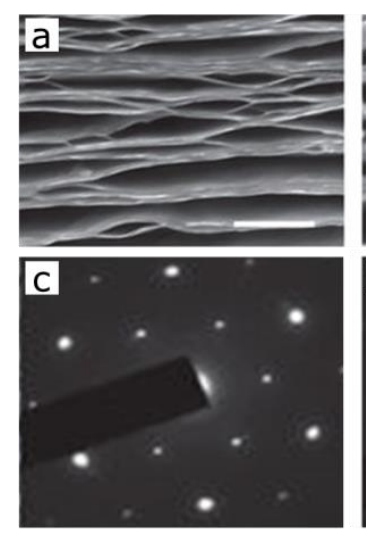

e
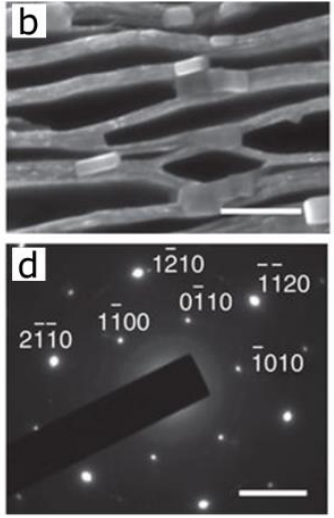

Si
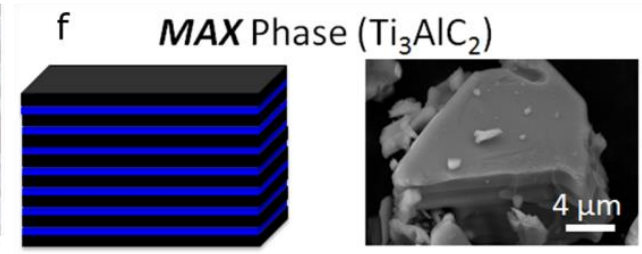

MAX phase particles samples synthesized

\section{Exfoliation}

Stacked MXene

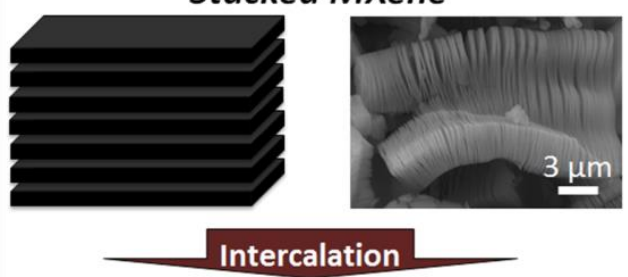

Chemical exfoliation of A-group element (Al) yielded stacked MXene $\left(\mathrm{Ti}_{3} \mathrm{C}_{2}\right)$

\section{Intercalated MXene}

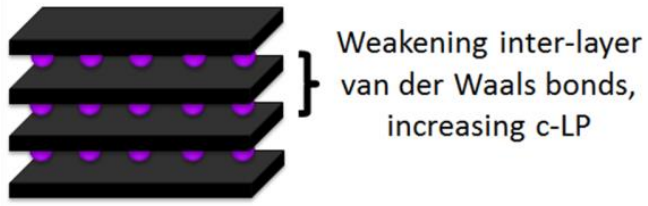

Intercalation between the layers of MXene

\section{Sonication}

Single 2D MXene Sheets
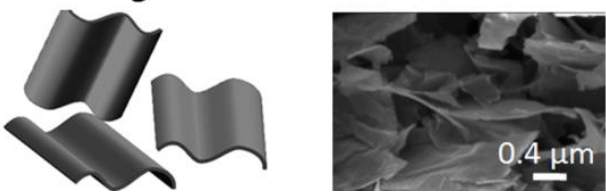

Weak sonication brakes inter-layer bonds

Figure 4. (a,b) SEM images of $\mathrm{F}_{-} \mathrm{Ti}_{3} \mathrm{C}_{2}$ sheets before (a) and after (b) intercalation with DMF and $\mathrm{HM}$ for $24 \mathrm{~h}$ at $80^{\circ} \mathrm{C}$ (Scale bars are $10 \mathrm{~nm}$ in both images). (c,d) SAED patterns of the $\mathrm{F}_{-} \mathrm{Ti}_{3} \mathrm{C}_{2}$ before (c) and after (d) intercalation (scale bars are $4 \mathrm{~nm}$ and $4 \mathrm{~nm}^{-1}$, respectively). (e) XRD patterns of $\mathrm{F}_{-} \mathrm{Ti}_{3} \mathrm{C}$ before treatment (i), after $30 \mathrm{~min}$ (blue) and 3 weeks (red) of treatment with DMSO (ii) as well as after urea treatment (iii). Schematic of delamination process of MXene flakes. Reproduced with permission. ${ }^{[28]}$ Copyright 2013, Nature Publishing Group.

Naguib et al. ${ }^{[30]}$ introduced large scale delamination technique in which the MXenes powders, including $\mathrm{Ti}_{3} \mathrm{CNT}_{\mathrm{x}}, \mathrm{V}_{2} \mathrm{CT}_{\mathrm{x}}$, and $\mathrm{Nb}_{2} \mathrm{CT}_{\mathrm{x}}$ were treated with organic base, tetrabutylammonium hydroxide $(\mathrm{TBAOH})$ to induce significant swelling, which subsequently weakens the bonds among the MXene layers. A mild hand shaking step or sonication in water could result in large scale single flakes of MXenes (Figure 5a). Strong organic bases, such as choline hydroxide as well as weak bases like n-butylamine were also tested and could enforce swelling effect in the MXenes. However, the observed effect was less profound than TBAOH.

The c-LP value increased to $36 \AA$ after 4 h-treatment in choline hydroxide and to $36.3 \AA ̊$ in n- 


\section{WILEY-VCH}

butylamine treated samples for $\mathrm{V}_{2} \mathrm{CT}_{\mathrm{x}}$ MXenes. XRD measurements of $\mathrm{V}_{2} \mathrm{CT}_{\mathrm{x}}$ treated with different solutions confirmed a significant shift in the 0002 peaks for TBAOH as compared to other basic solutions. Application of TBAOH for delamination of multilayered $\mathrm{Ti}_{4} \mathrm{~N}_{3} \mathrm{~T}_{\mathrm{x}}$ into single- or few-layered flakes followed by sonication step was also reported by Urbankowski et $a l{ }^{[45]}$ In this study, $\mathrm{Ti}_{4} \mathrm{AlN}_{3}$ was etched by molten fluoride salt and delaminated by TBOAH via hand-shaking for $5 \mathrm{~min}$ (Figure 5b). The resulting single- and few-layered MXene flakes were few hundred nanometers in size. Mashtalir et al. ${ }^{[29]}$ intercalated $\mathrm{Nb}_{2} \mathrm{CT}_{\mathrm{x}}$ by isopropylamine (i-PrA) aqueous solution diluted with DI water and stirred for $18 \mathrm{~h}$ at RT. The reason for choosing $\mathrm{i}-\operatorname{PrA}$ is that first, once $\mathrm{i}-\operatorname{PrA}$ is mixed with water, it forms ammonium cation $\mathrm{R}_{-} \mathrm{NH}_{3}{ }^{+}$, which can intercalate into layers of the MXene with taking the advantage of electrostatic forces (Figure 5c). Secondly, i-PrA molecules have optimum size that makes them able to overcome the steric hindrance during intercalation due to their small size. On the other hand, they are sufficiently big to push the MXene layers apart and accomplish the delamination process. After centrifuging for $10 \mathrm{~min}$, the intercalated $\mathrm{Nb}_{2} \mathrm{CT}_{\mathrm{x}}$ powder was sonicated in DI water for $1 \mathrm{~h}$. A considerable portion of the flakes were folded or curved that shows their favorable flexibility. This study also showed that i-PrA can be used for intercalation of other MXenes like $\mathrm{Nb}_{4} \mathrm{C}_{3} \mathrm{~T}_{\mathrm{x}}$ and $\mathrm{Ti}_{3} \mathrm{C}_{2} \mathrm{~T}_{\mathrm{x}} \cdot{ }^{[29]}$ 


\section{WILEY-VCH}
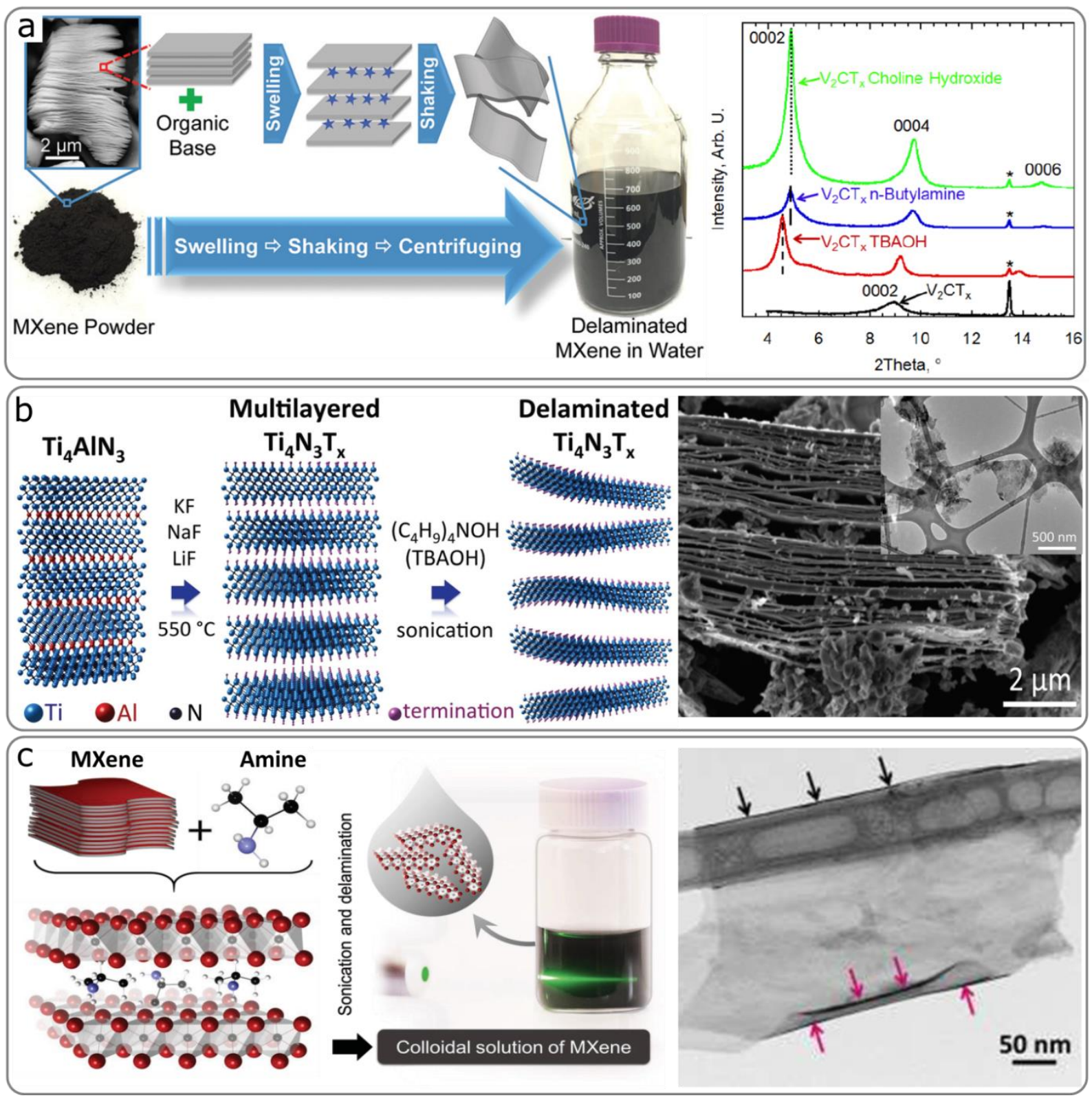

Figure 5. (a) Schematic illustration of MXene delamination process using TBAOH organic base to obtain multilayered MXene powder, which can remarkably swell and then form a stable colloidal solution by simply hand shaking. XRD peaks of $\mathrm{V}^{2} \mathrm{CT}_{\mathrm{x}}$ MXene sample before (black color) and after treating with various organic bases like TBAOH (red), n-butylamine (blue), and choline hydroxide (green) at room temperature for $4 \mathrm{~h}$. Reproduced with permission. ${ }^{[30]}$ Copyright 2015, Royal Society of Chemistry. (b) Schematic overview of $\mathrm{Ti}_{4} \mathrm{~N}_{3} \mathrm{~T}_{\mathrm{x}}$ synthesis by molten salt treatment of $\mathrm{Ti}_{4} \mathrm{AlN}_{3}$ at $550{ }^{\circ} \mathrm{C}$ under Ar, followed by TBAOH mediated delamination of the multilayered MXene. SEM image of $\mathrm{Ti}_{4} \mathrm{AlN}_{3}$ treated by molten salt shows typical accordion-like structures, indicating an evidence of successful etching of the $\mathrm{Ti}_{4} \mathrm{AlN}_{3}$ to form $\mathrm{Ti}_{4} \mathrm{~N}_{3}$. The top right inset shows TEM micrograph of several delaminated $\mathrm{Ti}_{4} \mathrm{~N}_{3} \mathrm{~T}_{\mathrm{x}}$ flakes. Reproduced with permission. ${ }^{[45]}$ Copyright 2016, Royal Society of Chemistry. (c) Schematic of $\mathrm{Nb}_{2} \mathrm{CT}_{\mathrm{x}}$ delamination process via isopropylamine intercalation. The blue, red, black and white spheres represent nitrogen, niobium, carbon, and hydrogen, respectively. In the TEM image, black and pink arrows show folded regions and curved edges of the delaminated $\mathrm{Nb}_{2} \mathrm{CT}_{\mathrm{x}}$ sheets, respectively. Reproduced with permission. ${ }^{[29]}$ Copyright 2015, Wiley-VCH. 


\section{WILEY-VCH}

Wang et al.$^{[50]}$ proposed a simple method for delamination of $\mathrm{Ti}_{3} \mathrm{C}_{2}$ with the assistance of aryl diazonium salts. The procedure was initiated with the intercalation of $\mathrm{HF}$-etched $\mathrm{Ti}_{3} \mathrm{C}_{2}$ multilayers with ions of $\mathrm{Na}^{+}$. The diazonium salt solution was then added slowly to the intercalated MXene solution while stirring at $0-5{ }^{\circ} \mathrm{C}$ for about $4 \mathrm{~h}$. Adding aryl groups to the negatively charged surfaces of MXenes can help weakening the cohesive bonding between the layers of the MXenes along the intercalating positive ions, which results in large scale multilayered flakes. Fluoride-free fabrication of single-layered $\mathrm{Ti}_{3} \mathrm{C}_{2}$ flakes by etching the $\mathrm{Ti}_{3} \mathrm{AlC}_{2}$ with $\mathrm{KOH}$ and water is also reported. ${ }^{[55]}$ The $\mathrm{OH}$ groups were able to take the place of $\mathrm{Al}$ in the $\mathrm{MAX}$ phase and by washing the solution with $\mathrm{H}_{2} \mathrm{O}$ to remove $\mathrm{KAlO}_{2}$ by-products, mono-layered $\mathrm{Ti}_{3} \mathrm{C}_{2}(\mathrm{OH})_{2}$ nanosheets with the thickness of about $1.5 \mathrm{~nm}$ could be fabricated. Most of the above-explained MXenes are fabricated through top-down methods, i.e. exfoliation of bulk precursors into monolayer or few-layer sheets, resulting in poor control over surface chemistry, morphology, structure and defects. Therefore, development of new bottom-up procedures is needed for better control over physico-chemical properties of MXenes. Furthermore, large scale synthesis of MXenes through safer and robust methods and expanding of the 2D-materials through synthesis of new MXenes require further investigation.

\section{Biomedical applications of MXenes}

\subsection{Antibacterial activity of MXenes}

Annually, many people pass away across the world from infectious diseases, such as dysentery and pneumonia. Different antibacterial agents (e.g. kanamycin, spectinomycin, and penicillin) have been administered by physicians to control or diminish the growth of microorganisms. ${ }^{[56]}$ However, over-usage of these bactericidal drugs have resulted in gradual resistance of bacteria, neutralizing the proper function of antibacterial molecules. ${ }^{[57]}$ This fact obliges the health communities to discover novel bactericidal compounds. ${ }^{[58]}$ Therefore, the main objective of a majority of studies in this field is to develop novel antibacterial agents to alleviate the gradual resistance phenomenon of various bacterial strains. In the recent decade, 


\section{WILEY-VCH}

the appearance of many 2D nanomaterials has brought an excellent chance to fabricate highly efficient antibacterial agents. Chemical and physical factors both play key roles in the antimicrobial activities of 2D materials against Gram-positive and Gram-negative bacteria. ${ }^{[59]}$ Increased permeability across the membrane, cell membrane rupture, reduced metabolic activity, DNA destruction, and cellular membrane stress induced by sharp edges of 2D materials (physical damage of cell membranes) have been reported as the main antibacterial mechanisms of novel 2D nanomaterials. ${ }^{[60]}$ The latest family of 2D materials - transition metal carbides, carbonitrides and nitrides nanosheets - are typically employed as high-potential antibacterial agents with high stability and long-life cycle. ${ }^{[17,60 e, 61]}$ Bestowed with large specific surface area, feasibility of chemical manipulation and functionalization, and promising potential for loading different antibacterial functional groups, MXenes are proposed as promising candidates to inhibit the growth of bacteria and fungi. Rasool et al. ${ }^{[17 a]}$ synthesized single- and few-layer $\mathrm{Ti}_{3} \mathrm{C}_{2} \mathrm{~T}_{\mathrm{x}}$ MXenes via wet-based selective chemical etching of "Al" in $\mathrm{Ti}_{3} \mathrm{AlC}_{2}$ phase along with delaminating $\mathrm{Ti}_{3} \mathrm{C}_{2} \mathrm{~T}_{\mathrm{x}}$ powders by ultrasonication for 30 minutes at 450 watts. Then, the antibacterial activities of single- and few-layer $\mathrm{Ti}_{3} \mathrm{C}_{2} \mathrm{~T}_{\mathrm{x}}$ MXene flakes were evaluated against Gram-negative E. coli and Gram-positive B. subtilis bacteria. They investigated the inhibition effect of MAX phase $\left(\mathrm{Ti}_{3} \mathrm{AlC}_{2}\right)$, unexfoliated (multilayer $\mathrm{Ti}_{3} \mathrm{C}_{2} \mathrm{~T}_{\mathrm{x}}$ ) and exfoliated (mono-layer $\mathrm{Ti}_{3} \mathrm{C}_{2} \mathrm{~T}_{\mathrm{x}}$ ) MXene sheets against both $E$. coli and $B$. subtilis bacteria. Based on the colony counting method, the order of antibacterial activity against both bacterial strains was mono-layer $\mathrm{Ti}_{3} \mathrm{C}_{2} \mathrm{~T}_{\mathrm{x}} \gg$ multi-layer $\mathrm{Ti}_{3} \mathrm{C}_{2} \mathrm{~T}_{\mathrm{x}}>\mathrm{Ti}_{3} \mathrm{AlC}_{2}$, showing the relationship between the thickness of MXenes and antibacterial activity. Also, they observed a sharp drop in the number of E. coli or B. subtilis bacteria colonies with increasing dosage of $\mathrm{Ti}_{3} \mathrm{C}_{2} \mathrm{~T}_{\mathrm{x}}$, which is shown in Figure 6a. A comparison between $\mathrm{Ti}_{3} \mathrm{C}_{2} \mathrm{~T}_{\mathrm{x}}$ and widely-used 2D antibacterial agent (graphene oxide) showed much greater antibacterial activity of MXene toward both the E. coli and B. subtilis. The optical densities (OD) growth curves of both E. coli and B. subtilis cells (Figure 6b) demonstrated dose-dependent 


\section{WILEY-VCH}

bactericidal activity of $\mathrm{Ti}_{3} \mathrm{C}_{2} \mathrm{~T}_{\mathrm{x}}$. To investigate the mechanism of the antibacterial effect, different morphological characterizations, such as SEM and TEM of the bacteria were tested after treatment with the MXenes. SEM images of bacterial cells of E. coli and B. subtilis (Figure 6c) showed no membrane damage or cell death in the absence of $\mathrm{Ti}_{3} \mathrm{C}_{2} \mathrm{~T}_{\mathrm{x}}$ MXene sheets. On the other hand, at $100 \mu \mathrm{g} / \mathrm{mL}$ of $\mathrm{Ti}_{3} \mathrm{C}_{2} \mathrm{~T}_{\mathrm{x}}$, bacterial cells of E. coli and B. subtilis showed obvious membrane damage and cytoplasm leakage. The red circles in panel 2 show this phenomenon obviously. Additionally, evidences of the cell wall and membrane damage were identified by TEM imaging (panel 3). TEM images of E. coli and B. subtilis, exposed to $200 \mu \mathrm{g} / \mathrm{mL}$ of $\mathrm{Ti}_{3} \mathrm{C}_{2} \mathrm{~T}_{\mathrm{x}}$, illustrated that MXene sheets can interact with the cellular membranes of both bacteria, strip down the cell walls and enter within the bacteria. ${ }^{[17 a]}$ Lactate dehydrogenase (LDH) release assay was also performed to quantitatively find the extent of cell damage, showing the concentration-dependent cytotoxicity of $\mathrm{Ti}_{3} \mathrm{C}_{2} \mathrm{~T}_{\mathrm{x}}$.
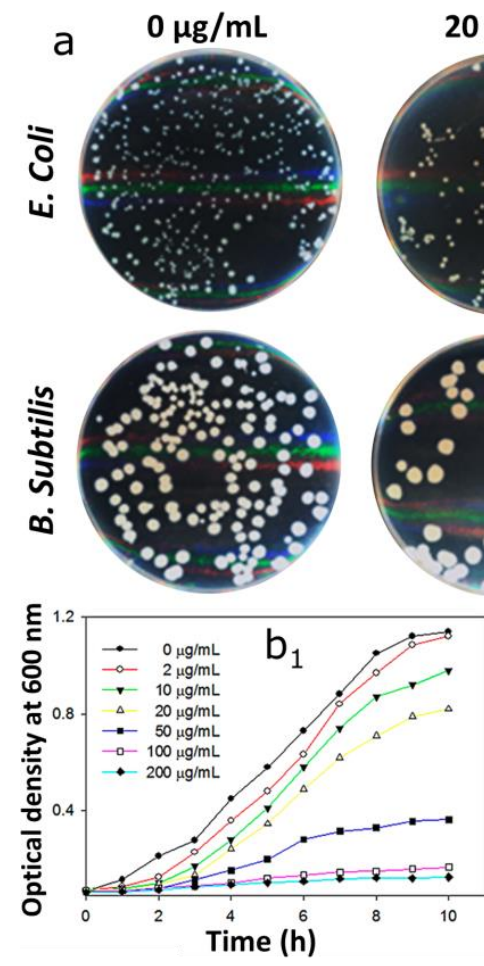
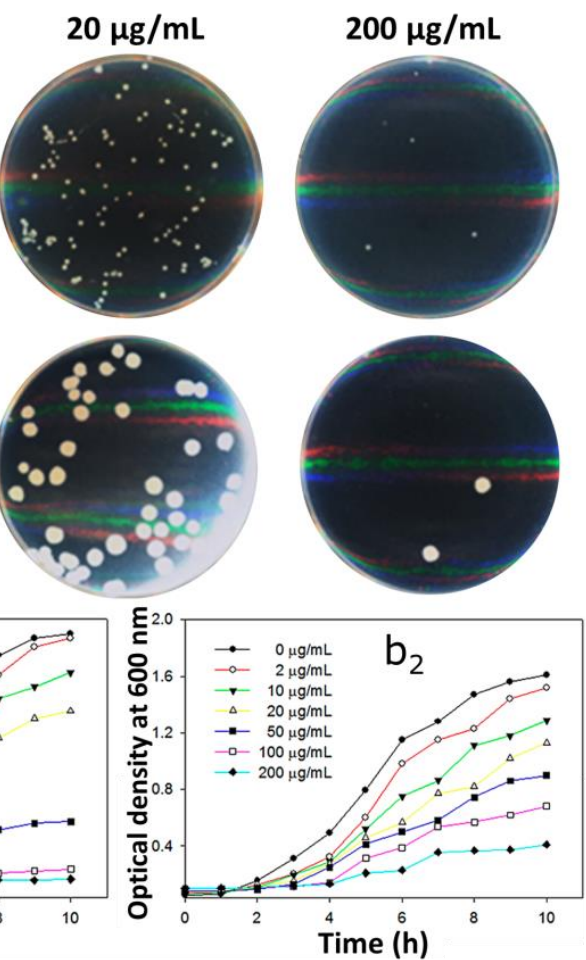
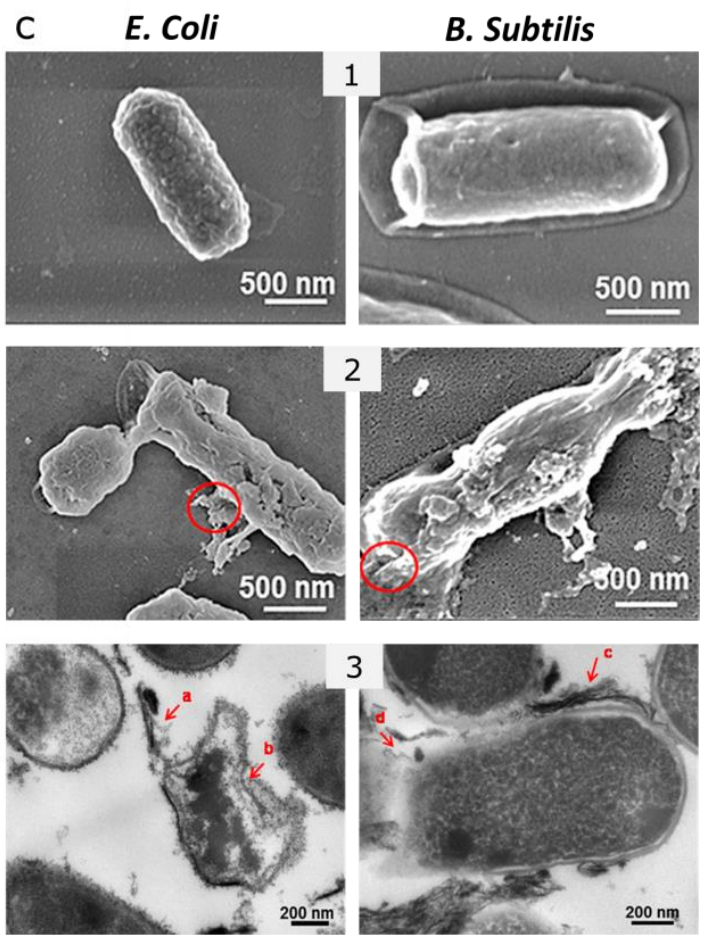

Figure 6. (a) Antibacterial activities of the $\mathrm{Ti}_{3} \mathrm{C}_{2} \mathrm{~T}_{\mathrm{x}}$ MXene sheets as a function of concentration. Photographs of agar plates used for the growth of E. coli and B. subtilis bacterial cells treated with $0 \mu \mathrm{g} / \mathrm{mL}$ (a), $20 \mu \mathrm{g} / \mathrm{mL}$ (b), and $200 \mu \mathrm{g} / \mathrm{mL}$ of $\mathrm{Ti}_{3} \mathrm{C}_{2} \mathrm{~T}_{\mathrm{x}}$. (b) Optical density-time chart of $E$. coli $\left(\mathrm{b}_{1}\right)$ and $B$. subtilis $\left(\mathrm{b}_{2}\right)$ in LB broth for bacterial suspensions loaded with various dosages of $\mathrm{Ti}_{3} \mathrm{C}_{2} \mathrm{~T}_{\mathrm{x}}$. SEM images of the E. coli and B. subtilis exposed to $0 \mu \mathrm{g} / \mathrm{mL}$ (panel 1) and $100 \mu \mathrm{g} / \mathrm{mL}$ (panel 2) of $\mathrm{Ti}_{3} \mathrm{C}_{2} \mathrm{~T}_{\mathrm{x}}$. Red circles show membrane 


\section{WILEY-VCH}

disruption and cytoplasm leakage. Panel 3 shows TEM images of E. coli and B. subtilis after exposure to $200 \mu \mathrm{g} / \mathrm{mL}$ of $\mathrm{Ti}_{3} \mathrm{C}_{2} \mathrm{~T}_{\mathrm{x}}$ nanosheets. Red arrows (a and c) show the accumulation of $\mathrm{Ti}_{3} \mathrm{C}_{2} \mathrm{~T}_{\mathrm{x}}$ nanosheets around the cell as well as cell wall rupture (b and d). Reproduced with permission. ${ }^{[17 \mathrm{a}]}$ Copyright 2016, American Chemical Society.

In another study, ${ }^{[60]}$ the same research group fabricated micrometer-thick $\mathrm{Ti}_{3} \mathrm{C}_{2} \mathrm{~T}_{\mathrm{x}} \mathrm{MXene-}$ based membranes with antibacterial properties. The fresh $\mathrm{Ti}_{3} \mathrm{C}_{2} \mathrm{~T}_{\mathrm{x}}$ MXene-based membranes showed the antibacterial rate of $67 \%$ against $E$. coli and $73 \%$ against $B$. subtilis as compared with that of polyvinylidene fluoride (PVDF) membrane used as control. Interestingly, the aged $\mathrm{Ti}_{3} \mathrm{C}_{2} \mathrm{~T}_{\mathrm{x}}$ MXene-based membranes could inhibit more than $99 \%$ of bacterial growth. According to the flow cytometry result, $70 \%$ of both bacteria were dead after exposure to the membranes for $24 \mathrm{~h}$. In line with other reports, ${ }^{[17 a]}$ damage of the cell surfaces was reported as the main mechanism of growth inhibition of both bacteria, which were morphologically confirmed via SEM and atomic force microscopy (AFM) analysis. In contrary to the $\mathrm{Ti}_{3} \mathrm{C}_{2} \mathrm{~T}_{\mathrm{x}}$ with superior toxicity toward bacteria, Jastrzębska et al. ${ }^{[61 b]}$ reported lack of bactericidal properties of $\mathrm{Ti}_{2} \mathrm{CT}_{\mathrm{x}}$ MXene against Sarcina, Staphylococcus aureus and Bacillus sp. Only when the bacterial cells sip into the expanded layers and placed between the individual sheets of the expanded $\mathrm{Ti}_{2} \mathrm{CT}_{\mathrm{x}}$, minor apoptosis for the Bacillus sp. strain was observed. A comparison between the observation of Rasool et al. ${ }^{[17 \mathrm{a}, 60 \mathrm{e}]}$ and Jastrzębska et al. ${ }^{[61 \mathrm{~b}]}$ indicates that the stoichiometry (configuration) of the MXenes play a key role in determining their toxicity and bioactivity towards bacteria cells. In a recent study, Jastrzębska et al. ${ }^{\text {[61a] }}$ investigated the antibacterial influence of the atomic structure of MXene sheets (i.e., $\mathrm{Ti}_{2} \mathrm{CT}_{\mathrm{x}}$ and $\mathrm{Ti}_{3} \mathrm{C}_{2} \mathrm{Tx}$ ) on the E. coli bacteria. They synthesized $\mathrm{Ti}_{2} \mathrm{C}$ and $\mathrm{Ti}_{3} \mathrm{C}_{2}$ MXene phases using same method from their parent $\mathrm{Ti}_{2} \mathrm{AlC}$ and $\mathrm{Ti}_{3} \mathrm{AlC}_{2}$ MAX phases at the same operational conditions. Synthesizing of both MXenes sheets in similar condition led to the same terminations (-F and $-\mathrm{OH}$ functional groups), which is commonly labeled by $\mathrm{T}_{\mathrm{x}}$. So, it was assumed that the only difference between the synthesized $\mathrm{Ti}_{2} \mathrm{C}$ and $\mathrm{Ti}_{3} \mathrm{C}_{2}$ MXene phases is the molecular structure. The results showed the inhibitory effect of $\mathrm{Ti}_{3} \mathrm{C}_{2}$ MXene phases 


\section{WILEY-VCH}

against E. coli, while $\mathrm{Ti}_{2} \mathrm{C}$ did not show any antibacterial property. Pandey et al. ${ }^{[62]}$ synthesized a novel Ag-decorated $\mathrm{Ti}_{3} \mathrm{C}_{2} \mathrm{~T}_{\mathrm{x}}$ MXene-based composite membrane with the capability of ultrafast water purification. The novel Ag-decorated $\mathrm{Ti}_{3} \mathrm{C}_{2} \mathrm{~T}_{\mathrm{x}}$ MXene-based composite membrane was fabricated with different percentage of the silver nanoparticles (AgNPs). The successful procedure of silver decoration by self-reduction of $\mathrm{AgNO}_{3}$ on the surface of MXene sheets were confirmed using morphological, functional and structural characterization methods. Interestingly, AgNPs were located between the MXene layers and formed a slit interspacing of $1-4 \mathrm{~nm}$. The created gaps act as channels to flow the water, leading to production of a membrane with high water flux (Figure 7a). The bactericidal properties of $21 \% \mathrm{Ag}$-decorated $\mathrm{Ti}_{3} \mathrm{C}_{2} \mathrm{~T}_{\mathrm{x}}$ membrane and $\mathrm{Ti}_{3} \mathrm{C}_{2} \mathrm{~T}_{\mathrm{x}}$ membrane were analyzed against E. coli. Interestingly, compared to the PVDF membrane used as control, more than 99\% cell growth inhibition for Ag-decorated $\mathrm{Ti}_{3} \mathrm{C}_{2} \mathrm{~T}_{\mathrm{x}}$ membrane and $60 \%$ for $\mathrm{Ti}_{3} \mathrm{C}_{2} \mathrm{~T}_{\mathrm{x}}$ membrane were observed (Figure $7 \mathrm{~b}$ ). The same results were obtained when the numbers of colonies grown on the different membranes were counted (Figure 7c). Although Pandey et $a l .{ }^{[62]}$ didn't mention, we believe the overall enhanced antibacterial activity can be attributed to both inherent antibacterial activity of $\mathrm{Ag}$ and $\mathrm{Ti}_{3} \mathrm{C}_{2} \mathrm{~T}_{\mathrm{x}}$ as well as the electrostatic adsorption of negatively-charged bacteria membrane due to positive charges of the decorated $\mathrm{Ag}$ on the surface of MXenes. The reported mechanism of bacterial growth inhibition was cell damage through particle penetration into the cells and reducing their metabolic activity. The SEM image of a bacterium on the PVDF membrane showed no membrane damage, while the bacterium exposed to Ag-decorated $\mathrm{Ti}_{3} \mathrm{C}_{2} \mathrm{~T}_{\mathrm{x}}$ membrane was crumpled with damaged membrane (Figure 7d). Since researchers have been able to experimentally synthesize many different types of MXene compositions. ${ }^{[7 c]}$ further studies are required to find the best type of them with maximum antibacterial activity. Due to their unique structure, MXenes can adopt different functionalities, which some of them may possess an undiscovered antibacterial potential that can be recommended as a good alternative for Ag NPs in near future. 


\section{WILEY-VCH}

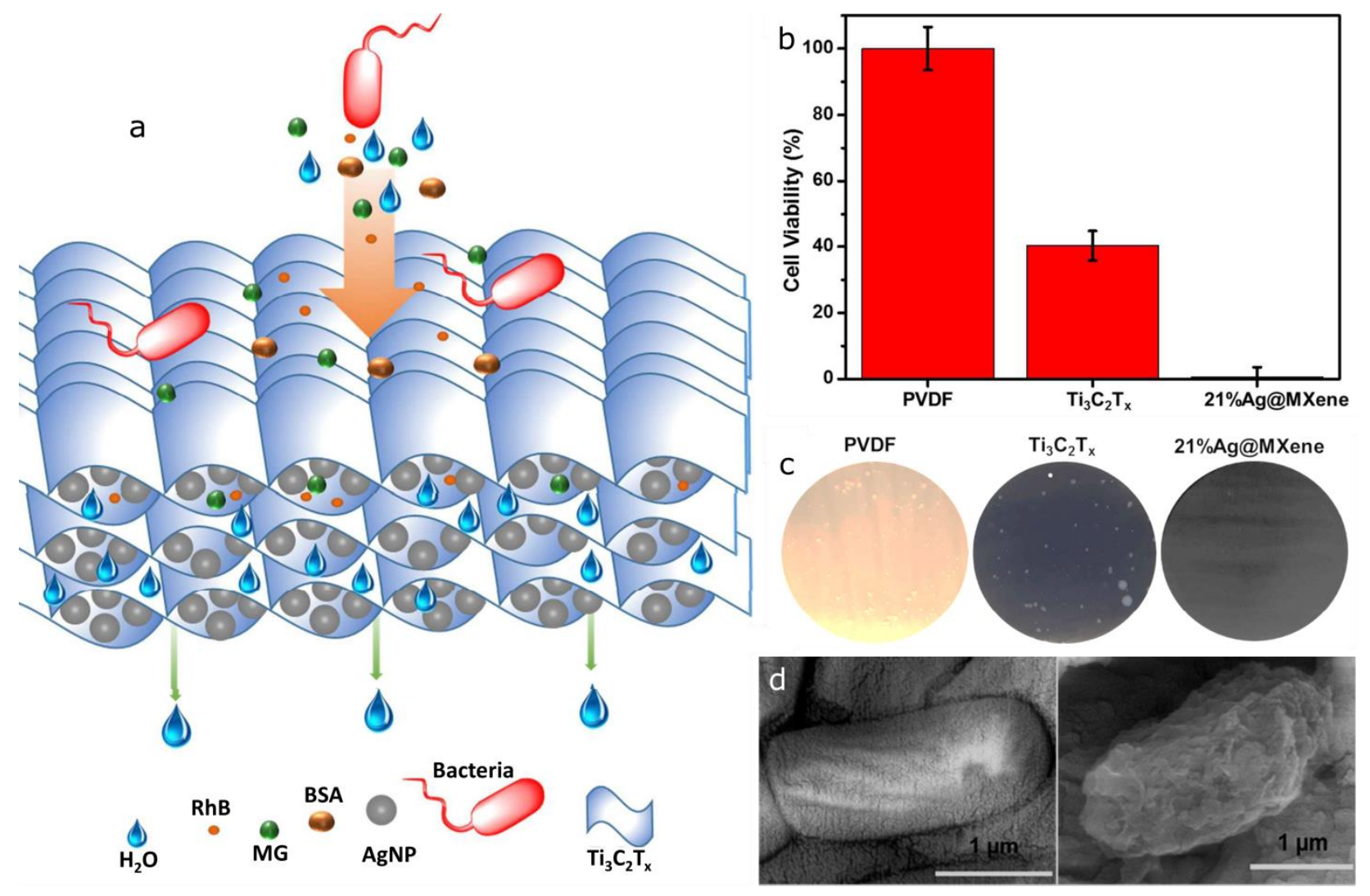

Figure 7. (a) Schematic structure of the $21 \%$ Ag-decorated $\mathrm{Ti}_{3} \mathrm{C}_{2} \mathrm{~T}_{\mathrm{x}}$ MXene-based membrane. (b) Cell viability measurements of E. coli strain. (c) Photographs of E. coli growth on PVDF, $\mathrm{Ti}_{3} \mathrm{C}_{2} \mathrm{~T}_{\mathrm{x}}$ MXene-based membrane and Ag-decorated $\mathrm{Ti}_{3} \mathrm{C}_{2} \mathrm{~T}_{\mathrm{x}}$ MXene-based membrane. (d) SEM images of a single E-coli bacterium on the PVDF (left) and Ag-decorated $\mathrm{Ti}_{3} \mathrm{C}_{2} \mathrm{~T}_{\mathrm{x}}$ MXene-based membrane surface (right). High resolution images showed no membrane damage in the presence of the PVDF and prevalent cell damage and loss of cell integrity when Ag-decorated $\mathrm{Ti}_{3} \mathrm{C}_{2} \mathrm{~T}_{\mathrm{x}}$ MXene-based membrane was used. Reproduced with permission. ${ }^{[62]}$ Copyright 2018, Royal Society of Chemistry.

\subsection{Photothermal therapy (PTT) of cancer}

Numerous investigations have identified nano-sized materials with various geometries and properties for cancer therapy through different principles. ${ }^{[63]}$ The rationale behind this practice is to improve antitumor efficacy and to minimize systemic side effects of conventional therapies to healthy tissues. As a novel approach, PTT is recommended for targeted heating of photothermally active nanomaterials at the site of cancer without damaging the surrounding healthy tissue. These materials absorb non-toxic electromagnetic radiation in the NIR window (650-900 nm) for the killing of cancer cells. The efficiency of in vivo PTT depends significantly on the depth of tumor tissue and its location, accumulation of light-responsive 


\section{WILEY-VCH}

materials and their light-to-heat conversion potential, as well as the light dose (i.e. light exciting time and light power density). MXenes are recently investigated for cancer therapy through tumor hyperthermia. ${ }^{[15 a, 15 b, 25,64]} \mathrm{Yu}$ et al. ${ }^{[15 a]}$ used Ti-MXene quantum dots (QDs) for this purpose. Prior to thermotherapy investigation, they initially revealed negligible in vitro toxicity of QDs on HeLa, MCF-7, U251 and HEK 293 cell lines even at high concentration (Figure 8a $\mathrm{a}_{1}$ ). In-vivo biocompatibility studies, such as body weight screening, blood test, and hematoxylin and eosin (H\&E) staining for histological monitoring also indicated no significant signs of abnormality (Figure $8 \mathrm{a}_{2}$ and $8 \mathrm{a}_{3}$ ). For example, H\&E staining displayed no obvious tissue-damage in the tested organs. Moreover, white blood cells, hemoglobin and platelets were recorded within normal range. These results proven that $\mathrm{Ti}$ based MXene QDs have no side effect or cytotoxicity to mice at a wide range of concentration. Next, NIR based thermotherapy with synthesized 2D MXenes demonstrated the enhancement of the surface temperature of tumor tissue to $\sim 60{ }^{\circ} \mathrm{C}$ within 5 min of laser irradiation, which was logically sufficient to ablate tumor. Remarkably, tumors were completely eliminated without reoccurrence in a 14-day period in animals under treatment with Ti-based MXene QDs and NIR irradiation (Figure 8a4). In contrary, the temperature of tumor tissue in the control group, which does not receive MXene particles, demonstrated a slight change under the same dosage of irradiation. 


\section{WILEY-VCH}
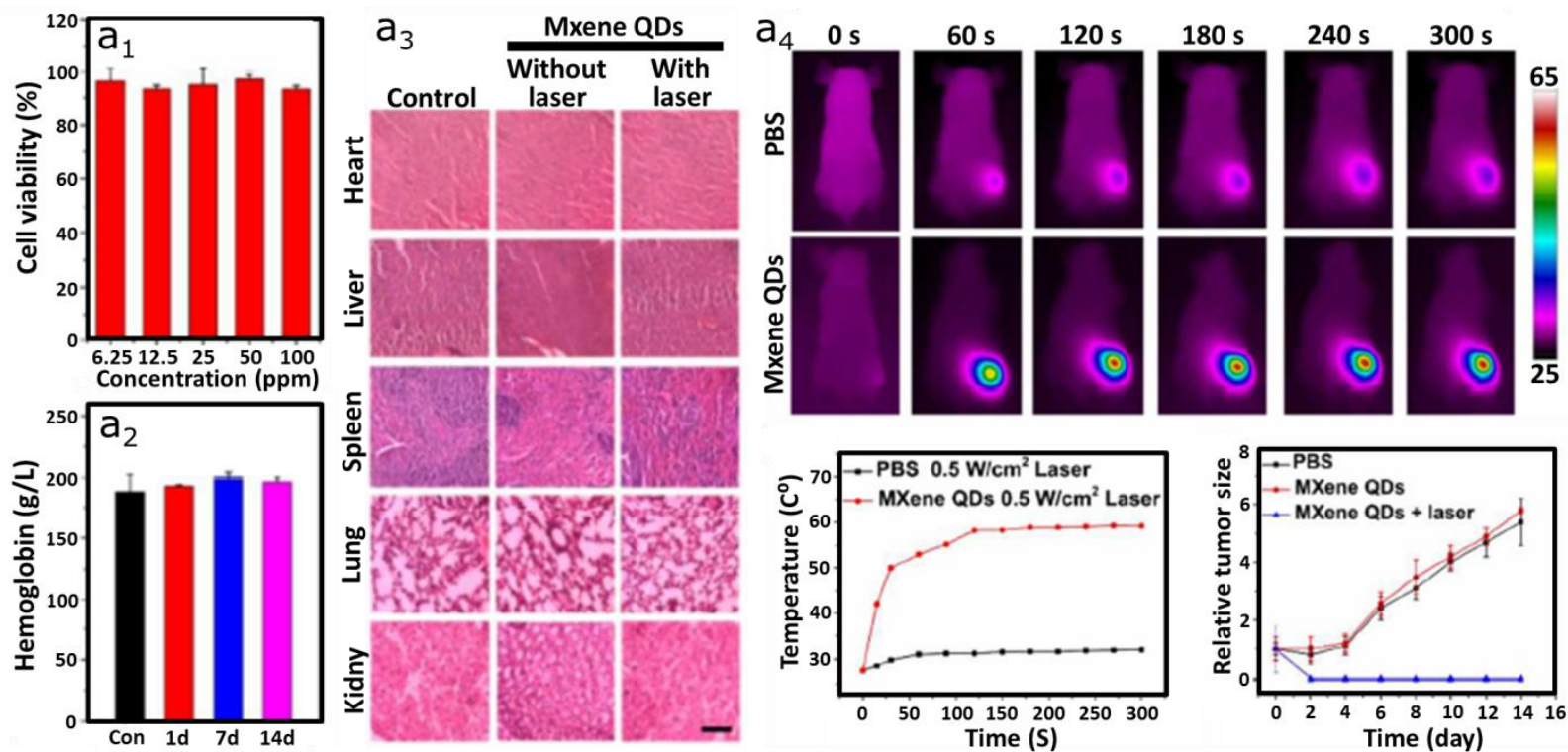

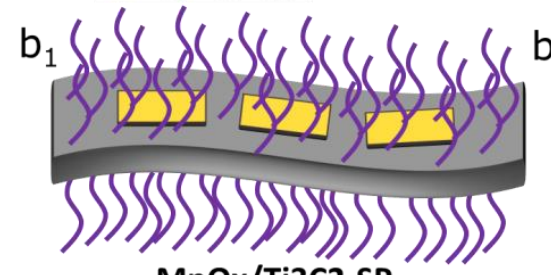

MnOx/Ti3C2-SP

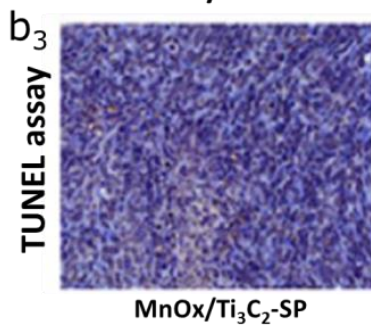

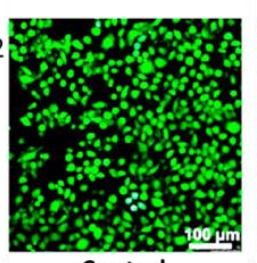

Control

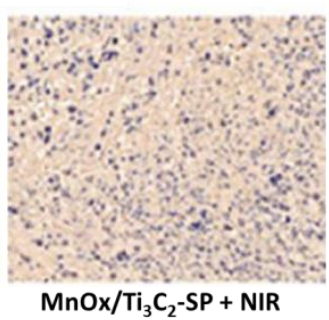

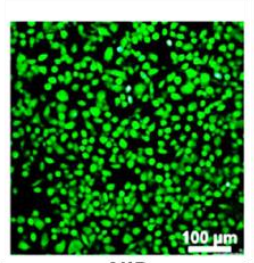

NIR

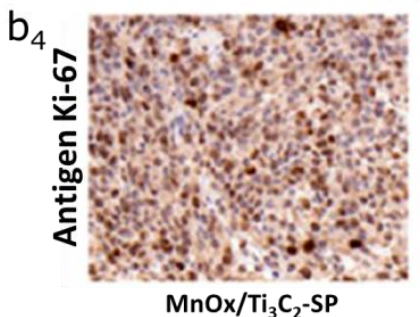

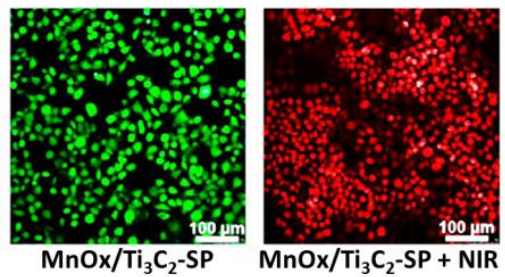

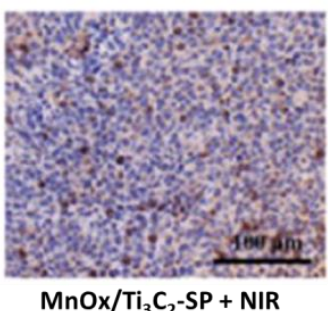

Figure 8. $\left(\mathrm{a}_{1}\right)$ Viability of HEK293 cells after treatment with various concentrations of TiMXene QDs for $48 \mathrm{~h}$. Viability test on HeLa, MCF-7, and U251 cells showed the same trend. $\left(a_{2}\right)$ The change of hemoglobin and other biological blood parameters were very low at days 1, 7, and 14 post injections of nanosheets to the healthy Balb/c mice. The untreated healthy Balb/c mice were considered as controls. $\left(\mathrm{a}_{3}\right)$ Histological data obtained from the heart, liver, spleen, lung and kidney of the MXene-treated mice showed no damage to tested organs at days 1,7 , and 14 post-injection (scale bar is $100 \mu \mathrm{m}$ ). The images shown are from day 14. $\left(\mathrm{a}_{4}\right)$ Photothermal images, temperature plot, and time-dependent tumor size in a mice cancerous model after treatments with phosphate-buffered saline (PBS; negative control) and MXene QDs followed with a NIR laser irradiation. Reproduced with permission. ${ }^{[15 a]}$ Copyright 2017, Royal Society of Chemistry. ( $\left.b_{1}\right)$ Schematic illustration of the $\mathrm{MnOx} / \mathrm{Ti}_{3} \mathrm{C}_{2}-\mathrm{SP}$ composite nanosheets. $\left(b_{2}\right)$ Fluorescence images of viable (green) and dead (red) 4T1 cancer cells after the different treatments, including the control group, NIR group, $\mathrm{MnOx} / \mathrm{Ti}_{3} \mathrm{C}_{2}-\mathrm{SP}$ group, and $\mathrm{MnOx} / \mathrm{Ti}_{3} \mathrm{C}_{2}-\mathrm{SP}+\mathrm{NIR}$ group. TUNEL staining and Antigen Ki-67 immunofluorescence staining of tumor tissues of animal treated with $\mathrm{MnOx} / \mathrm{Ti}_{3} \mathrm{C}_{2}-\mathrm{SP}$ and $\mathrm{MnOx} / \mathrm{Ti}_{3} \mathrm{C}_{2}-\mathrm{SP}+\mathrm{NIR}$. Reproduced with permission. ${ }^{[15 b]}$ Copyright 2017, American Chemical Society.

In vitro PTT against the tumor cells was also examined by Dai et al. ${ }^{[15 b]}$ They showed the photothermal-conversion ability of manganese oxide nanoparticles and soybean phospholipid 


\section{WILEY-VCH}

(SP) modified 2D titanium carbide MXenes $\left(\mathrm{MnOx} / \mathrm{Ti}_{3} \mathrm{C}_{2}-\mathrm{SP}\right.$ ) (Figure $8 \mathrm{~b}_{1}$ ) on $4 \mathrm{~T} 1$ breast cancer cell line model. Photothermal-ablation efficiency was tested via exposure of 2D composite to $808 \mathrm{~nm}$ laser at different powers. The small planar size of nanosheets could guarantee efficient endocytosis and localization within the cytoplasm of cancer cells. Tumor temperature in the MXene + NIR group increased within 10 min of laser irradiation, which is sufficient to destroy cancer cells. Comparatively, no significant temperature increment was recorded in the group solely treated with NIR laser. This observation shows high tumorsuppressing effects of the MXene through NIR mediated PTT as it was proved by live-dead co-staining of 4T1 cells with calcine AM (green) and propidium iodide (PI; red) (Figure 8b 2 ). In-vivo biocompatibility analysis was further systematically examined by intravenous administration of 2D composite to healthy mice with different dosages. The result indicated no change during the whole feeding period without notable toxicology profile. Furthermore, H\&E staining of major organs was performed to evaluate pathological changes after the injection of nanosheets, indicating no significant damage to different organs tested, supporting low biotoxicity and high biocompatibility of $\mathrm{MnOx} / \mathrm{Ti}_{3} \mathrm{C}_{2}-\mathrm{SP} \mathrm{MXenes}$ in vivo. Tumor sections of an animal model treated with MXenes and $808 \mathrm{~nm}$ laser irradiation were collected for H\&E staining, TUNEL assay, and Ki-67 antibody staining. Necrosis of tumor cells was visible in both $\mathrm{H} \& \mathrm{E}$ and TUNEL images of the group treated with $\mathrm{MnOx} / \mathrm{Ti}_{3} \mathrm{C}_{2}-\mathrm{SP}+\mathrm{NIR}$, indicating the high antitumor efficiency of $\mathrm{MnOx} / \mathrm{Ti}_{3} \mathrm{C}_{2}-\mathrm{SP}$ mediated PTT (Figure $8 \mathrm{~b}_{3}$ ). The Ki-67 antibody staining also showed significant suppression of cancer cell proliferation in vivo (Figure 8b $\mathrm{b}_{4}$ ). Interestingly, this study revealed the improved biocompatibility of the $\mathrm{Ti}_{3} \mathrm{C}_{2}$ nanosheets after SP coating since high viability was observed even in high concentrations tested. In another study, increased concentration of bare $\mathrm{Ti}_{3} \mathrm{C}_{2}$ resulted in reduced cell viability as well as cell-type dependent toxicity. ${ }^{[64]}$ To verify the correlation of decreased cell viability after MXene treatment with induced oxidative stress, intracellular reactive oxygen species were measured using DCF-DA. After $24 \mathrm{~h}$ of incubating $2 \mathrm{D} \mathrm{Ti}_{3} \mathrm{C}_{2}$ nanosheets with 


\section{WILEY-VCH}

different cell lines, a statistically significant increase in fluorescence intensity (a parameter proportional to the level of intracellular reactive oxygen species) was observed. ${ }^{[64]}$

Theranostic nanomedicines of $2 \mathrm{D} \mathrm{Ti}_{3} \mathrm{C}_{2}$ MXene nanosheets are also reported for concurrent diagnostic imaging and therapy through surface engineering of the MXenes by GdW 10 -based polyoxometalates (POMs). ${ }^{[65]}$ The $\mathrm{GdW}_{10} @ \mathrm{Ti}_{3} \mathrm{C}_{2}$ composite could effectively eradicate tumor tissue after simultaneous hyperthermia treatment as well as MR and CT imaging guidance toward tumor cells. $\mathrm{GdW}_{10}$ nanoclusters were served as the contrast agent. This investigation was a creative strategy for broadening the biomedical applications of MXenes via surface functionalization.

Moreover, a novel ultra-thin 2D niobium carbide-polyvinylpyrrolidone $\left(\mathrm{Nb}_{2} \mathrm{C}-\mathrm{PVP}\right)$ MXene (Figure 9a) was studied by Lin et al. ${ }^{[15 c]}$ as biocompatible phototherapeutic agent for highly efficient in vivo ablation of tumor in mouse. The highlighted advantages of using $\mathrm{Nb}_{2} \mathrm{C}$ nanosheets prepared by hybrid liquid-exfoliation methodology was deep tissue PTT compared to other conventional nanoparticles, high photothermal conversion efficiency $(36.4 \%$ at NIR-I and $45.65 \%$ at NIR-II), and negligible deterioration of NIR absorbance, suggesting the $\mathrm{Nb}_{2} \mathrm{C}$ MXene as a long-lasting photothermal agent for PTT mediated cancer therapy. The Vis-NIR absorbance peak of the Au nanorods (Au NRs) weakened significantly after laser irradiation under the same condition as tested for $\mathrm{Nb}_{2} \mathrm{C}$ MXene (Figure $9 b_{1}$ and $9 b_{2}$ ), clearly confirming better photostability performance of $\mathrm{Nb}_{2} \mathrm{C}$ MXenes compared to the traditional PTT agents (Figure $9 b_{3}$ and $9 b_{4}$ ). The developed MXenes demonstrated no significant toxicity both in vitro and in vivo in spite of efficient in vivo tumor ablation through NIR-I or NIR-II absorbance and heat production in the tumor site (Figure 9c). This finding confirms the clinical-translation potential of $\mathrm{Nb}_{2} \mathrm{C}$ as a PTT agent. ${ }^{[15 \mathrm{c}]}$ 


\section{WILEY-VCH}
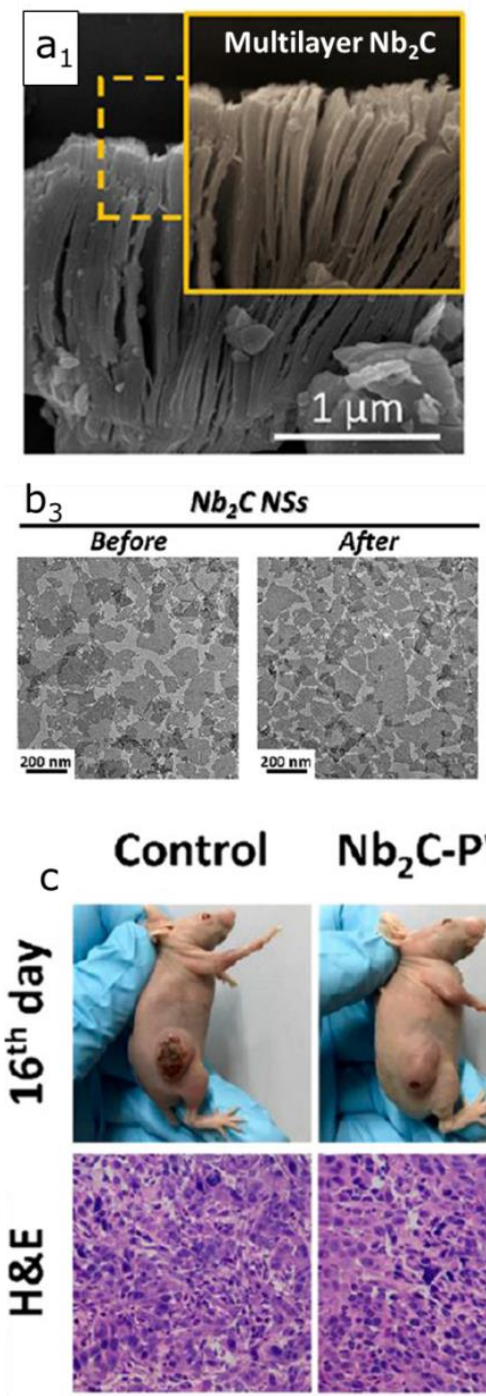
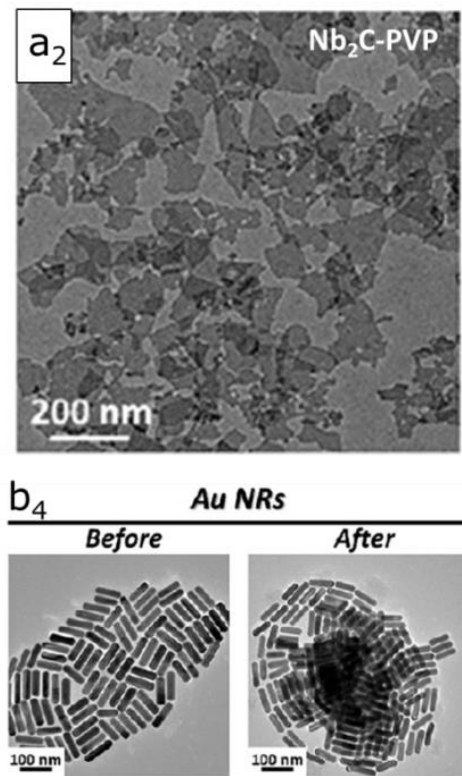

NIR-I

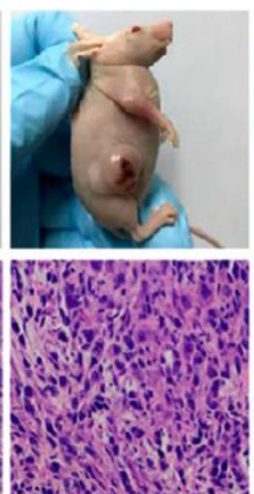

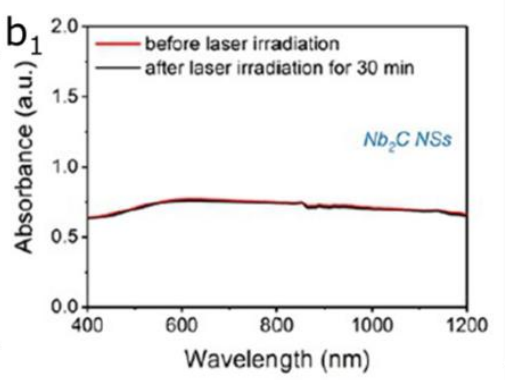

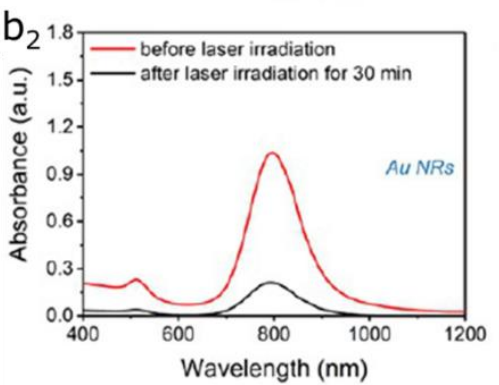

$\mathrm{Nb}_{2} \mathrm{C}-\mathrm{PVP} \quad \mathrm{Nb}_{2} \mathrm{C}-\mathrm{PVP}$

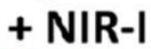

+ NIR-II
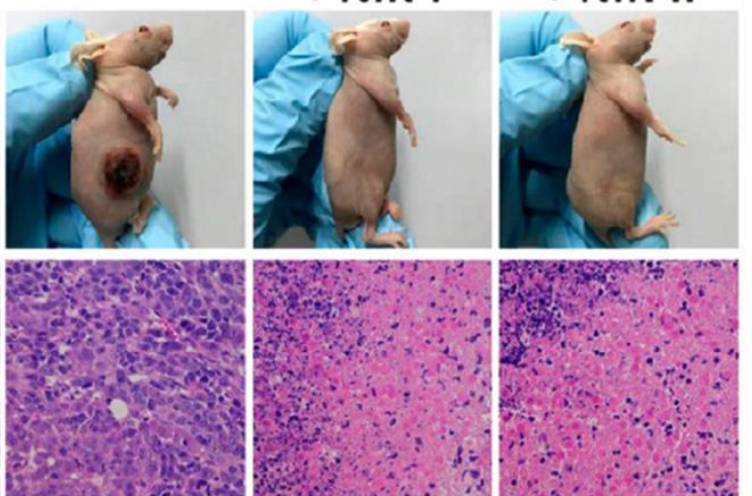

Figure 9. (a) SEM image of $\mathrm{Nb}_{2} \mathrm{C}$ multilayer and TEM image of $\mathrm{Nb}_{2} \mathrm{C}$ after PVP coating. Vis-NIR absorbance spectra of (b1) $\mathrm{Nb}_{2} \mathrm{C}$ nanosheets and (b2) Au NRs before and after laser radiation for $30 \mathrm{~min}$, indicating the well-maintained photothermal performance of $\mathrm{Nb}_{2} \mathrm{C}$. This is confirmed with TEM ( $b_{3}$ and $b_{4}$ ) imaging of the both particles. MXene nanosheets could maintain their dispersibility while and Au NRs aggregated after NIR irradiation. (c) Photographs of tumor regions of mice model 16 days after different treatments. H\&E staining of tumor sections revealed the effectiveness of in vivo PTT and increased number of dead cells through intratumoral administrations of $\mathrm{Nb}_{2} \mathrm{C}-\mathrm{PVP}$ and subsequent treatment under $1064 \mathrm{~nm}$ NIR laser irradiation. Reproduced with permission. ${ }^{[15 \mathrm{c}]}$ Copyright 2017, American Chemical Society.

The impact of tantalum (Ta) based MXenes on tumor ablation was explored in another study. The fabricated $\mathrm{Ta}_{4} \mathrm{C}_{3}$ nanosheets were surface engineered with $\mathrm{MnO}_{\mathrm{x}}$ to provide a high-performance theranostic nano-agent for efficient combat against cancer tissues. ${ }^{[16]}$ The surface temperature of tumors, assessed by infrared thermal imaging camera, was sufficiently 


\section{WILEY-VCH}

high for tumor ablation after 10 min of exposing MXene treated animals to the NIR laser. The $\mathrm{MnOx}-\mathrm{Ta}_{4} \mathrm{C}_{3}: \mathrm{SP}$ treated mice were reported healthy after 60 days of treatment without any observation of tumor recurrence. In contrary, survival rate was continuously diminished in the other groups treated with laser or nanosheets alone, confirming high in vivo therapeutic efficiency of PTT by means of Ta-based MAX materials. In addition, H\&E staining analysis as well as TUNEL and Ki-67 antibody staining of tumor slices were examined to study the mechanism of photothermal effect after $24 \mathrm{~h}$ of NIR irradiation.

\subsection{Drug delivery}

One of the main biomedical applications of nanosheets is drug delivery, particularly through rate-controlled release or synergistic therapy for alleviating disease progress. ${ }^{[66]}$ As of today, cancer is one of the main challenges facing mankind and causes numerous deaths worldwide every year. Similar to many other types of nanoparticles that can attack cancer cells efficiently through controlled drug release and enhancing cellular uptake of the payloads $^{[67]}$, MXenes were preliminary investigated as a tool for combatting cancer. ${ }^{[19 b, 25]}$ Han et al. ${ }^{[19 \mathrm{~b}]}$ reported ultrathin SP modified $\mathrm{Ti}_{3} \mathrm{C}_{2}$ nanosheets as efficient drug carrier and synergistic therapeutic agent for tumor eradication. The nanosheets exhibited $\mathrm{pH}$-responsive and NIR laser-triggered operations with the ability of monitoring during cancer therapy. Doxorubicin (Dox), a potent chemotherapeutic medicine, was used as a model drug. UV-Vis analysis of absorption peaks confirmed the successful loading of the drug onto the surface of $\mathrm{Ti}_{3} \mathrm{C}_{2}$-SP. The high drug-loading was mainly due to the ionic interaction occurred between the negatively charged surface of $\mathrm{Ti}_{3} \mathrm{C}_{2}$-SP MXenes and positively charged Dox molecules. Besides, zeta potential changes proved the electrostatic interaction of the drug with the MXenes. The $\mathrm{Ti}_{3} \mathrm{C}_{2}$ MXenes not only exhibited high drug-loading capability of $211.8 \%$, but also showed both pH-sensitive and on-demand NIR laser-triggered drug release. Figure 10a 


\section{WILEY-VCH}

shows unique $\mathrm{pH}$ dependence release of the Dox from $\mathrm{Ti}_{3} \mathrm{C}_{2}$-SP MXenes. After $12 \mathrm{~h}$, drug release in $\mathrm{pH}$ values of $7.4,6.0$ and 4.5 reached to $14.2 \%, 33.9 \%$ and $58.0 \%$, respectively. It is presumed that $\mathrm{H}^{+}$can interfere with the electrostatic interaction between Dox and $\mathrm{Ti}_{3} \mathrm{C}_{2}-\mathrm{SP}$ and accelerates drug release. NIR irradiation at $808 \mathrm{~nm}$ could also increase the release rate in all three tested $\mathrm{pH}$ values (Figure $10 \mathrm{a}_{2}$ ) due to the local thermal effect. Intracellular drugdelivery capability of $\mathrm{Ti}_{3} \mathrm{C}_{2}$-SP was evaluated by means of confocal laser scanning microscopy (CLSM), showing the intracellular red fluorescence of loaded Dox after $4 \mathrm{~h}$ of coincubation with 4T1 cancer cells (Figure 10a $)$. This observation indicates that the $\mathrm{Ti}_{3} \mathrm{C}_{2}-\mathrm{SP}$ could be endocytosed into cancer cells and release the loaded payloads in the mildly acidic intracellular microenvironment. The live and dead staining of the cancer cells also proved higher cell-killing effect of Dox@ $\mathrm{Ti}_{3} \mathrm{C}_{2}$-SP compared to free Dox, which can be attributed to enhanced cellular endocytosis when nanosheets are used as carrier. The Dox@ $\mathrm{Ti}_{3} \mathrm{C}_{2}-\mathrm{SP}$ combined with NIR irradiation caused the highest cell death due to the synergistic effect of PTT and chemotherapy (Figure 10a4). Notably, it seems the low accumulation of the Dox@ $\mathrm{Ti}_{3} \mathrm{C}_{2}-\mathrm{SP}$ in the tumor site through passive targeting was sufficient to achieve desirable therapeutic outcome. Nevertheless, we believe future studies can explore surface modification with active-targeting antibodies, peptides or polymers to further enhance the delivery efficiency of $\mathrm{Ti}_{3} \mathrm{C}_{2}$-SP nanosheets for getting better response or reducing the dose of nanosheets. For example, another study demonstrated active targeting through layer-by-layer Dox and hyaluronic acid (HA) surface coating on the $\mathrm{Ti}_{3} \mathrm{C}_{2}$ platforms, achievable due to the negatively charged hydroxyl groups available on the surface of the nanosheet. ${ }^{[25]}$ As shown in Figure $10 b_{1}$, HA coated MXenes could target cancer cells through high affinity to CD44 receptors available on the cell membrane. After cellular uptake, Dox molecules could get released from the MXene and induce apoptosis, which further improves the anticancer effect obtained from NIR irradiation and temperature elevation within the cancer cells. Drug loading capacity was as high as $84.2 \%$ and enhanced tumor accumulation was achieved through both 


\section{WILEY-VCH}

active targeting to CD44-positive tumor cells and enhanced permeability and retention (EPR) effect. Temperature- and $\mathrm{pH}$-triggered drug release (Figure $10 \mathrm{~b}_{2}$ ) could render outstanding benefits to the system for localized chemotherapy and PTT. In vivo experiments were carried out to clarify remarkable tumor ablation effect of the drug loaded nanosheets at a low dose when NIR laser is applied (Figure $10 b_{3}$ and $b_{4}$ ). Fluorescence assisted biodistribution screening showed high accumulation of the drug within the tumor and very low amount in spleen, lung and heart.
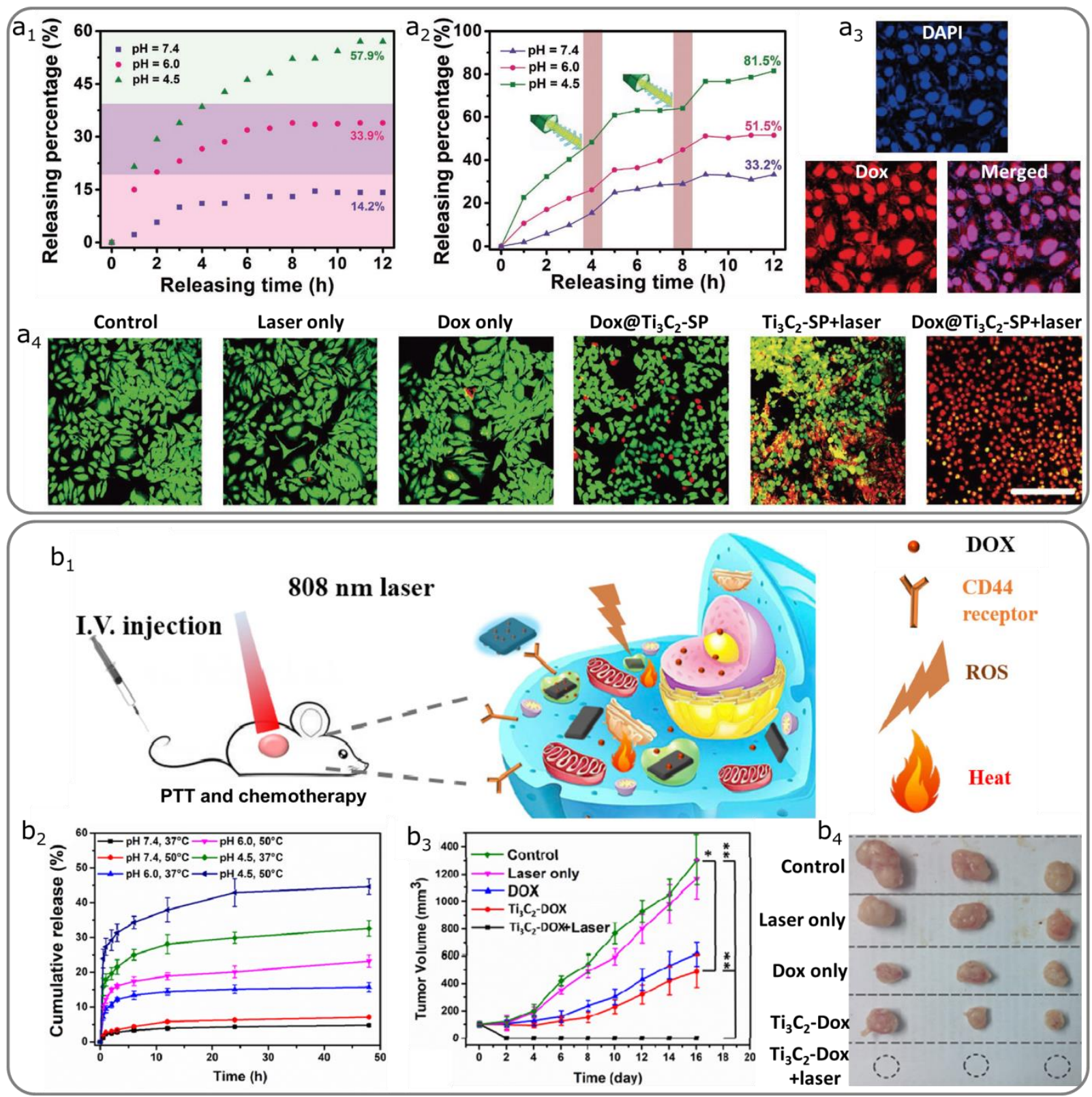

Figure 10. In vitro release profile of Dox from Dox @ $\mathrm{Ti}_{3} \mathrm{C}_{2}-\mathrm{SP}$ nanosheets in buffer solutions at various $\mathrm{pH}$ values $(\mathrm{pH}=7.4,6.0$, and 4.5$)\left(\mathrm{a}_{1}\right)$ and with or without $808 \mathrm{~nm}$ laser irradiation 


\section{WILEY-VCH}

at different $\mathrm{pH}$ values $\left(\mathrm{a}_{2}\right)$. ( $\left.\mathrm{a}_{3}\right)$ In vitro cellular uptake of the Dox after the co-incubation of the 4T1 cells with Dox@Ti3C2-SP for $4 \mathrm{~h}$. Red fluorescence represents Dox released or within the $\mathrm{Ti}_{3} \mathrm{C}_{2}-\mathrm{SP}$ and blue fluorescence is representative of cell nucleus. (a4) Live and dead cell co-staining of the $4 \mathrm{~T} 1$ cells after different treatments. The green fluorescence represents live cells and red fluorescence represents dead cells. Scale bar is $50 \mu \mathrm{m}$. Reproduced with permission. ${ }^{[19 b]}$ Copyright 2018, Wiley-VCH. $\left(b_{1}\right)$ The release profiles of the drug from the $\mathrm{Ti}_{3} \mathrm{C}_{2}$-Dox with/without irradiation $\left(808 \mathrm{~nm}, 0.8 \mathrm{~W} \mathrm{~cm}^{-2}\right)$ at $\mathrm{pH}$ values of 4.5, 6.0, and 7.4. $\left(b_{2}\right)$ Tumor growth curves $(\mathrm{n}=4$, mean $\pm \mathrm{SD}, * \mathrm{P}<0.05, * * \mathrm{P}<0.01)$ during treatment of the animal model with the drug loaded nanosheets. $\left(b_{3}\right)$ Digital photographs of tumors from different groups of animals. Reproduced with permission. ${ }^{[25]}$ Copyright 2017, American Chemical Society.

One of the main challenges of applying MXenes in drug delivery is the lack of confined space in their structure for the high loading of drug molecules. Researchers have so far benefited from the large surface area of MXene for the conjugation of therapeutic molecules. This approach might suffer from low loading capacity, possibility of suppressed therapeutic functionality of drugs if the conjugation is through covalent bonding, and also undesirable drug release profile (very slow if conjugated through covalent bonding or burst release if physically attached to the surface of MXenes). In an elaborately designed study, the surface nanopore engineering of $\mathrm{Ti}_{3} \mathrm{C}_{2}$ MXene was performed through facile sol-gel chemistry. Under the alkaline synthetic condition, the surface of MXene was coated with a thin layer of mesoporous-silica ( $\left.\mathrm{Ti}_{3} \mathrm{C}_{2} @ \mathrm{mMSNs}\right)$ using cetanecyltrimethylammonium chloride (CTAC) as the mesopore-directing agent and tetraethylorthosilicate (TEOS) as the silica precursor (Figure 11a). Arginine-glycine-aspartic acid (RGD) was used as a targeting ligand and Dox was used as anticancer drug molecule. The surface-nanopore engineering could combine the advantages of MXenes as photothermal-conversion nanoagents and porous silica as drugdelivery vector (Figure 11b). The acidity-responsive property (Figure 11c) of the nanocomposite can be attributed to the decrease of electrostatic interaction between the drug and the porous shell at lower $\mathrm{pH}$ values, facilitating a controllable release in tumor region. NIR laser-induced hyperthermic stimulus of the drug release could also be observed (Figures 


\section{WILEY-VCH}

11d). The elevation of NIR power could also increase the rate of drug release due to the faster heat-stimulated dissociation of the strong binding between the drug and silica shell.
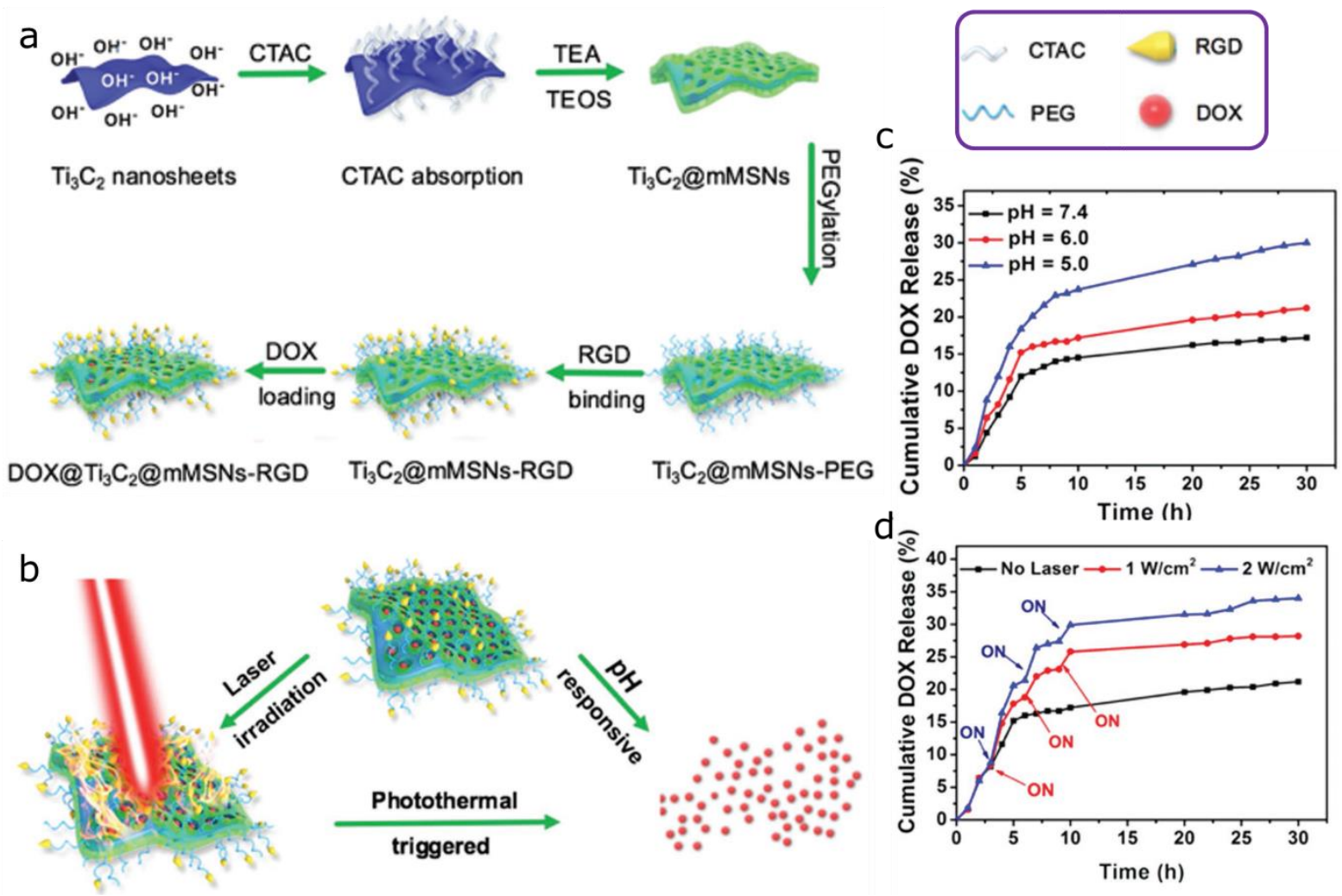

Figure 11. (a) Schematic illustration of the surface-nanopore engineering of $\mathrm{Ti}_{3} \mathrm{C}_{2} \mathrm{MXenes}$. The procedure includes CTAC absorption, TEOS mediated mesoporous-silica coating, surface PEGylation, conjugating RGD ligand, and drug loading. (b) Schematic representation of the obtained multifunctionality from the designed carrier. (c) Cumulative drug release from the coated MXenes dispersed in PBS with different pH values. (d) NIR laser-triggered cumulative drug release at elevated power density. Reproduced with permission ${ }^{[19 a]}$. Copyright 2018 , Wiley-VCH.

\subsection{MXene nanosheets for bioimaging}

\subsubsection{Photoacoustic imaging (PAI)}

PAI is a hybrid non-invasive biomedical imaging technology that shines non-ionizing laser pulses on biological tissues, and then, measures ultrasonic emission generated through the conversion of light into the heat within tissues. Photoacoustic effect refers to the conversion of initial laser light to ultrasonic waves, which can be detected by ultrasonic transducers for further image production. There is growing interest in the clinical community for employing new light absorbing materials to visualize biological organs or tissues in animals or human 


\section{WILEY-VCH}

with simultaneous high contrast and high spatial resolution. Titanium carbide MXene quantum dots (MQDs) have strong and wide NIR absorption range that can be considered as a desirable criteria for PAI of tumors. ${ }^{[15 a]}$ The concept of MXene based PAI is shown in Figure 12a. The screening of the PA images of titanium carbide MQDs at different excitation wavelengths $(680,710,740,770,790$, and $808 \mathrm{~nm})$ demonstrated that the optimal PA signal occurs at the wavelength of $680 \mathrm{~nm}$ (Figure 12b). Moreover, the PA signal of the samples constantly increased at higher concentrations of $\mathrm{Ti}_{3} \mathrm{C}_{2}$ QDs, proving the suitability of MQDs for PAI applications (Figure 12c). The mass extinction coefficient, a numeric for describing the optical absorption capability was $52.8 \mathrm{Lg}^{-1} \mathrm{~cm}^{-1}$ at $808 \mathrm{~nm}$ for MQDs, which is remarkably higher than any other photothermal materials reported so far. For instance, AU nanorods, reduced $\mathrm{GO}, \mathrm{TiS}_{2}$ nanosheet, $\mathrm{MoS}_{2}, \mathrm{FeS}$ and $\mathrm{Bi}_{2} \mathrm{~S}_{3}$ nanoflowers have shown a mass extinction of 13.9, 24.6, 28.6, 29.215 .5 and $20.5 \mathrm{Lg}^{-1} \mathrm{~cm}^{-1}$, respectively. ${ }^{[68]}$ The in vivo imaging of mice (at $680 \mathrm{~nm}$ wavelength) intratumorally injected with MQDs showed a high PA signal intensity in tumors with an increase of approximately 0.7 -fold when exposed to laser irradiation, indicating the effectiveness of the MQDs as contrast agents for PA imaging guided cancer therapy.

Biocompatible $\mathrm{MnOx} / \mathrm{Ta}_{4} \mathrm{C}_{3}$-SP composite nanosheets are also tested as contrastenhancing agent for PA imaging due to their high photothermal-conversion capability. The PA signal showed a linear relation with the concentration of Ta element in $\mathrm{MnOx} / \mathrm{Ta}_{4} \mathrm{C}_{3}-\mathrm{SP}$, pointing out the desirable capability of $\mathrm{MnOx} / \mathrm{Ta}_{4} \mathrm{C}_{3}-\mathrm{SP}$ nanosheets for PA imaging. Besides, as shown in Figure $12 \mathrm{~d}$, the in vivo PAI capability of $\mathrm{MnOx} / \mathrm{Ta}_{4} \mathrm{C}_{3}-\mathrm{SP}$ composite nanosheets in 4T1 tumor bearing mice represented rapid enhancement of PA signals, which could be easily detected within the time range of $10-60$ min post injection. ${ }^{[16]}$ Contrary to $\mathrm{MnOx} / \mathrm{Ta}_{4} \mathrm{C}_{3}-\mathrm{SP}$ composites, the in vivo study of $\mathrm{MnOx} / \mathrm{Ti}_{3} \mathrm{C}_{2}-\mathrm{SP}$ nanosheets demonstrated a gradual enhancement in PA signal and prolonged observation time of $24 \mathrm{~h}$, mainly attributed to the slow accumulation of the $\mathrm{MnOx} / \mathrm{Ti}_{3} \mathrm{C}_{2}-\mathrm{SP}$ composited within tumor via the enhanced 


\section{WILEY-VCH}

permeability and retention (EPR) effect ${ }^{[15 b]}$. In general, $\mathrm{Ta}_{4} \mathrm{C}_{3}$ MXenes have revealed much higher photothermal-conversion efficiency as compared to that of $\mathrm{Ti}_{3} \mathrm{C}_{2}$ MXenes. That is the reason for observing bigger $\mathrm{PA}$ values for $\mathrm{Ta}_{4} \mathrm{C}_{3}-\mathrm{SP}$ compared to $\mathrm{MnOx} / \mathrm{Ti}_{3} \mathrm{C}_{2}-\mathrm{SP}$ as a function of MXene concentration (Figure 12e). ${ }^{[15 b, 15 e]} \mathrm{Nb}_{2} \mathrm{C}-\mathrm{PVP}$ nanosheets have also shown strong NIR-absorbance at the excitation light of $704 \mathrm{~nm}$ and high photothermal conversion efficiency for PA imaging applications. ${ }^{[15 \mathrm{c}]}$ In general, as a highly promising imaging modality approach, MXene-based PAI can hopefully break through the penetration limitation of traditional optical imaging techniques due to its low tissue-attenuation coefficient. This can afford the real time monitoring of biological structures and imagingguided evaluation of the therapeutic process. ${ }^{[69]}$
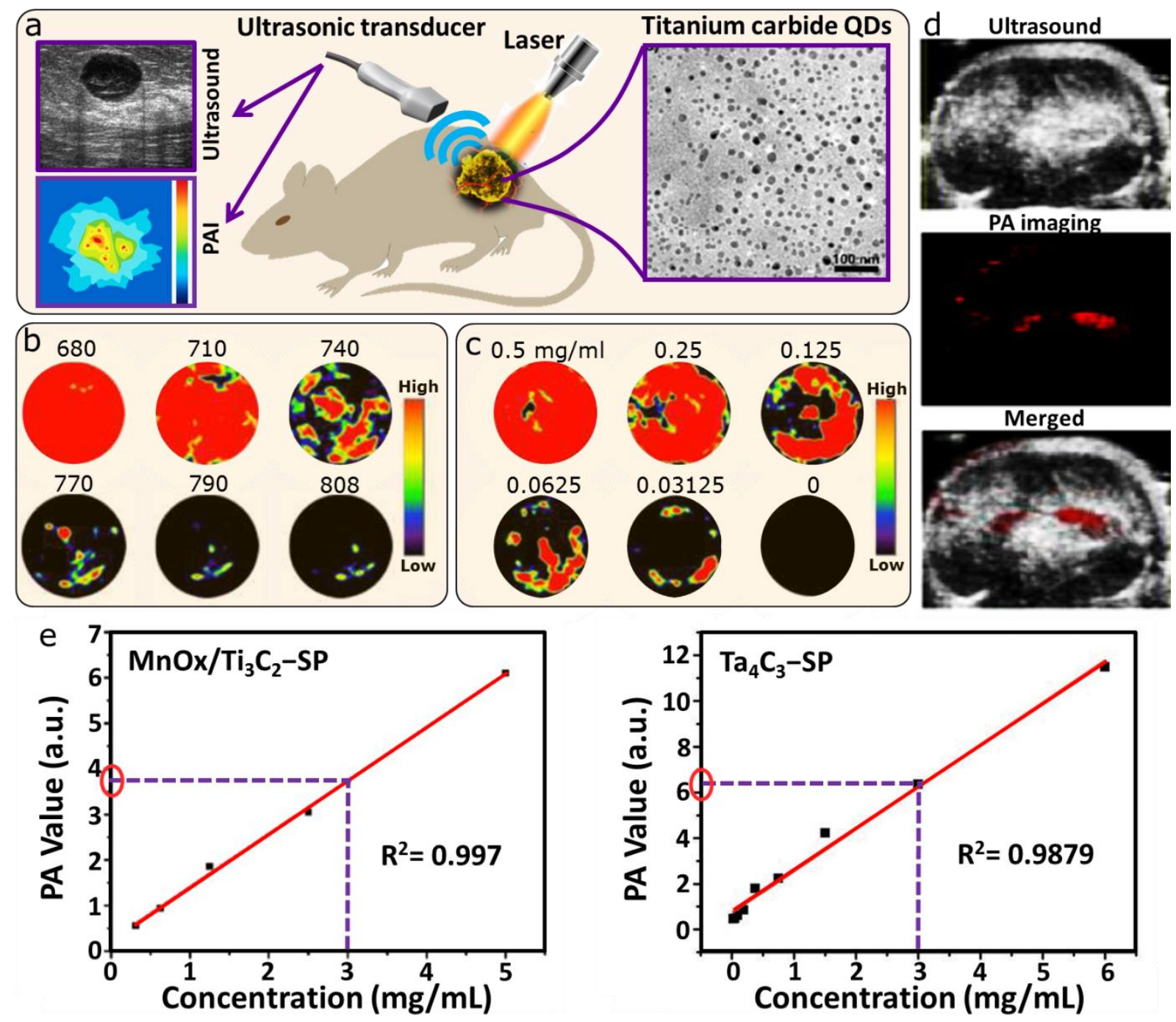

Figure 12. (a) The Schematic representation of MXene mediated PAI. Upon exposure to the NIR laser, the tissue constituents absorb light, undergo thermoelastic expansion, and 


\section{WILEY-VCH}

subsequently produce ultrasound signals (photoacoustic effect), which can be detected by an ultrasound sensor. (b) PA images of MQDs at different excitation wavelengths. (c) PA images of different concentrations of the MQDs at $680 \mathrm{~nm}$. Reproduced with permission. ${ }^{[15 a]}$ Copyright 2013, Royal Society of Chemistry. (d) Contrast-enhanced in vivo PA imaging by $\mathrm{MnOx} / \mathrm{Ta}_{4} \mathrm{C}_{3}-\mathrm{SP}$ composite nanosheets after $60 \mathrm{~min}$ of MXene injection. Reproduced with permission. ${ }^{[16]}$ Copyright 2017, American Chemical Society. (e) In vitro PA values of $\mathrm{MnOx} / \mathrm{Ti}_{3} \mathrm{C}_{2}-\mathrm{SP}$ and $\mathrm{Ta}_{4} \mathrm{C}_{3}-\mathrm{SP}$ buffer solutions as a function of concentration. Tantalum carbide MXenes produce higher PA signals compared to titanium carbide nanosheets. Reproduced with permission. ${ }^{[15 b, 15 e]}$ Copyright 2017, American Chemical Society and Wiley$\mathrm{VCH}$.

\subsubsection{Magnetic resonance imaging (MRI)}

As a non-invasive imaging tool, MRI technique possesses favorable spatial resolution, high soft tissue contrast, and absence of ionizing radiation. Therefore, applying this technology for bioimaging is of interest and various types of contrast agents are designed to further enhance the sensitivity of MRI for obtaining information-rich images. Recently, research efforts have been shifted towards the design and synthesis of new nanomaterials to improve the quality and specificity of MRI. Different nanostructures and magnetic alloys, such as nickel, iron, and gadolinium are utilized for MRI. ${ }^{[70]}$ Manganese $(\mathrm{Mn})$ based materials are newly developed paramagnetic agents with relatively higher biosafety and lower toxicity as MRI contrast agents in comparison to other aforementioned materials ${ }^{[15 b]}$. For example, manganese oxide nanomaterials have attracted much attention of biomedical communities due to their great potentials in bioimaging. ${ }^{[71]}$ In situ growing of manganese oxide nanoparticles on $\mathrm{Ti}_{3} \mathrm{C}_{2}$ and $\mathrm{Ta}_{4} \mathrm{C}_{3}$ MXenes was proposed by triggering the redox reaction between the reducing surface of MXenes and strongly oxidative $\mathrm{MnO}_{4}$ to synthesize $\mathrm{MnOx} / \mathrm{Ti}_{3} \mathrm{C}_{2}$ and $\mathrm{MnOx} / \mathrm{Ta}_{4} \mathrm{C}_{3}$ nanosheets for MRI. ${ }^{[15 b, 16]}$ The MnOx-functional patterns on the MXene nanosheets are $\mathrm{pH}-$ and glutathione (GSH)-sensitive, known as important criteria for tumor imaging applications. The $\mathrm{pH}-$ responsiveness capability of the $\mathrm{MnO}_{\mathrm{x}}$ based nancomposites are due to instability of $\mathrm{Mn}-\mathrm{O}$ bonds in mild acidic and reductive conditions of tumor microenvironment. ${ }^{[15 \mathrm{~b}]}$

Superparamagnetic $\mathrm{Fe}_{3} \mathrm{O}_{4}$ nanoparticles (IONP) have been extensively explored as the efficient contrast agents for $\mathrm{T}_{2}$-weighted MR imaging. ${ }^{[72]}$ Therefore, the surface attachment of 


\section{WILEY-VCH}

the IONP on the $\mathrm{Ta}_{4} \mathrm{C}_{3}$ MXenes has been recently explored to endow these novel nanosheets with contrast-enhanced $\mathrm{T}_{2}$-weighted MR imaging capability. ${ }^{[73]}$ Figure 13a and b shows the schematic procedure of $\mathrm{Ta}_{4} \mathrm{C}_{3}$-IONP-SP synthesis as well as imaging and elemental analysis for the confirmation of successful formation of the composite. The particles not only showed very promising photothermal ablation of cancer cells, proved by Calcein-AM and propidium iodide (PI) co-staining of 4T1 (Figure 13c) cells, but also revealed a remarkable concentration-dependent and contrast-enhanced negative $\mathrm{T}_{2}$-weighted $\mathrm{MR}$ signals (Figure $\left.13 \mathrm{~d}_{1}\right)$. The $\mathrm{Ta}_{4} \mathrm{C}_{3}-\mathrm{IONP}-\mathrm{SP}$ composites showed a $\mathrm{T}_{2}$ relaxivity of $205.46 \mathrm{mM}^{-2} \mathrm{~s}^{-1}$, which is significantly higher than that of commercially available $\mathrm{T}_{2}$ contrast agents (ferumoxsil: 72.0 $\mathrm{mM}^{-2} \mathrm{~s}^{-1}$; and ferumoxide: $\left.98.3 \mathrm{mM}^{-2} \mathrm{~s}^{-1}\right)$. This observation is mainly attributed to the high magnetic saturation value, high transverse relaxivity, and magnetic aggregation-enhanced MRI performance of Ta4C3-IONP-SP nanosheets. The in vivo $\mathrm{T}_{2}$-weighted MRI of 4T1 tumor-bearing mice allograft also verified regions of hypointense $\mathrm{T}_{2}$ signal in tumor sites that became more intense along with the imaging time. The capability of Ta4C3-IONP-SPs in enhancing the in vivo quantitative $\mathrm{T}_{2}$ negative signal values in tumor tissue is shown in Figure $13 \mathrm{~d}_{2}$. The intensity of the signal was reduced over time. Based on these results, it is expected that superparamagnetic $\mathrm{Ta}_{4} \mathrm{C}_{3}$-IONP-SPs can desirably monitor the therapeutic process in vivo through MRI imaging. 


\section{WILEY-VCH}

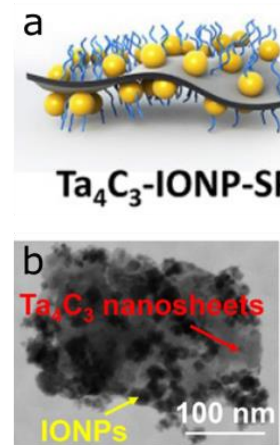

SP modified

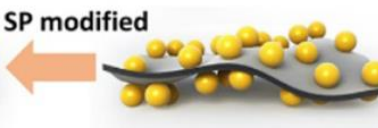

IONP
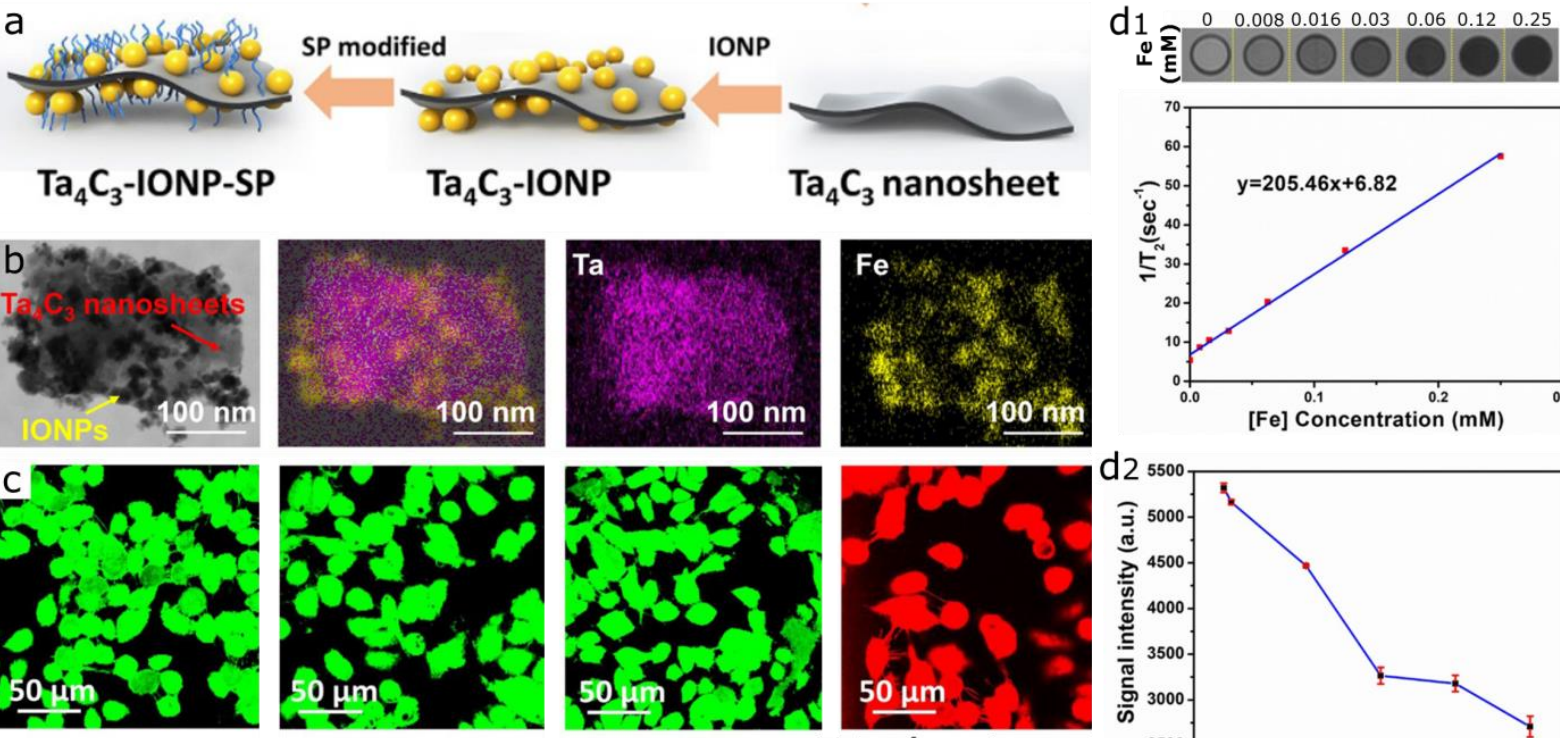

Control $\mathrm{Ta}_{4} \mathrm{C}_{3}-$ IONP $\mathrm{Ta}_{4} \mathrm{C}_{3}$ nanosheet
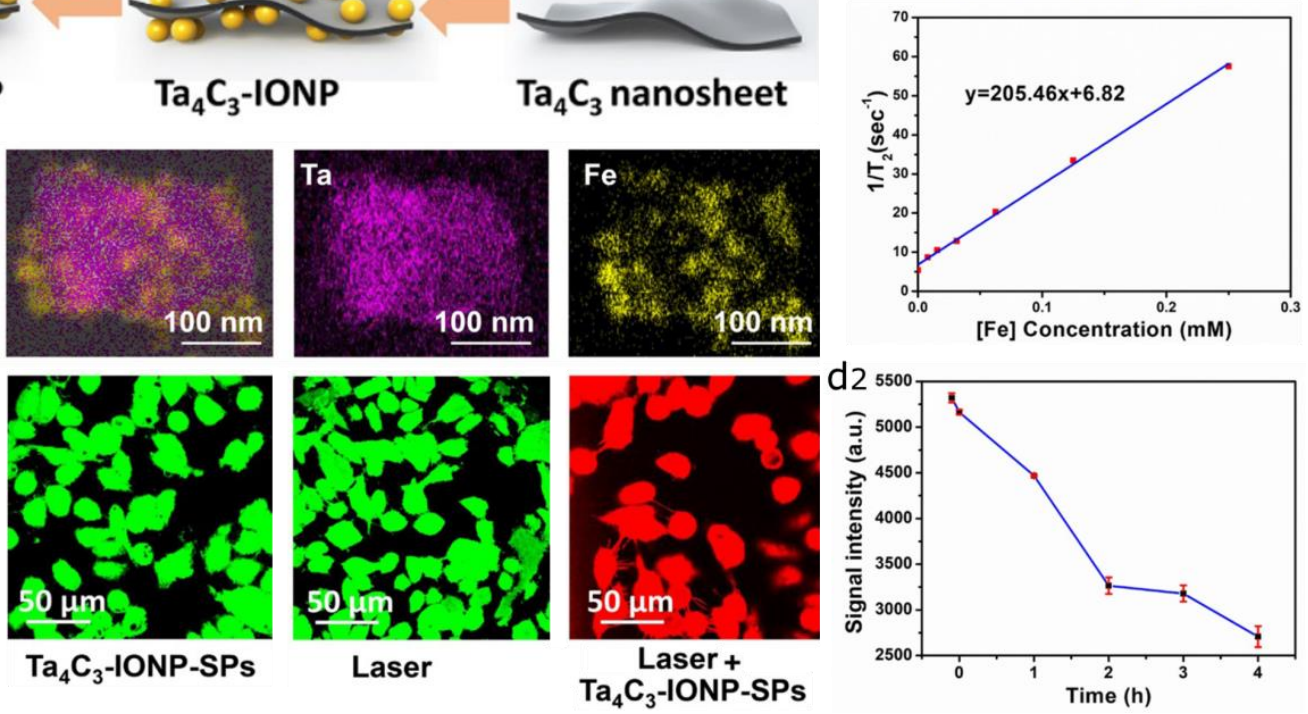

Figure 13. (a) Schematic overview of the fabrication process of $\mathrm{Ta}_{4} \mathrm{C}_{3}-\mathrm{IONP}-\mathrm{SPs}$ nanosheets used for dual-modal contrast-enhanced MRI/CT imaging-guided photothermal ablation of cancer cells. (b) TEM images of the fabricated $\mathrm{Ta}_{4} \mathrm{C}_{3}$-IONP nanosheets and corresponding element mapping images, demonstrating the uniform distribution of $\mathrm{Ta}$ (purple) and $\mathrm{Fe}$ (yellow) elements in the matrix of the composite. (c) Confocal fluorescence images of the cells co-stained with calcein AM (green, live cells) and PI (red, cells) after different treatments. $\left(\mathrm{d}_{1}\right)$ In vitro $\mathrm{T}_{2}$-weighted MRI and $\mathrm{T}_{2}$ relaxivity of the MXene composites. $\left(\mathrm{d}_{2}\right) \mathrm{T}_{2^{-}}$ weighted MRI signal intensities of tumor site at different time points after the i.v injection of $\mathrm{Ta}_{4} \mathrm{C}_{3}$-IONP-SPs MXenes. Reproduced with permission. ${ }^{[73]}$ Copyright 2018, Ivyspring International Publisher.

\subsubsection{X-ray computed tomography (CT) and optical imaging}

Computed tomography (CT) is one of most powerful techniques for recognizing metastases with high spatial resolution and deep tissue penetration. ${ }^{[74]}$ Recently, 2D materials have attracted the interest of scientific community for biomedical applications due to their unique physiochemical and structural properties. ${ }^{[1 \mathrm{a},}$ 15d] High atomic number elements such as bismuth, cesium, tin, tantalum, lanthanides, and tungsten are known as potential materials for CT imaging due to their ability for attenuating X-rays. ${ }^{[75]} \mathrm{Ta}_{4} \mathrm{C}_{3}$, as an MXene family, is a new intriguing contrast agent candidate in CT applications due to high atomic number of Tantalum (Z=73), high X-ray attenuation (Ta: $4.3 \mathrm{~cm}^{2} \mathrm{~kg}^{-1}$ at $100 \mathrm{eV}$ ), and ability for surface engineering as compared to other rivals, such as gold. ${ }^{[73,76]}$ Dai et al. ${ }^{[16]}$ have studied the 


\section{WILEY-VCH}

application of $\mathrm{Ta}_{4} \mathrm{C}_{3}$ composite nanosheets for contrast enhanced CT imaging application. In situ growth of manganese oxide nanoparticle on the surface of $\mathrm{Ta}_{4} \mathrm{C}_{3}$ was conducted by redox reaction to produce $\mathrm{MnO}_{\mathrm{x}} / \mathrm{Ta}_{4} \mathrm{C}_{3}$ MXenes, which their surfaces were further modified with SP to enhance biocompatibility and dispersity of the nanosheets. It was shown that there is linear relationship between Ta concentration and Hounsfield units (HU) of the composite such that increasing the Ta concentration results in higher contrast and resolution in vitro. Application of $\mathrm{MnOx} / \mathrm{Ta}_{4} \mathrm{C}_{3}$-SP for in vivo $\mathrm{CT}$ was studied by intravenous (i.v) injection of $\mathrm{MnO}_{\mathrm{x}} / \mathrm{Ta}_{4} \mathrm{C}_{3}$ SP composite to Balb/c mice bearing $4 \mathrm{~T} 1$ tumors. A strong contrast in the mice tumor was observed with a raise of $\mathrm{HU}$ value from 78 before the i.v injection to $132 \mathrm{HU}$ after the i.v injection, which proves the abilities of $\mathrm{MnO}_{\mathrm{x}} / \mathrm{Ta}_{4} \mathrm{C}_{3}$-SP for contrast-enhanced CT imaging. Similar to $\mathrm{MnOx} / \mathrm{Ta}_{4} \mathrm{C}_{3}$-SP composites, Lin et al. ${ }^{[15 \mathrm{e}]}$ showed linear relationship between $\mathrm{Ta}$ concentration and $\mathrm{HU}$ for $\mathrm{Ta}_{4} \mathrm{C}_{3}$-SP nanosheets (Figure 14a $\mathrm{a}_{1}$ ). Besides, they found that $\mathrm{Ta}_{4} \mathrm{C}_{3}$-SP provides higher contrast compared to iopromide, a commercial iodine-based $\mathrm{CT}$ contrast agent used in the clinic (Figure 14a $\mathrm{a}_{2}$ ). In vivo $\mathrm{CT}$ imaging of 4T1-tumor-bearing mice showed the enhancement of $\mathrm{HU}$ from 83 before the injection to 232 after the injection (Figure $14 \mathrm{a}_{3}$ and $\mathrm{a}_{4}$ ). In another study, the growth of iron oxide nanoparticles (IONP) on the surface of Tantalum carbide was performed in-situ to form $\mathrm{Ta}_{4} \mathrm{C}_{3}-\mathrm{IONP} .{ }^{[73]}$ The process was followed by surface modification with SP to increase the biocompatibility of the $\mathrm{Ta}_{4} \mathrm{C}_{3}-\mathrm{IONP}$ MXenes. A linear relationship between concentration of $\mathrm{Ta}_{4} \mathrm{C}_{3}-\mathrm{IONP}-\mathrm{SP}$ and measured $\mathrm{HU}$ was observed in vitro, which was higher than iodine-based agents at the same concentration. For in vivo $\mathrm{CT}$ imaging of $4 \mathrm{~T} 1$ cell-bearing breast-cancer nude mice, gradual contrast improvement in transverse, coronal and 3D-rendering CT images of $\mathrm{Ta}_{4} \mathrm{C}_{3}-\mathrm{IONP}-\mathrm{SP}$ after the i.v injection suggests this composite as $\mathrm{CT}$ contrast probe in the imaging of breast tumors.

In addition to different types of 2D materials (e.g., $\mathrm{MoS}_{2}$, Graphene, phosphorene, etc.) investigated for the fabrication of QDs and optical bio-imaging purposes, ${ }^{[77]}$ MXene derived QDs are recently fabricated since they favorably exhibit unique chemical- and photo-stability, 


\section{WILEY-VCH}

high dispersibility in both hydrophobic and hydrophilic media (due to existence of polar and non-polar functional groups), low cytotoxicity, and tunable photoluminescence (PL) properties that are tunable by changing the size, shape or functionality of the prepared QDs. ${ }^{[78]}$ Zhou et al. ${ }^{[78 b]}$ synthesized amphiphilic carbide-derived graphene quantum dots (GQDs) through solvothermal treatment of $\mathrm{Ti}_{3} \mathrm{C}_{2} \mathrm{~T}_{\mathrm{x}}$ MXenes in dimethylformamide (DMF), which acted as a nitrogen-doping agent for the formation of highly fluorescent GQDs (Figure 14b 1 ). The prepared QDs showed excitation-dependent PL behaviors such that changing the excitation wavelength from 300 to 440 shifted the emission peak from $390 \mathrm{~nm}$ to $490 \mathrm{~nm}$. Cytotoxicity was tested by studying viability of $293 \mathrm{~T}$ cells and MCF-7 cancer cells. The results showed close to $90 \%$ viability at $400 \mathrm{ug} / \mathrm{mL}$ concentration of the QDs. The carbidederived GQDs were proposed as a promising light-emitting composite, which could be applied for fluorescent ink and cellular imaging investigations (Figure $14 \mathrm{~b}_{2}-\mathrm{b}_{5}$ ).

Xue et al. ${ }^{[79]}$ fabricated monolayer photoluminescent $\mathrm{Ti}_{3} \mathrm{C}_{2}$ MQDs by hydrothermal method in which the resulting morphology, size and thickness of the prepared QDs could be tuned by changing the reaction temperature from $100{ }^{\circ} \mathrm{C}$ to $150{ }^{\circ} \mathrm{C}$. Results showed that MQDs that were prepared at $100{ }^{\circ} \mathrm{C}$ and $120{ }^{\circ} \mathrm{C}$ exhibit high quantum yield of $9.9 \%$ and 8.9\%, which makes them great candidates for multicolor imaging applications. No significant change in the intensity of the PL was observed at different $\mathrm{pH}$ values. This indicates favorable surface passivation of the MQDs and possibility of usage in different $\mathrm{pH}$ conditions. Imaging potentials of the MQDs were tested by in vitro imaging of RAW264.7 cells. Merged confocal and bright-field images showed that the MQDs mainly locate in the vicinity of the cell membrane and penetrate to the cytoplasm without a remarkable interaction with the nucleus, indicating that the MQDs will not induce genetic disruption. Biocompability of the MQDs was tested on RAW264.7 cells and it was noted that MQDs prepared at $150{ }^{\circ} \mathrm{C}$ are not suitable for bio-applications due to excessive amount of carbon in their structures. 


\section{WILEY-VCH}
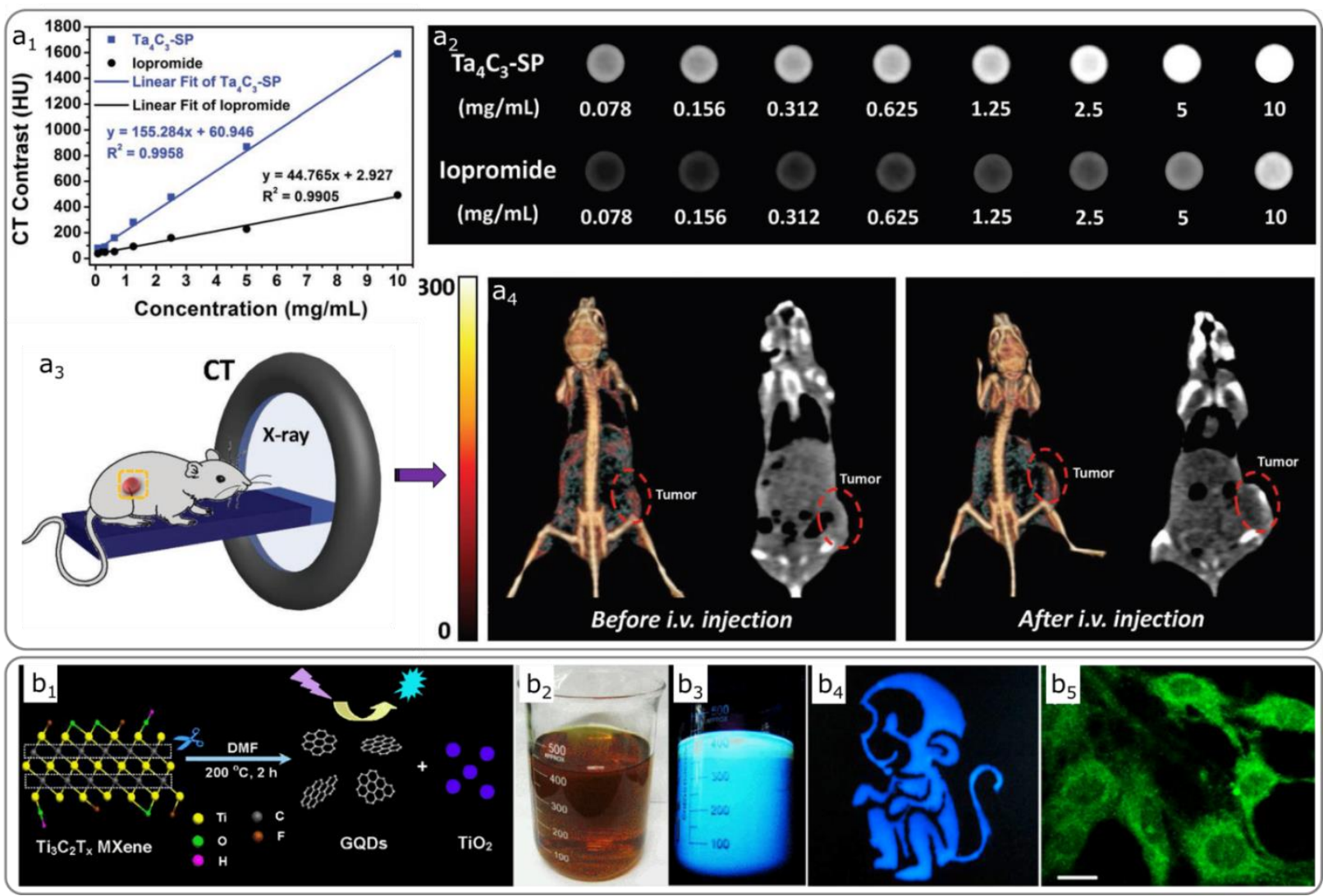

Figure 14. $\left(\mathrm{a}_{1}\right)$ In vitro $\mathrm{CT}$ contrast values and $\left(\mathrm{a}_{2}\right) \mathrm{CT}$ images of $\mathrm{Ta}_{4} \mathrm{C}_{3}-\mathrm{SP}$ nanosheet solutions and iopromide solutions at different concentrations. (a3) and (a4) represent schematic of in vivo $\mathrm{CT}$ imaging and in vivo $\mathrm{CT}$ imagings, respectively. The 3D reconstruction CT (left) and CT contrast (right) images of mice before and after i.v injection $\left(10 \mathrm{mg} \mathrm{mL}{ }^{-1}, 200 \mu \mathrm{L}\right)$ for $24 \mathrm{~h}$. Reproduced with permission. ${ }^{[15 \mathrm{e}]}$ Copyright 2017, WileyVCH. $\left(b_{1}\right)$ Schematic representation of solvothermal treatment of $\mathrm{Ti}_{3} \mathrm{C}_{2} \mathrm{~T}_{\mathrm{x}}$ MXene in DMF at $200{ }^{\circ} \mathrm{C}$ for $2 \mathrm{~h}$ to fabricate QDs. ( $\mathrm{b}_{2}$ and $\mathrm{b}_{3}$ ) photographs of the fabricated GQDs at daylight and $365 \mathrm{~nm}$ UV light. $\left(\mathrm{b}_{4}\right)$ Image of a fluorescent "Monkey" pattern under $365 \mathrm{~nm}$ UV light. (b5) CLSM images of MCF-7 cells treated with GQDs for $2 \mathrm{~h}$ by excitation at $488 \mathrm{~nm}$. Reproduced with permission. ${ }^{[78 b]}$ Copyright 2017 , Elsevier B.V.

\subsection{MXene biosensors: fabrication and biomedical applications}

Due to the combined surface hydrophilicity, metallic conductivity, and 2D layered atomic structure,${ }^{[35,80]}$ exploitation of MXenes in biosensing have sparked great interests. ${ }^{\left[80 \mathrm{c},{ }^{81]}\right.}$ These materials are promising candidates to create biologically compatible devices for rapid, easy and label-free detection of biological events. MXenes are applied for the fabrication of wearable gas sensors ${ }^{[18 c]}$ that can efficiently operate at room temperature. ${ }^{[7 a]}$ For instance, $\mathrm{Ti}_{3} \mathrm{C}_{2} \mathrm{~T}_{\mathrm{x}}$ nanosheets were produced by removal of $\mathrm{Al}$ atoms from $\mathrm{Ti}_{3} \mathrm{AlC}_{2}$ and integrated on flexible polyimide platforms using a simple solution casting method in order to detect 


\section{WILEY-VCH}

methanol, ethanol, ammonia, and acetone gas (Figure 15). ${ }^{[21]}$ The developed device is proposed for continuous physiological monitoring of different gases in human breath for early illness detection. For example, ammonia can be measured for the monitoring of lung disorders and acetone is generated in diabetic patients. ${ }^{[82]}$ The sensing performance of the fabricated wearable device is ascribed to the effective adsorption/desorption of the sensing molecules on the surface of $\mathrm{Ti}_{3} \mathrm{C}_{2} \mathrm{~T}_{\mathrm{x}}$ sheets, ${ }^{[83]}$ which leads to the alteration in the electrical performance of the MXene surface. The $\mathrm{Ti}_{3} \mathrm{C}_{2} \mathrm{~T}_{\mathrm{x}}$ device exhibited a p-type sensing behavior, attributed to the water and oxygen molecules adsorbed on the surface during the etching process of Al. Surface adsorption of gas molecules to the partially charged surface functional groups of the MXene will reduce the concentration of charge carriers on the $\mathrm{Ti}_{3} \mathrm{C}_{2} \mathrm{~T}_{\mathrm{x}}$ film, resulting in the sensing of increased resistance.
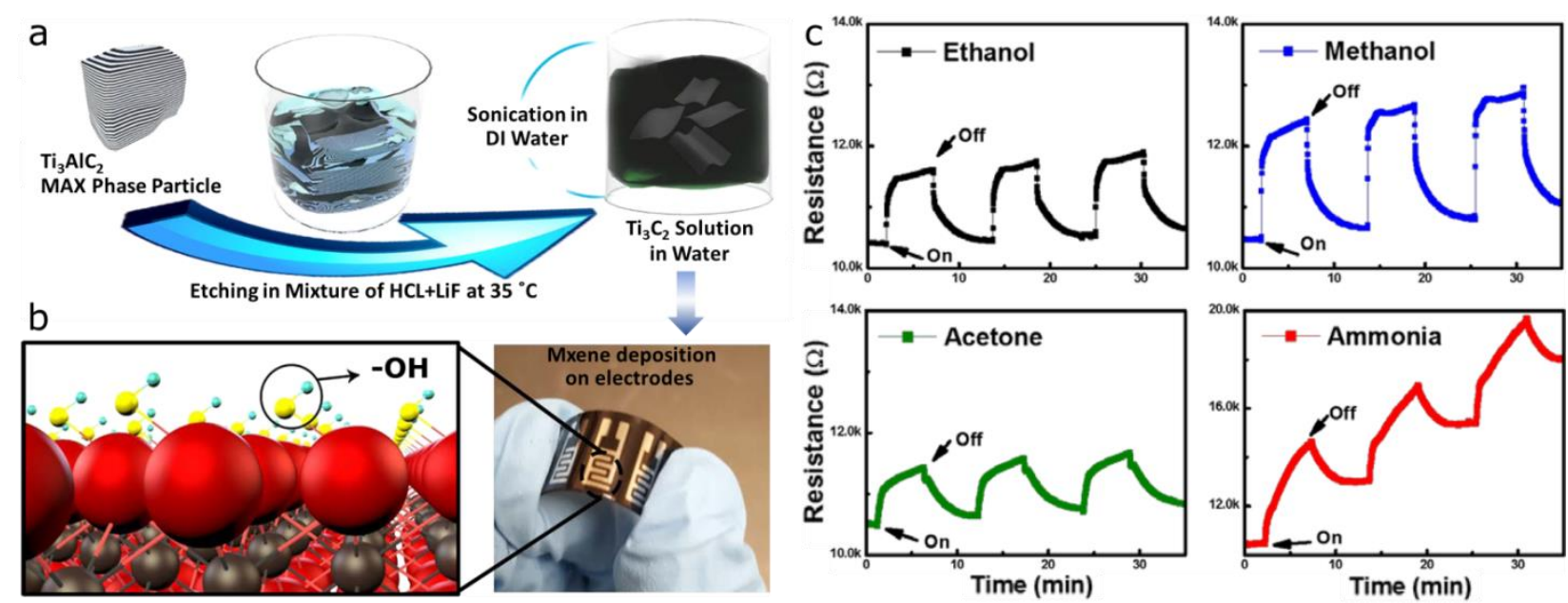

Figure 15. (a) Schematic representation of $\mathrm{Ti}_{3} \mathrm{C}_{2} \mathrm{~T}_{\mathrm{x}}$ synthesis procedure. (b) Image of fabricated electrodes after MXene deposition and schematic illustration of surface functional groups on the nanosheets. (c) Sensing of $100 \mathrm{ppm}$ ethanol, methanol, acetone, and ammonia gas using $\mathrm{Ti}_{3} \mathrm{C}_{2} \mathrm{~T}_{\mathrm{x}}$ device at room temperature $\left(25^{\circ} \mathrm{C}\right)$. The initial resistance of the device was around $10 \mathrm{k} \Omega$. Upon the introduction of gases, the resistance was amplified, and it was diminished without the gases, showing a p-type sensing behavior. Reproduced with permission. ${ }^{[21]}$ Copyright 2017, American Chemical Society.

One of the main principles for the fabrication of mediator-free electrochemical biosensors is direct electron transfer (DET) between an enzyme and an electrode. Since electroactive center is deeply embedded within the structure of proteins and DET process does not occur 


\section{WILEY-VCH}

very effectively, MXenes with excellent enzyme immobilization abilities are proposed to facile the DET for better performance of the electrochemical biosensing. ${ }^{[81 b]} \mathrm{Ti}_{3} \mathrm{C}_{2}$ MXene with paralleled flake-like structure were able to entrap an enzyme within the interior areas of nanolayers and accelerate the mobility of charge carriers for better electrical communication and mediator-free biosensing of $\mathrm{H}_{2} \mathrm{O}_{2}$ in a linear range from 0.1 to $260 \mu \mathrm{M}$ and very low detection limit of $20 \mathrm{nM}^{[81 \mathrm{~b}]} \mathrm{TiO}_{2}$ can also be loaded onto MXenes in order to endow the $\mathrm{H}_{2} \mathrm{O}_{2}$ sensing device with two main advantages ${ }^{[84]}$ including 1) increased surface area available for enzyme adsorption compared to the bare MXene and 2) providing a desirable microenvironment for the better stability and activity of enzymes due to the favorable biocompatibility of $\mathrm{TiO}_{2}$. Detection of $\mathrm{H}_{2} \mathrm{O}_{2}$ is very important for the development of oxidase-based biosensors and it is utilizable in numerous applications, such as food industry as well as in pharmaceutical, clinical, and environmental samples. ${ }^{[85]}$ In a recent work, electrochemical performance of $\mathrm{Ti}_{3} \mathrm{C}_{2} \mathrm{~T}_{\mathrm{X}}$ in an aqueous solution for potential sensing of $\mathrm{H}_{2} \mathrm{O}_{2}$ resulted in a limit of detection of $0.7 \mathrm{nM}$ and very short response time of nearly $10 \mathrm{~s}{ }^{[18 \mathrm{~b}]}$

Au/MXene nanoplatforms are also tested as transducers for electrochemical-based enzymatic detection and quantification of glucose. ${ }^{[86]}$ Physical adsorption (drop casting) of glucose oxidase (GOx) enzyme, as recognition element, on Nafion solubilized Au/MXene nanocomposite embedded over glassy carbon electrode (GCE) resulted in an amperometric glucose biosensor. Nafion solution was used for the better adhesion of enzyme molecules to the GCE. ${ }^{[87]}$ Au nanoparticles could facilitate the electron exchange between the electroactive center of GOx and the electrode. Linear amperometric response in the glucose concentration range of 0.1 to $18 \mathrm{mM}$ was achieved for the GOx/Au/MXene/Nafion/GCE biosensor. Excellent stability, repeatability, high sensitivity of $4.2 \mu \mathrm{AmM}^{-1} \mathrm{~cm}^{-2}$ and a detection limit of $5.9 \mu \mathrm{M}(\mathrm{S} / \mathrm{N}=3)$ were highlighted as significant characteristics of the fabricated biosensor. GCE is a popular biosensor immobilization matrix due to its mechanical stability, compactness, solidity, and impermeability to gasses and liquids. ${ }^{[88]}$ Physical adsorption was 


\section{WILEY-VCH}

used in order to incorporate enzymes to $\mathrm{Au} / \mathrm{MXene}$ transducers without changing their native conformation. ${ }^{[89]}$ In this study, particular attention was paid to the performance of the developed electrochemical biosensor in terms of sensitivity, selectivity, detection limit and linearity range by improving the specific surface area, conductivity, charge transfer properties and more importantly the catalytic activity of the sensing matrix. Increased surface area could produce more current, which in turn, improved the sensitivity and linearity of the biosensor.

Detection of cells and macromolecules by $\mathrm{Ti}_{3} \mathrm{C}_{2}$ MXene is also reported. The simplicity of applying MXenes for micromachining and printing various geometries with large contact surfaces is a pragmatic capability to probe cellular functions in a biologically relevant context. In future, this property might detract the popularity of other complicated and low-yield/highcost manufacturing procedures (e.g., chemical vapor deposition, epitaxial growth or mechanical exfoliation) for the fabrication of Field-Effect Transistor (FET) devices. In a pioneering work, micropattering of ultrathin conductive $\mathrm{Ti}_{3} \mathrm{C}_{2}$ on glass substrates could fabricate FET transistors for highly sensitive label-free detection of dopamine neurotransmitters (Figure 16a). ${ }^{[90]}$ The detection was based on doping effect, provoked by the $\mathrm{p}-\mathrm{p}$ interaction between dopamine and the electrons from the terminal groups (e.g., $\mathrm{OH}$ or F). The micropatterns were created by microcontact printing $(\mu \mathrm{CP})$ of ultrathin MXene using PDMS stamps, which was then printed onto 3-aminopropyltriethoxysilane (APTES) modified coverslips (Figure 16b and c). Real-time monitoring of changes in the conductance of the device could be measured for varying concentrations of dopamine (Figure 16d). This device was also successfully tested for the monitoring of spiking activity in primary hippocampal neurons, schematically shown in Figure 16e. Desirable safety of MXenes in long term cultures was a remarkable characteristic, recognized with normal morphology of neurons with visible neurites on the MXene substrates (Figure 16f). Cell monitoring is also reported by Xue et al. ${ }^{[79]}$, who synthesized photoluminescent $\mathrm{Ti}_{3} \mathrm{C}_{2}$ MQDs through a hydrothermal method for in vitro bio-imaging of RAW264.7 cells. MXenes usually exhibit low photoluminescence, 


\section{WILEY-VCH}

which significantly limits their usage in optical sensing. This study showed that the ultrasmall and atomically thin $\mathrm{Ti}_{3} \mathrm{C}_{2}$ MQDs exhibit excitation dependent PL spectra with quantum yields around $10 \%$ due to small lateral size of MXenes $(<10 \mathrm{~nm})$, which causes strong quantum confinement. In fact, $\mathrm{Ti}_{3} \mathrm{C}_{2}$ MXenes possess small bandgap (around $0.1 \mathrm{eV}$ ), which can be enlarged through quantum effects to achieve luminescence emission.
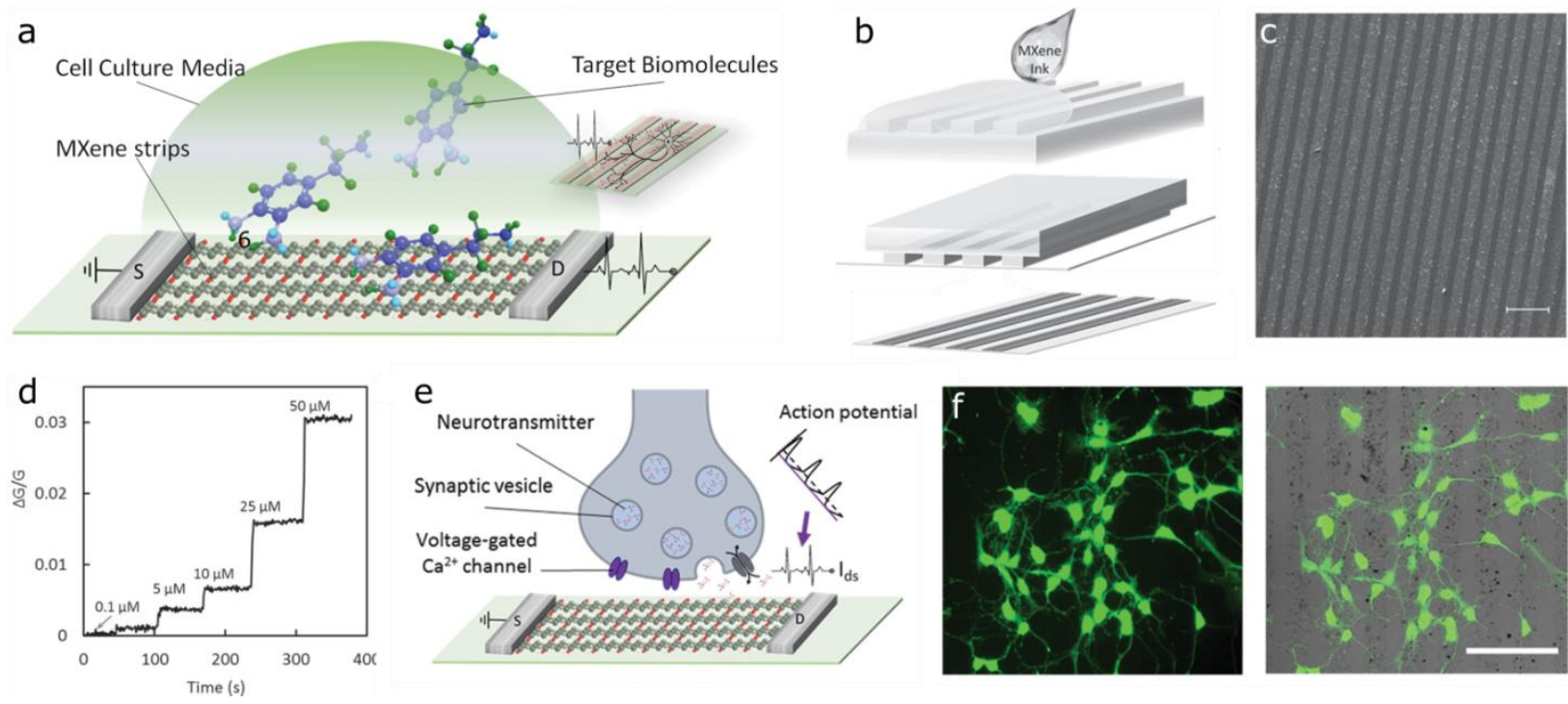

Figure 16. (a) Schematic illustration of a MXene biosensing device working based on FET. (b) Micropattering of MXene on glass substrates using $\mu \mathrm{CP}$. MXene aqueous solution was used to ink PDMS stamps, which was then printed onto 3-aminopropyltriethoxysilane modified coverslips. Several layers of MXene stripes were placed on the coverslips after removal of the stamps (c), providing an active surface to bind small biomolecules, which in turn alter the conductivity of stripes for biosensing application. (d) Fluctuation of conductivity on an MXene device for dopamine concentrations varying from $100 \times 10^{-9} \mathrm{M}$ to $50 \times 10^{-6} \mathrm{M}$. (e) Working principle of MXene-based FET device to for real-time monitoring of spiking activity in cultured primary hippocampal neurons. The released neurotransmitters will bind to the MXene surface to induce fluctuation of electrical signals. (f) Fluorescence image of immunostained neurons (left panel). The right panel is merged with bright-field channel to show good compatibility of the neuron cells with the MXene micropattern. The ultrathin thickness $(\approx 5 \mathrm{~nm})$ of the MXene micropatterns would make the device nearly transparent and does not cause any interference with traditional microscopic imaging. Scale bar is $100 \mu \mathrm{m}$. Reproduced with permission. ${ }^{[90]}$ Copyright 2016, Wiley-VCH.

Although metal oxide semiconductors (MOS) are currently good candidates for sensing purposes, they simultaneously generate high signal and low noise just at high temperature, a critical limitation for using them in portable sensing devices. MXenes are proposed as an alternative owing to their sensing capability at room temperature. Unlike MOS-based sensors 


\section{WILEY-VCH}

that atmosphere-dependent surface conductivity governs their sensing mechanism, charge transfer from adsorbed molecules plays a key role in the sensing mechanism of 2D MXenes. The co-existence of metallic conductivity and fully covered surface functionalities provide a unique opportunity for 1) detecting high signal as the abundant functional groups on the surface provide adsorption sites for strong binding with analytes and 2) minimizing the noise due to the intrinsic high metallic conductivity. Benefited from these properties, very sensitive detection of volatile organic compounds is reported for the early diagnosis of diseases. ${ }^{[18 c]}$ $\mathrm{Ti}_{3} \mathrm{C}_{2} \mathrm{~T}_{\mathrm{x}}$ MXene films, shown in Figure $17 \mathrm{a}_{1}$ were able to detect acetone, ethanol and ammonia at very low limit of detection of less than 100 parts per billion (ppb), surpassing the best sensors thus far reported (Figure $\left.17 \mathrm{a}_{2}\right) \cdot{ }^{[18 c]}$ Interestingly, $\mathrm{Ti}_{3} \mathrm{C}_{2} \mathrm{~T}_{\mathrm{x}}$ sensors were able to show resistance alteration for different types of gases (oxidizing or reducing type) adsorbed on their surface, indicating that the charge carrier transport could be hindered with various gases adsorbed. This phenomenon cannot be observed in sensors made of semiconducting materials because the response is dependent on electron-accepting or -donating properties of adsorbed analytes as well as the dominating charge carrier type ( $\mathrm{p}-$, n-type) of the sensing material. ${ }^{[91]}$ Therefore, it is concluded that the positive response of $\mathrm{Ti}_{3} \mathrm{C}_{2} \mathrm{~T}_{\mathrm{x}}$ MXene films to different gases is associated to its reduced metallic conductivity due to the blockage of charge carriers and increased resistance upon gas adsorption.

Combining conductive materials into the backbone of elastic hydrogels is a new research direction for the fabrication of wearable electronics, point-of-care devices, and also developing soft robotics. Conductive nanostructures were recently incorporated into the 3D network of hydrogels to improve their sensitivity. ${ }^{[92]}$ However, limitations originated from viscous deformations and rearrangement of the hydrogel network by an electric field are still remained, consequently compromising sensing reliability due to the unstable noises and signal fluctuation. ${ }^{[93]}$ A viscoelastic hydrogel containing $\mathrm{Ti}_{3} \mathrm{C}_{2} \mathrm{~T}_{\mathrm{x}}$ MXene is recently fabricated (Figure 17b), outperforming all hydrogel based strain sensors. ${ }^{[18 d]}$ Outstanding tensile strain 


\section{WILEY-VCH}

sensitivity, remarkable stretchability (> 3400\%; Figure $17 \mathrm{~b}_{1}$ ), high conductivity, rapid selfhealing ability (Figure $17 \mathrm{~b}_{2}$ ), and adhesiveness to human skin are the noteworthy characteristics of the fabricated hydrogel. The hydrogel could conveniently detect complex motions, such as full hand movement (Figure $17 \mathrm{~b}_{3}$ ) when adhered to the knuckle. Distinct resistance values were detectable for different gestures, shown as zero, one, two, three, four, and five. The signals were also fully recoverable. Sensing the direction of motion was also detectable, confirmed through placement of the hydrogel in the middle of the forehead to distinguish facial expressions, such as smiling and frowning (Figure 17b $\mathrm{b}_{4}$.

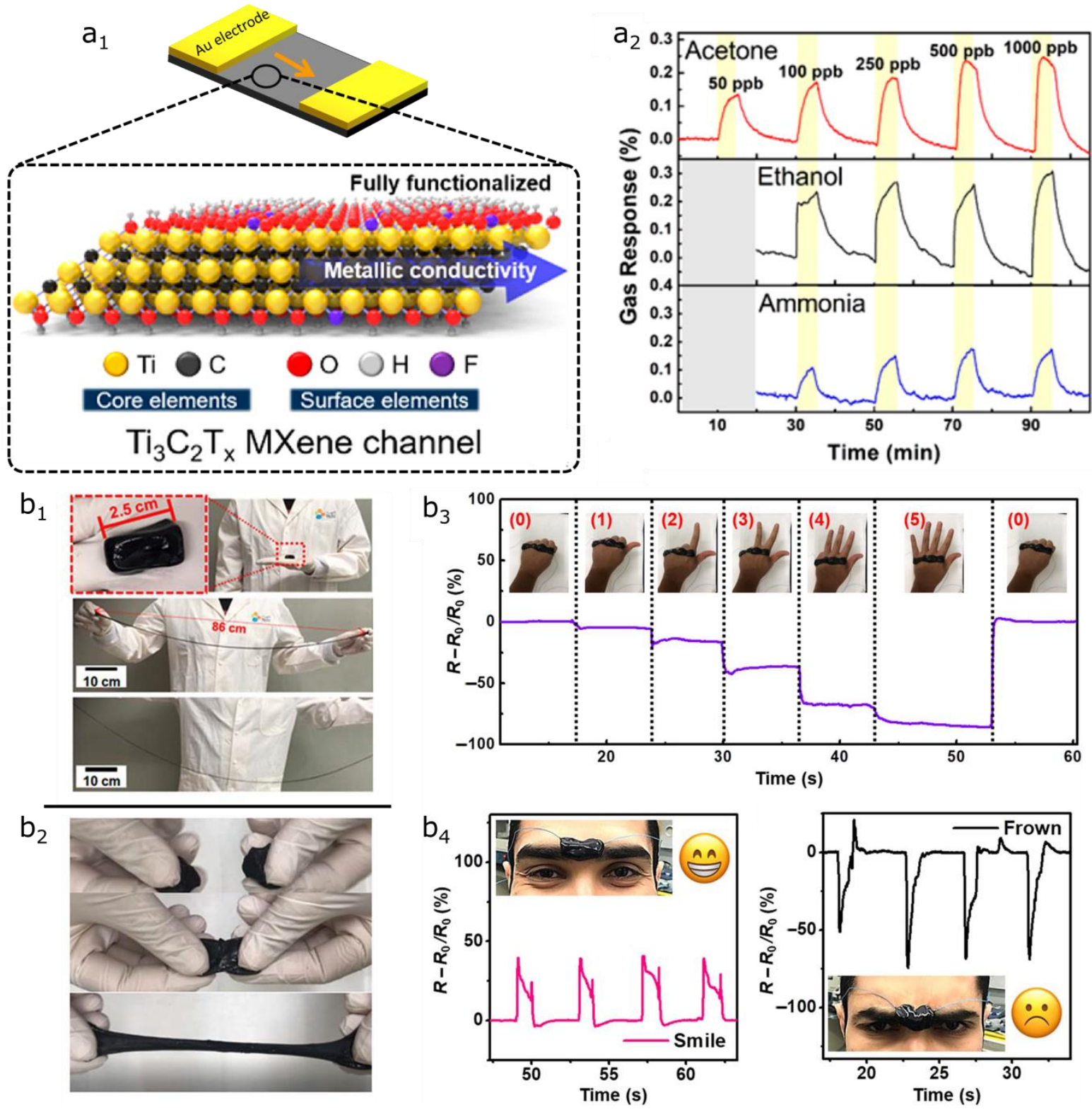




\section{WILEY-VCH}

Figure 17. $\left(\mathrm{a}_{1}\right)$ Schematic illustration of the atomic structure and surface characterizations of $\mathrm{Ti}_{3} \mathrm{C}_{2} \mathrm{~T}_{\mathrm{x}}$ films fabricated for gas sensing. $\left(\mathrm{a}_{2}\right)$ The response of $\mathrm{Ti}_{3} \mathrm{C}_{2} \mathrm{~T}_{\mathrm{x}}$ sensors at room temperature to different gases in ppb concentration range (50-1000 ppb). High-resolution was observed even at very low gas concentrations, and the gradual increase of concentration resulted in constant increase of obtained response. Reproduced with permission. ${ }^{[18 c]}$ Copyright 2018, American Chemical Society. Photographs of the $\left(b_{1}\right)$ stretchability and $\left(b_{2}\right)$ selfhealability of MXene-hydrogel. In $b_{2}$, MXene-hydrogel was first cut in two pieces (top). They were then gently touched (middle) to test its healability. Interestingly, the healed hydrogel could retain the original stretchability observed before cutting (bottom). The self-healing property was improved after using MXenes in the structure of hydrogel, mainly due to the increased number of hydrogen bonds with the functional groups of MXenes. The sensing performance of MXene-hydrogel was distinguished through resistance change in response to $\left(b_{3}\right)$ different hand gestures and $\left(b_{4}\right)$ facial expressions. Reprinted with permission. ${ }^{[18 d]}$ Copyright 2018, AAAS.

MXene-based nanostructures with plasmonic properties are recently studied as substrates for surface-enhanced Raman spectroscopy (SERS), a promising technique for identification of small quantities of molecules due to its adaptability as well as highly efficient, noninvasive and versatile nature. ${ }^{[94]}$ One-step hybridization of silver, gold and palladium NPs (Ag, Au and $\mathrm{Pd}$ ) with $\mathrm{Ti}_{3} \mathrm{C}_{2} \mathrm{~T}_{\mathrm{x}}$ MXene nanosheets in an aqueous solution could produce a highly sensitive substrate for SERS application, tested for the detection of methylene blue (MB) with calculated enhancement factors on the order of $10^{5}$ due to the synergistic effects between nanoparticles and MXene sheets. ${ }^{[95]}$ Two-dimensional $\mathrm{Ti}_{3} \mathrm{C}_{2} \mathrm{~T}_{\mathrm{x}}$ MXene SERS substrates have also been manufactured by spray-coating on a glass substrate to detect different dyes, with calculated enhancement factors reaching $\sim 10^{6} \cdot{ }^{[96]}$ This study found the percentage of MXene surface deposition on glass slides as a significant factor affecting SERS based detection efficiency of sensing analytes. All above-discussed studies demonstrate the feasibility of using MXenes as a new generation of versatile matrix for futuristic fabrication of advanced biosensors with a wide range of applications in biomedical analysis. 


\section{WILEY-VCH}

\subsection{Applications of MXenes in implants}

One of the featured applications of ceramic biomaterials recently proposed for further investigation is the surface coating of metal implants in order to reduce their surface oxidation and creation of a brittle interface between the implant and surrounding tissues. For example, while $\mathrm{Ti}$ is the most used metal implant due to its high biocompatibility, large availability and low price, it doesn't still have the title of an ideal material owing to its oxidation and the formation of $\mathrm{TiO}_{2}$ on its surface. ${ }^{[97]}$ This oxidized layer might fracture and induce toxicity due to the formation of small particles and induction of fibrotic and foreign body reactions, which will eventually lead to the implant failure through its encapsulation within a soft tissue. ${ }^{[98]}$ In order to avoid these drawbacks that decrease patient satisfaction and enhance economic and social burden, MXenes are suggested as ceramic materials suitable for the surface coating of the implants. For this purpose, the first step is to understand the biological responses of host tissue cells to the MXene bio-interfaces. Chen $e t a l .{ }^{[23]}$ investigated the biocompatibility of $\mathrm{Ti}_{3} \mathrm{AlC}_{2}, \mathrm{Ti}_{3} \mathrm{SiC}_{2}$, and $\mathrm{Ti}_{2} \mathrm{AlN}$ with preosteoblasts and fibroblasts through cell adhesion, proliferation, and differentiation and compared the results with pure $\mathrm{Ti}$ and $\mathrm{Ti}-6 \mathrm{Al}-4 \mathrm{~V}$ alloy as traditional Ti-based materials used for implantation. Compared to non-coated Ti-based specimens, the spreading of preosteoblast on MXenes, particularly $\mathrm{Ti}_{2} \mathrm{AlN}$, was clearly promoted at initial stages of proliferation, reaching to $2901 \mu \mathrm{m}^{2} / \mathrm{cell}$. This value was quite larger than 2372 and $2450 \mu \mathrm{m}^{2} /$ cell that were reported for Ti alloy and pure Ti, respectively (calculated using ImageTool 3.0 based on confocal images shown in Figure 18a). The water contact angle measurement of the implant surfaces demonstrated the correlation of higher hydrophilicity and the increased adhesion and spread of cells on $\mathrm{Ti}_{2} \mathrm{AlN}$ samples (Figure 18b). $\mathrm{Ti}_{2} \mathrm{AlN}$ exhibited the highest biocompatibility and cell affinity because of the surface formation of $\operatorname{TiN}_{x} \mathrm{O}_{y}$, which shows better biological performance compared to the $\mathrm{TiC}_{\mathrm{x}} \mathrm{O}_{\mathrm{y}}$ formed on the surface of $\mathrm{Ti}_{3} \mathrm{AlC}_{2}$ and $\mathrm{Ti}_{3} \mathrm{SiC}_{2}$, as well as $\mathrm{TiO}_{2}$ formed on the surface of noncoated Ti implants. This is mainly resulted from the stronger affinity of the $\mathrm{Ca}^{2+}$ ions to the 


\section{WILEY-VCH}

$\mathrm{TiN}_{\mathrm{x}} \mathrm{O}_{\mathrm{y}}$ present on the surface of $\mathrm{Ti}_{2} \mathrm{AlN}$ compared to the other oxidized forms tested. In another study performed by Veronesi et al. ${ }^{[20]}$, titanium carbide (TiC) coated implants were placed within rabbit femurs to improve the formation of bone around the implant as compared to the bare Ti implant. Interestingly, histological studies could not find any fibrous tissue, sign of necrosis, inflammatory reaction, osteolysis or tissue degeneration for any of $\mathrm{Ti}$ and $\mathrm{TiC}$ implants. This finding means all types of MXenes would not be able to improve the biological performance of implants.

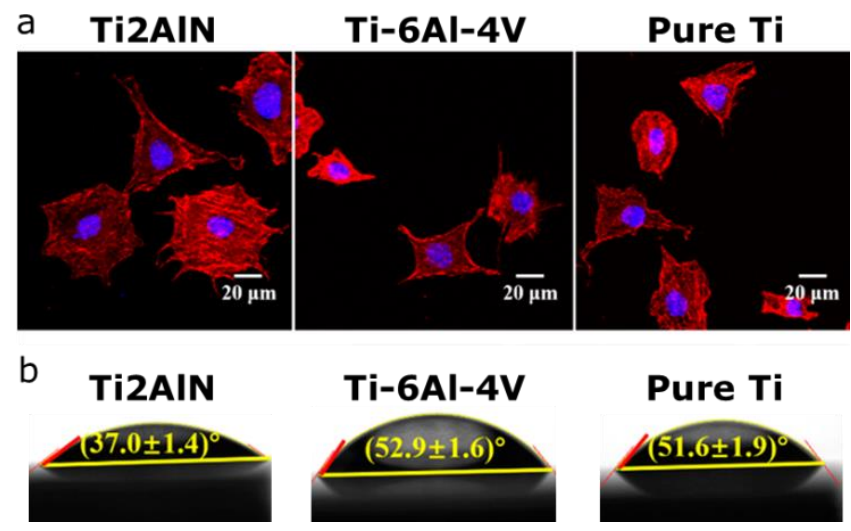

Figure 18. (a) CLSM images of MC3T3-E1 cells attached on the surface of $\mathrm{Ti}_{2} \mathrm{AlN}$, $\mathrm{Ti}-6 \mathrm{Al}-4 \mathrm{~V}$ alloy, and pure Ti after $3 \mathrm{~h}$ of incubation. Phalloidin and DAPI co-staining was performed for the imaging of the filamentous actin (red) and nucleus (blue), respectively (initial cell density was $1 \times 10^{4}$ cells $/ \mathrm{mL}$ ). The cells could spread and occupy larger areas of Ti2AlN compared to the other implants. (b) Contact angle experiment performed with deionized water to determine the hydrophilicity of surfaces. Reproduced with permission. ${ }^{[23]}$ Copyright 2017, American Chemical Society.

\section{Conclusion and outlook}

Since the first report on synthesis of $\mathrm{Ti}_{3} \mathrm{C}_{2}$ in 2011, various types of 2D MXene sheets have been explored through the selective chemical etching of " $A$ " in $M_{n+1} A X_{n}$ phases, where " $M$ ", " $\mathrm{A}$ " and " $\mathrm{X}$ " are the transition metal, the main group sp-element, and carbon or nitrogen elements, respectively. Tunable optical and magnetic properties of Mxenes have made them attractive for various biomedical applications, such as biosensing and different sorts of bioimaging techniques. Also, MXenes possess a unique potential for drug delivery, theranostics, tissue engineering and antibacterial applications. Low cytotoxicity, high surface 


\section{WILEY-VCH}

area, as well as strong and wide NIR absorption make MXenes' family one of the furthermost promising materials for aforementioned biomedical applications. However, challenges for their clinical translation are still not fully addressed. Although several studies have shown desirable short-term biocompatibility of the MXenes, systematic assessment of long-term in vivo biosafety is essential for the expansion of their biomedical applications. The chronic impact of these nanosheets on the histology and normal performance of various organs and tissues as well as the genotoxicity, immunogenicity, and biodistribution of these materials should be investigated in future. In addition, the effect of surface coatings on the biological behavior of MXenes needs further clarification. In addition, in order to fully realize the bioapplications of 2D MXenes, there are several fundamental challenges herewith: precise control over size, components, and surface chemical functionalization of the MXenes. These research fields should expand further in future, though the flow rate of investigations in the last years is significantly promising and the better control over these parameters has resulted in the design of MXenes with enhanced potential for drug delivery and phototherapy. These achievements can be expanded more through the design of multifunctional hybrid materials composed of MXenes. Moreover, instead of top-down methods that lack the control of size distribution and reproducibility, more efforts should be devoted to bottom-up synthesis of MXenes for better control over size, geometry and surface terminations. For example, it is worthy to develop new synthesis methods for the fabrication of morphologies beyond nanosheets, i.e., nanotubes, nanocages, or spherical structures. PAI in the NIR-II window should also be investigated due to its high tissue penetration depth compared to NIR-I light. Additionally, optical properties of MXenes, their response to ultrasound, desirable composition of MXenes for SERS application, and radioactive metal labeling of MXenes for PET are worth investigating. More efforts should also be devoted to improve the low yield for mass production of MXenes. Through all these future investigations, it is expected to observe 


\section{WILEY-VCH}

a rapid growing in the synthesis of new families of MXenes and their bright perspective in biomedical sciences.

\section{Acknowledgements}

M.-A.S acknowledges financial support from the Academy of Finland (decision no. 317316), Iran's National Elites Foundation, and Iran Nanotechnology Initiative Council.

\section{Conflict of Interest}

The authors declare no conflict of interest.

Received: ((will be filled in by the editorial staff))

Revised: ((will be filled in by the editorial staff)) Published online: ((will be filled in by the editorial staff)) 


\section{WILEY-VCH}

References

[1] a) Y. Chen, L. Wang, J. Shi, Nano Today 2016, 11, 292; b) X. Li, J. Shan, W. Zhang, S. Su, L. Yuwen, L. Wang, Small 2017, 13, 1602660\%@ 1613.

[2] Q. Weng, X. Wang, X. Wang, Y. Bando, D. Golberg, Chemical Society Reviews 2016, 45, 3989.

[3] a) X. Ding, H. Liu, Y. Fan, Advanced healthcare materials 2015, 4, 1451; b) H. E. Karahan, C. Wiraja, C. Xu, J. Wei, Y. Wang, L. Wang, F. Liu, Y. Chen, Advanced healthcare materials 2018, $1701406 \%$ @ 2192.

[4] J. R. Choi, K. W. Yong, J. Y. Choi, A. Nilghaz, Y. Lin, J. Xu, X. Lu, Theranostics 2018, 8, 1005.

[5] P. Ares, J. J. Palacios, G. Abellán, J. Gómez-Herrero, F. Zamora, Advanced Materials 2018, 30,1703771\%@0935.

[6] M. Naguib, M. Kurtoglu, V. Presser, J. Lu, J. Niu, M. Heon, L. Hultman, Y. Gogotsi, M. W. Barsoum, Advanced Materials 2011, 23, 4248.

[7] a) M. Alhabeb, K. Maleski, B. Anasori, P. Lelyukh, L. Clark, S. Sin, Y. Gogotsi, Chemistry of Materials 2017, 29, 7633; b) K. Huang, Z. Li, J. Lin, G. Han, P. Huang, Chemical Society Reviews 2018; c) B. Anasori, M. R. Lukatskaya, Y. Gogotsi, Nature Reviews Materials 2017, 2,16098\%@2058.

[8] B. Anasori, Y. Xie, M. Beidaghi, J. Lu, B. C. Hosler, L. Hultman, P. R. C. Kent, Y. Gogotsi, M. W. Barsoum, ACS nano 2015, 9, 9507.

[9] a) Z. W. Seh, K. D. Fredrickson, B. Anasori, J. Kibsgaard, A. L. Strickler, M. R. Lukatskaya, Y. Gogotsi, T. F. Jaramillo, A. Vojvodic, ACS Energy Letters 2016, 1, 589; b) H. Wang, Y. Wu, X. Yuan, G. Zeng, J. Zhou, X. Wang, J. W. Chew, Advanced Materials 2018, 30, 1704561\%@0935.

[10] C. E. Ren, K. B. Hatzell, M. Alhabeb, Z. Ling, K. A. Mahmoud, Y. Gogotsi, The journal of physical chemistry letters 2015, 6, 4026.

[11] F. Shahzad, M. Alhabeb, C. B. Hatter, B. Anasori, S. M. Hong, C. M. Koo, Y. Gogotsi, Science 2016, 353, 1137.

[12] M. Ghidiu, M. R. Lukatskaya, M.-Q. Zhao, Y. Gogotsi, M. W. Barsoum, Nature 2014, 516, $78 \% @ 1476$.

[13] Q. Tang, Z. Zhou, P. Shen, Journal of the American Chemical Society 2012, 134, 16909.

[14] A. D. Dillon, M. J. Ghidiu, A. L. Krick, J. Griggs, S. J. May, Y. Gogotsi, M. W. Barsoum, A. T. Fafarman, Advanced Functional Materials 2016, 26, 4162.

[15] a) X. Yu, X. Cai, H. Cui, S.-W. Lee, X.-F. Yu, B. Liu, Nanoscale 2017, 9, 17859; b) C. Dai, H. Lin, G. Xu, Z. Liu, R. Wu, Y. Chen, Chemistry of Materials 2017, 29, 8637; c) H. Lin, S. Gao, C. Dai, Y. Chen, J. Shi, Journal of the American Chemical Society 2017, 139, 16235; d) H. Lin, X. Wang, L. Yu, Y. Chen, J. Shi, Nano letters 2016, 17, 384; e) H. Lin, Y. Wang, S. Gao, Y. Chen, J. Shi, Advanced Materials 2018, 30,1703284\%@0935.

[16] C. Dai, Y. Chen, X. Jing, L. Xiang, D. Yang, H. Lin, Z. Liu, X. Han, R. Wu, ACS Nano 2017, 11, 12696.

[17] a) K. Rasool, M. Helal, A. Ali, C. E. Ren, Y. Gogotsi, K. A. Mahmoud, ACS nano 2016, 10, 3674; b) F. Alimohammadi, M. Sharifian Gh, N. H. Attanayake, A. C. Thenuwara, Y. Gogotsi, B. Anasori, D. R. Strongin, Langmuir 2018.

[18] a) L. Wu, X. Lu, Z.-S. Wu, Y. Dong, X. Wang, S. Zheng, J. Chen, Biosensors and Bioelectronics 2018, 107, 69; b) L. Lorencová, T. Bertok, E. Dosekova, A. Holazová, D. Paprckova, A. Vikartovská, V. Sasinková, J. Filip, P. Kasák, M. Jerigová, Electrochimica acta 2017, 235, 471; c) S. J. Kim, H.-J. Koh, C. E. Ren, O. Kwon, K. Maleski, S.-Y. Cho, B. Anasori, C.-K. Kim, Y.-K. Choi, J. Kim, ACS nano 2018, 12 , 


\section{WILEY-VCH}

986; d) Y.-Z. Zhang, K. H. Lee, D. H. Anjum, R. Sougrat, Q. Jiang, H. Kim, H. N. Alshareef, Science Advances 2018, 4, eaat0098.

[19] a) Z. Li, H. Zhang, J. Han, Y. Chen, H. Lin, T. Yang, Advanced Materials 2018, 1706981; b) X. Han, J. Huang, H. Lin, Z. Wang, P. Li, Y. Chen, Advanced healthcare materials 2018, 7, 1701394\%@2192.

[20] F. Veronesi, G. Giavaresi, M. Fini, G. Longo, C. A. Ioannidu, A. S. d'Abusco, F. Superti, G. Panzini, C. Misiano, A. Palattella, Materials Science and Engineering: $C$ 2017, 70, 264.

[21] E. Lee, A. VahidMohammadi, B. C. Prorok, Y. S. Yoon, M. Beidaghi, D.-J. Kim, ACS applied materials \& interfaces 2017, 9, 37184.

[22] a) N. Gao, Y. Miyamoto, H. Oonishi, D. Zhang, Journal of materials science letters 2002, 21, 783; b) T. L. Ngai, L. Lu, J. Chen, J. Zhang, Y. Li, Ceramics International 2014, 40, 5343; c) S. L. Shi, W. Pan, M. H. Fang, Z. Y. Fang, Journal of the American Ceramic Society 2006, 89, 743.

[23] K. Chen, N. Qiu, Q. Deng, M.-H. Kang, H. Yang, J.-U. Baek, Y.-H. Koh, S. Du, Q. Huang, H.-E. Kim, ACS Biomaterials Science \& Engineering 2017, 3, 2293.

[24] M. Naguib, O. Mashtalir, J. Carle, V. Presser, J. Lu, L. Hultman, Y. Gogotsi, M. W. Barsoum, ACS nano 2012, 6, 1322.

[25] G. Liu, J. Zou, Q. Tang, X. Yang, Y. Zhang, Q. Zhang, W. Huang, P. Chen, J. Shao, $\mathrm{X}$. Dong, ACS applied materials \& interfaces 2017, 9, 40077.

[26] J. Emmerlich, D. Music, P. Eklund, O. Wilhelmsson, U. Jansson, J. M. Schneider, H. Högberg, L. Hultman, Acta Materialia 2007, 55, 1479.

[27] Z. Sun, International Materials Reviews 2011, 56, 143.

[28] O. Mashtalir, M. Naguib, V. N. Mochalin, Y. Dall'Agnese, M. Heon, M. W. Barsoum, Y. Gogotsi, Nature communications 2013, 4, $1716 \%$ \% 2041.

[29] O. Mashtalir, M. R. Lukatskaya, M. Q. Zhao, M. W. Barsoum, Y. Gogotsi, Advanced Materials 2015, 27, 3501.

[30] M. Naguib, R. R. Unocic, B. L. Armstrong, J. Nanda, Dalton transactions 2015, 44, 9353.

[31] a) X. Sang, Y. Xie, M.-W. Lin, M. Alhabeb, K. L. Van Aken, Y. Gogotsi, P. R. C. Kent, K. Xiao, R. R. Unocic, ACS nano 2016, 10, 9193; b) A. Lipatov, M. Alhabeb, M. R. Lukatskaya, A. Boson, Y. Gogotsi, A. Sinitskii, Advanced Electronic Materials 2016,2,1600255\%@2199.

[32] M. R. Lukatskaya, O. Mashtalir, C. E. Ren, Y. Dall'Agnese, P. Rozier, P. L. Taberna, M. Naguib, P. Simon, M. W. Barsoum, Y. Gogotsi, Science 2013, 341, 1502.

[33] N. C. Osti, M. Naguib, A. Ostadhossein, Y. Xie, P. R. Kent, B. Dyatkin, G. Rother, W. T. Heller, A. C. Van Duin, Y. Gogotsi, ACS applied materials \& interfaces 2016, 8,8859 .

[34] H.-W. Wang, M. Naguib, K. Page, D. J. Wesolowski, Y. Gogotsi, Chemistry of Materials 2015, 28, 349.

[35] L. H. Karlsson, J. Birch, J. Halim, M. W. Barsoum, P. O. Persson, Nano letters 2015, $15,4955$.

[36] J. Halim, S. Kota, M. R. Lukatskaya, M. Naguib, M. Q. Zhao, E. J. Moon, J. Pitock, J. Nanda, S. J. May, Y. Gogotsi, Advanced Functional Materials 2016, 26, 3118.

[37] a) T. Hu, M. Hu, Z. Li, H. Zhang, C. Zhang, J. Wang, X. Wang, Physical Chemistry Chemical Physics 2016, 18, 20256; b) J. Xu, J. Shim, J. H. Park, S. Lee, Advanced Functional Materials 2016, 26, 5328.

[38] X. Fei, J. Neilson, Y. Li, V. Lopez, S. J. Garrett, L. Gan, H.-J. Gao, L. Gao, Nano Letters 2017, 17, 2887.

[39] M. Naguib, J. Halim, J. Lu, K. M. Cook, L. Hultman, Y. Gogotsi, M. W. Barsoum, Journal of the American Chemical Society 2013, 135, 15966. 


\section{WILEY-VCH}

[40] R. Meshkian, L.-Å. Näslund, J. Halim, J. Lu, M. W. Barsoum, J. Rosen, Scripta Materialia 2015, 108, 147.

[41] J. Zhou, X. Zha, F. Y. Chen, Q. Ye, P. Eklund, S. Du, Q. Huang, Angewandte Chemie 2016, 128, 5092.

[42] J. Halim, M. R. Lukatskaya, K. M. Cook, J. Lu, C. R. Smith, L.-Å. Näslund, S. J. May, L. Hultman, Y. Gogotsi, P. Eklund, Chemistry of Materials 2014, 26, 2374.

[43] A. Feng, Y. Yu, Y. Wang, F. Jiang, Y. Yu, L. Mi, L. Song, Materials \& Design 2017, $114,161$.

[44] L. Wang, H. Zhang, B. Wang, C. Shen, C. Zhang, Q. Hu, A. Zhou, B. Liu, Electronic Materials Letters 2016, 12, 702.

[45] P. Urbankowski, B. Anasori, T. Makaryan, D. Er, S. Kota, P. L. Walsh, M. Zhao, V. B. Shenoy, M. W. Barsoum, Y. Gogotsi, Nanoscale 2016, 8, 11385.

[46] T. Li, L. Yao, Q. Liu, J. Gu, R. Luo, J. Li, X. Yan, W. Wang, P. Liu, B. Chen, Angewandte Chemie International Edition 2018, 57, 6115.

[47] X. Xie, Y. Xue, L. Li, S. Chen, Y. Nie, W. Ding, Z. Wei, Nanoscale 2014, 6, 11035.

[48] P. Urbankowski, B. Anasori, K. Hantanasirisakul, L. Yang, L. Zhang, B. Haines, S. J. May, S. J. Billinge, Y. Gogotsi, Nanoscale 2017, 9, 17722.

[49] M. Alhabeb, K. Maleski, T. S. Mathis, A. Sarycheva, C. B. Hatter, S. Uzun, A. Levitt, Y. Gogotsi.

[50] H. Wang, J. Zhang, Y. Wu, H. Huang, G. Li, X. Zhang, Z. Wang, Applied Surface Science 2016, 384, 287.

[51] M. Naguib, Y. Gogotsi, Accounts of chemical research 2014, 48, 128.

[52] T. Zhang, L. Pan, H. Tang, F. Du, Y. Guo, T. Qiu, J. Yang, Journal of Alloys and Compounds 2017, 695, 818.

[53] A. Vaughn, J. Ball, T. Heil, D. Morgan, G. Lampronti, G. Maršalkaite, C. L. Raston, N. P. Power, S. Kellici, Chemistry-A European Journal 2017.

[54] X. Wang, S. Kajiyama, H. Iinuma, E. Hosono, S. Oro, I. Moriguchi, M. Okubo, A. Yamada, Nature communications 2015, 6, 6544.

[55] G. Li, L. Tan, Y. Zhang, B. Wu, L. Li, Langmuir 2017, 33, 9000.

[56] H. Z. Zardini, A. Amiri, M. Shanbedi, M. Maghrebi, M. Baniadam, Colloids and Surfaces B: Biointerfaces 2012, 92, 196.

[57] a) M. O. Sommer, C. Munck, R. V. Toft-Kehler, D. I. Andersson, Nature Reviews Microbiology 2017, 15, 689; b) D. Davies, Nature reviews Drug discovery 2003, 2, 114.

[58] S. Fernandez-Lopez, H.-S. Kim, E. C. Choi, M. Delgado, J. R. Granja, A. Khasanov, K. Kraehenbuehl, G. Long, D. A. Weinberger, K. M. Wilcoxen, Nature 2001, 412, 452.

[59] a) C. Liu, D. Kong, P.-C. Hsu, H. Yuan, H.-W. Lee, Y. Liu, H. Wang, S. Wang, K. Yan, D. Lin, Nature nanotechnology 2016, 11, 1098; b) J. Li, G. Wang, H. Zhu, M. Zhang, X. Zheng, Z. Di, X. Liu, X. Wang, Scientific reports 2014, 4, 4359.

[60] a) S. Liu, T. H. Zeng, M. Hofmann, E. Burcombe, J. Wei, R. Jiang, J. Kong, Y. Chen, ACS nano 2011, 5, 6971; b) I. Y. Kim, S. Park, H. Kim, S. Park, R. S. Ruoff, S. J. Hwang, Advanced Functional Materials 2014, 24, 2288; c) Y. Tu, M. Lv, P. Xiu, T. Huynh, M. Zhang, M. Castelli, Z. Liu, Q. Huang, C. Fan, H. Fang, Nature nanotechnology 2013, 8, nnano. 2013.125; d) O. Akhavan, E. Ghaderi, ACS nano 2010, 4, 5731; e) K. Rasool, K. A. Mahmoud, D. J. Johnson, M. Helal, G. R. Berdiyorov, Y. Gogotsi, Scientific Reports 2017, 7.

[61] a) A. M. Jastrzębska, E. Karwowska, T. Wojciechowski, W. Ziemkowska, A. Rozmysłowska, L. Chlubny, A. Olszyna, Journal of Materials Engineering and Performance 1; b) A. Jastrzębska, E. Karwowska, D. Basiak, A. Zawada, W. 


\section{WILEY-VCH}

Ziemkowska, T. Wojciechowski, D. Jakubowska, A. Olszyna, Int. J. Electrochem. Sci 2017, 12, 2159.

[62] R. P. Pandey, K. Rasool, E. Vinod, B. Aissa, Y. Gogotsi, K. A. Mahmoud, Journal of Materials Chemistry A 2018.

[63] a) E. A. Sykes, J. Chen, G. Zheng, W. C. Chan, ACS nano 2014, 8, 5696; b) M.-A. Shahbazi, N. Shrestha, E. Mäkilä, F. Araújo, A. Correia, T. Ramos, B. Sarmento, J. Salonen, J. Hirvonen, H. A. Santos, Nano Research 2015, 8, 1505; c) R. Toy, P. M. Peiris, K. B. Ghaghada, E. Karathanasis, Nanomedicine 2014, 9, 121; d) B. HerranzBlanco, M. A. Shahbazi, A. R. Correia, V. Balasubramanian, T. Kohout, J. Hirvonen, H. A. Santos, Advanced healthcare materials 2016, 5, 1904; e) A. Correia, M.-A. Shahbazi, E. Mäkilä, S. r. Almeida, J. Salonen, J. Hirvonen, H. 1. A. Santos, ACS applied materials \& interfaces 2015, 7, 23197.

[64] A. M. Jastrzębska, A. Szuplewska, T. Wojciechowski, M. Chudy, W. Ziemkowska, L. Chlubny, A. Rozmysłowska, A. Olszyna, Journal of hazardous materials 2017, 339, 1.

[65] L. Zong, H. Wu, H. Lin, Y. Chen, Nano Research 1.

[66] a) W. Chen, J. Ouyang, H. Liu, M. Chen, K. Zeng, J. Sheng, Z. Liu, Y. Han, L. Wang, J. Li, Advanced Materials 2017, 29; b) S. Mitra, H. S. Sasmal, T. Kundu, S. Kandambeth, K. Illath, D. Díaz Díaz, R. Banerjee, Journal of the American Chemical Society 2017, 139, 4513; c) G. Shim, M.-G. Kim, J. Y. Park, Y.-K. Oh, Advanced drug delivery reviews 2016, 105, 205.

[67] a) P. Figueiredo, V. Balasubramanian, M.-A. Shahbazi, A. Correia, D. Wu, C. G. Palivan, J. T. Hirvonen, H. A. Santos, International journal of pharmaceutics 2016, 511, 794; b) A. Wicki, D. Witzigmann, V. Balasubramanian, J. Huwyler, Journal of controlled release 2015, 200, 138.

[68] a) J. T. Robinson, K. Welsher, S. M. Tabakman, S. P. Sherlock, H. Wang, R. Luong, H. Dai, Nano research 2010, 3, 779; b) J. T. Robinson, S. M. Tabakman, Y. Liang, H. Wang, H. Sanchez Casalongue, D. Vinh, H. Dai, Journal of the American Chemical Society 2011, 133, 6825; c) X. Qian, S. Shen, T. Liu, L. Cheng, Z. Liu, Nanoscale 2015, 7, 6380; d) S. S. Chou, B. Kaehr, J. Kim, B. M. Foley, M. De, P. E. Hopkins, J. Huang, C. J. Brinker, V. P. Dravid, Angewandte Chemie 2013, 125, 4254; e) K. Yang, G. Yang, L. Chen, L. Cheng, L. Wang, C. Ge, Z. Liu, Biomaterials 2015, 38, 1; f) Z. Xiao, C. Xu, X. Jiang, W. Zhang, Y. Peng, R. Zou, X. Huang, Q. Liu, Z. Qin, J. Hu, Nano Research 2016, 9, 1934.

[69] L. V. Wang, S. Hu, science 2012, 335, 1458.

[70] a) N. Lee, D. Yoo, D. Ling, M. H. Cho, T. Hyeon, J. Cheon, Chemical reviews 2015, 115, 10637; b) T.-H. Shin, Y. Choi, S. Kim, J. Cheon, Chemical Society Reviews 2015, 44, 4501.

[71] Z. Zhao, J. Bao, C. Fu, M. Lei, J. Cheng, Chemistry of Materials 2017.

[72] a) W. Chen, P. Yi, Y. Zhang, L. Zhang, Z. Deng, Z. Zhang, ACS applied materials \& interfaces 2011, 3, 4085; b) G. Wang, W. Gao, X. Zhang, X. Mei, Scientific reports 2016, 6, 28258.

[73] Z. Liu, H. Lin, M. Zhao, C. Dai, S. Zhang, W. Peng, Y. Chen, Theranostics 2018, 8, 1648.

[74] a) L. Cheng, J. Liu, X. Gu, H. Gong, X. Shi, T. Liu, C. Wang, X. Wang, G. Liu, H. Xing, Advanced materials 2014, 26, 1886; b) X. Pan, J. Siewerdsen, P. J. La Riviere, W. A. Kalender, Medical physics 2008, 35, 3728.

[75] a) S. Rathnayake, J. Mongan, A. S. Torres, R. Colborn, D. W. Gao, B. M. Yeh, Y. Fu, Contrast media \& molecular imaging 2016, 11, 254; b) P. F. FitzGerald, R. E. Colborn, P. M. Edic, J. W. Lambert, A. S. Torres, P. J. Bonitatibus Jr, B. M. Yeh, Radiology 2015, 278, 723. 


\section{WILEY-VCH}

[76] Y. Jin, Y. Li, X. Ma, Z. Zha, L. Shi, J. Tian, Z. Dai, Biomaterials 2014, 35, 5795.

[77] Y. Xu, X. Wang, W. L. Zhang, F. Lv, S. Guo, Chemical Society Reviews 2018.

[78] a) M. Buzaglo, M. Shtein, O. Regev, Chemistry of Materials 2015, 28, 21; b) L. Zhou, F. Wu, J. Yu, Q. Deng, F. Zhang, G. Wang, Carbon 2017, 118, 50.

[79] Q. Xue, H. Zhang, M. Zhu, Z. Pei, H. Li, Z. Wang, Y. Huang, Y. Huang, Q. Deng, J. Zhou, Advanced Materials 2017, 29.

[80] a) S. Kajiyama, L. Szabova, K. Sodeyama, H. Iinuma, R. Morita, K. Gotoh, Y. Tateyama, M. Okubo, A. Yamada, ACS nano 2016, 10, 3334; b) M. Naguib, J. Come, B. Dyatkin, V. Presser, P.-L. Taberna, P. Simon, M. W. Barsoum, Y. Gogotsi, Electrochemistry Communications 2012, 16, 61; c) Y. Cai, J. Shen, G. Ge, Y. Zhang, W. Jin, W. Huang, J. Shao, J. Yang, X. Dong, ACS nano 2017, 12, 56.

[81] a) H. Liu, C. Duan, C. Yang, W. Shen, F. Wang, Z. Zhu, Sensors and Actuators B: Chemical 2015, 218, 60; b) F. Wang, C. Yang, C. Duan, D. Xiao, Y. Tang, J. Zhu, Journal of The Electrochemical Society 2015, 162, B16.

[82] a) F. Di Francesco, R. Fuoco, M. G. Trivella, A. Ceccarini, Microchemical journal 2005, 79, 405; b) W. Miekisch, J. K. Schubert, G. F. Noeldge-Schomburg, Clinica chimica acta 2004, 347, 25.

[83] a) B. Xiao, Y.-c. Li, X.-f. Yu, J.-b. Cheng, Sensors and Actuators B: Chemical 2016, 235, 103; b) X.-f. Yu, Y.-c. Li, J.-b. Cheng, Z.-b. Liu, Q.-Z. Li, W.-z. Li, X. Yang, B. Xiao, ACS applied materials \& interfaces 2015, 7, 13707.

[84] F. Wang, C. Yang, M. Duan, Y. Tang, J. Zhu, Biosensors and Bioelectronics 2015, 74, 1022.

[85] a) B. Modrzejewska, A. Guwy, R. Dinsdale, D. Hawkes, Water research 2007, 41, 260; b) H. Qi, C. Zhang, X. Li, Sensors and Actuators B: Chemical 2006, 114, 364; c) B. Zhang, Y. Cui, H. Chen, B. Liu, G. Chen, D. Tang, Electroanalysis 2011, 23, 1821.

[86] R. Rakhi, P. Nayak, C. Xia, H. N. Alshareef, Scientific reports 2016, 6, 36422.

[87] K. Zargoosh, M. javad Chaichi, M. Shamsipur, S. Hossienkhani, S. Asghari, M. Qandalee, Talanta 2012, 93, 37.

[88] a) M. Baghayeri, Rsc Advances 2015, 5, 18267; b) X. Du, Z. Miao, D. Zhang, Y. Fang, M. Ma, Q. Chen, Biosensors and Bioelectronics 2014, 62, 73.

[89] R. Nenkova, J. Wu, Y. Zhang, T. Godjevargova, Analytical Letters 2015, 48, 1297.

[90] B. Xu, M. Zhu, W. Zhang, X. Zhen, Z. Pei, Q. Xue, C. Zhi, P. Shi, Advanced Materials 2016, 28, 3333.

[91] S. Mao, S. Cui, G. Lu, K. Yu, Z. Wen, J. Chen, Journal of Materials Chemistry 2012, 22, 11009.

[92] a) Y. Wang, C. Zhu, R. Pfattner, H. Yan, L. Jin, S. Chen, F. Molina-Lopez, F. Lissel, J. Liu, N. I. Rabiah, Science advances 2017, 3, e1602076; b) C. S. Boland, U. Khan, G. Ryan, S. Barwich, R. Charifou, A. Harvey, C. Backes, Z. Li, M. S. Ferreira, M. E. Möbius, Science 2016, 354, 1257; c) J. Cao, C. Lu, J. Zhuang, M. Liu, X. Zhang, Y. Yu, Q. Tao, Angewandte Chemie 2017, 129, 8921.

[93] a) L. Cai, L. Song, P. Luan, Q. Zhang, N. Zhang, Q. Gao, D. Zhao, X. Zhang, M. Tu, F. Yang, W. Zhou, Q. Fan, J. Luo, W. Zhou, P. M. Ajayan, S. Xie, Scientific Reports 2013, 3, 3048; b) J. T. Muth, D. M. Vogt, R. L. Truby, Y. Mengüç, D. B. Kolesky, R. J. Wood, J. A. Lewis, Advanced Materials 2014, 26, 6307.

[94] a) D. Cialla, A. März, R. Böhme, F. Theil, K. Weber, M. Schmitt, J. Popp, Analytical and bioanalytical chemistry 2012, 403, 27; b) B. Sharma, R. R. Frontiera, A.-I. Henry, E. Ringe, R. P. Van Duyne, Materials today 2012, 15, 16.

[95] E. Satheeshkumar, T. Makaryan, A. Melikyan, H. Minassian, Y. Gogotsi, M. Yoshimura, Scientific reports 2016, 6, 32049. 


\section{WILEY-VCH}

[96] A. Sarycheva, T. Makaryan, K. Maleski, E. Satheeshkumar, A. Melikyan, H. Minassian, M. Yoshimura, Y. Gogotsi, The Journal of Physical Chemistry C 2017, 121, 19983.

[97] X. Liu, P. K. Chu, C. Ding, Materials Science and Engineering: R: Reports 2004, 47, 49.

[98] a) M. Bächle, R. J. Kohal, Clinical Oral Implants Research 2004, 15, 683; b) L. Saldaña, N. Vilaboa, Acta biomaterialia 2010, 6, 1649; c) M. J. Dalby, N. Gadegaard, R. O. Oreffo, Nature materials 2014, 13, 558; d) C. Wu, W. Wang, B. Tian, X. Liu, X. Qu, Z. Zhai, H. Li, F. Liu, Q. Fan, T. Tang, Biochemical pharmacology 2015, 93, 59. 


\section{WILEY-VCH}

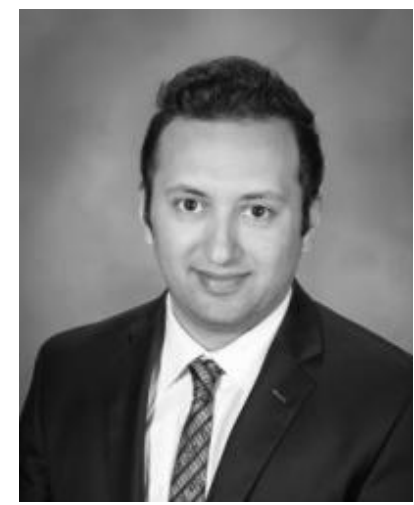

Mohammadreza Soleymaniha is currently a Ph.D. candidate in the Department of Mechanical Engineering at Texas A\&M University, College Station, USA. His research interests include scanning probe nanolithography, nanofabrication and development of 2D materials for various applications.

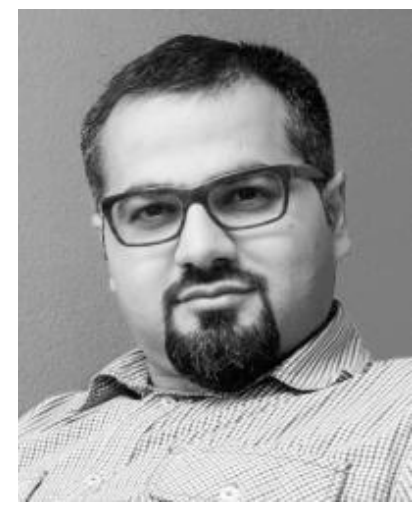

Mohammad-Ali Shahbazi received his PhD in 2015 from University of Helsinki, Finland. He is currently a postdoc fellow at Department of Micro- and Nanotechnology, Technical University of Denmark. His research interest is to shape the future of multifunctional medicines through the combination of material science and nanotechnology.

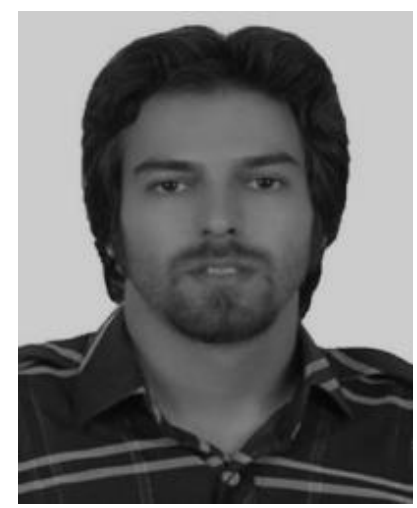

Alireza Rafieerad has received Ph.D. degree in Mechanical Engineering (Biomechanics) from University of Malaya and currently is a post-doctoral research fellow at Department of Physiology, University of Manitoba, Canada. His research focuses on advanced biomaterials and derived smart nanocomposites. 


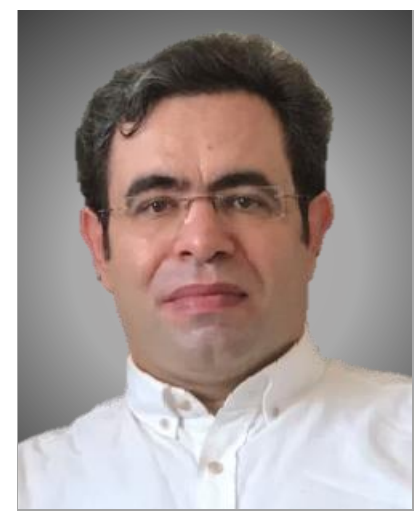

Aziz Maleki received his Ph.D. degree in organic chemistry from the Institute for Advanced Studies in Basic Sciences, Zanjan, Iran. He is currently an assistant professor at Department of Pharmaceutical Nanotechnology, Zanjan University of Medical Sciences, Zanjan, Iran. His research interests focus on the fabrication and characterization of novel mesoporous and 2D materials for catalytic and biomedical applications.

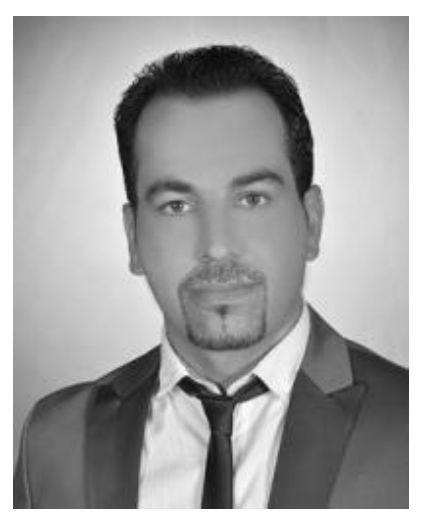

Ahmad Amiri received his Ph.D. degree in Mechanical Engineering from University of Malaya. He is currently an assistant professor at the Department of Mechanical Engineering, Texas A\&M University, USA. His research interests include the growth, fabrication, and characterization of 2D materials and carbon nanofibers for different applications. 


\section{WILEY-VCH}

MXene nanosheets are currently under investigation as a platform for various biomedical applications. Herein, an overview of requirements for the successful synthesis of MXenes is provided. Biological impacts of MXenes as well as their promoting role in drug delivery, cancer therapy, theranostics, and biosensing are highlighted.

Keywords: MXenes; photothermal therapy; drug delivery; theranostics; Biosensor.

Mohammadreza Soleymaniha, Mohammad-Ali Shahbazi*, Ali Reza Rafieerad, Aziz Maleki, Ahmad Amiri*

Promoting Role of MXene Nanosheets in Biomedical Sciences: Therapeutic and Biosensing Innovations

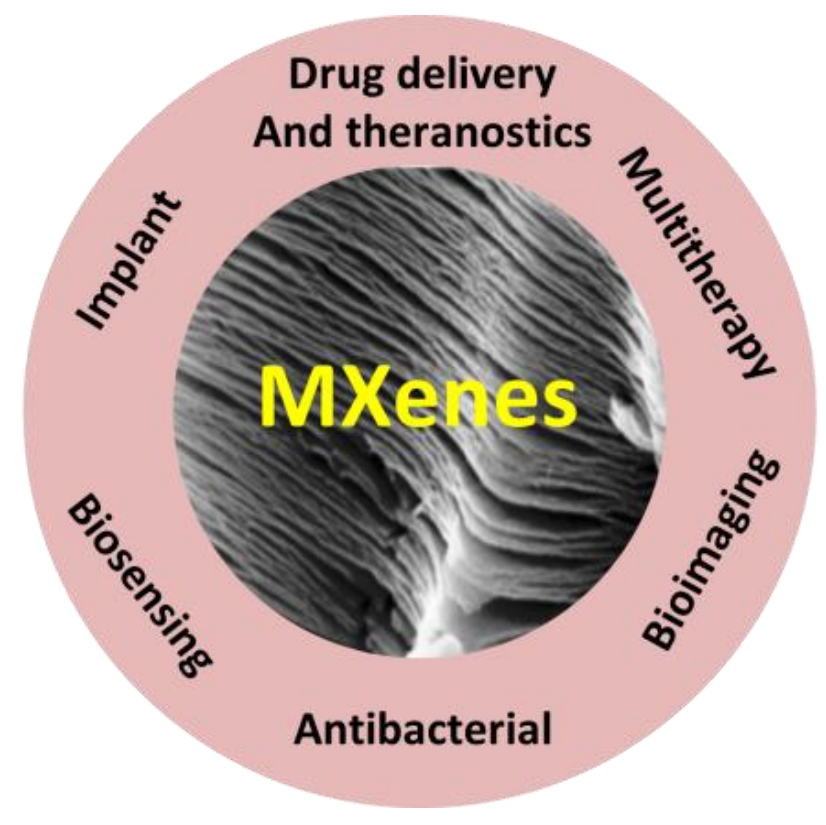

